NBER WORKING PAPER SERIES

\title{
TAX POLICY AND LUMPY INVESTMENT BEHAVIOR: EVIDENCE FROM CHINA'S VAT REFORM
}

\author{
Zhao Chen \\ Xian Jiang \\ Zhikuo Liu \\ Juan Carlos Suárez Serrato \\ Daniel Xu \\ Working Paper 26336 \\ http://www.nber.org/papers/w26336
}

\section{NATIONAL BUREAU OF ECONOMIC RESEARCH \\ 1050 Massachusetts Avenue \\ Cambridge, MA 02138 \\ October 2019}

We are very grateful for comments from Claudio Agostini, James Albertus, Pat Bayer, Youssef Benzarti, Peter Blair, Richard Blundell, Dorian Carloni, David Cashin, Raj Chetty, Wei Cui, Mike Devereux, Mark Duggan, Naomi Feldman, Erin Ferris, Amy Finkelstein, John Friedman, Dan Garrett, Brent Glover, Austan Goolsbee, Francois Gourio, Irem Guceri, Nathaniel Hendren, Jim Hines, Caroline Hoxby, Hilary Hoynes, Wojciech Kopczuk, Brian Kovak, Camille Landais, Andrea Lanteri, Attila Lindner, Li Liu, Byron Lutz, Andrew MacCallum, Neale Mahoney, Joana Naritomi, Eric Ohrn, Emily Oster, Andreas Peichl, Petra Persson, Emmanuel Saez, David Seim, Nicolas Serrano-Velarde, Jesse Shapiro, John Shoven, Sebastian Siegloch, Joel Slemrod, Bryce Steinberg, Alisa Tazhitdinova, Matt Turner, Danny Yagan, Owen Zidar, Peter Zorn, Gabriel Zucman, and Eric Zwick, as well as from seminar participants at ASSA, Berkeley, Brown, Carnegie Mellon, the Chicago Fed, Duke, the Federal Reserve Board, LSE/UCL, the Michigan-Columbia-World Bank VAT Conference, NBER Public Economics, Oslo, Oxford University CBT, Stanford, Stockholm, the Triangle Applied Microeconomics Conference, UCSB, University of Munich, University of Utah UTAXI Conference, and ZEW. Yuxuan He and Kelly Yang provided outstanding research assistance. This project is funded by NSF grant \#17300024. All errors remain our own. The views expressed herein are those of the authors and do not necessarily reflect the views of the National Bureau of Economic Research.

NBER working papers are circulated for discussion and comment purposes. They have not been peerreviewed or been subject to the review by the NBER Board of Directors that accompanies official NBER publications.

(C) 2019 by Zhao Chen, Xian Jiang, Zhikuo Liu, Juan Carlos Suárez Serrato, and Daniel Xu. All rights reserved. Short sections of text, not to exceed two paragraphs, may be quoted without explicit permission provided that full credit, including (C) notice, is given to the source. 
Tax Policy and Lumpy Investment Behavior: Evidence from China's VAT Reform Zhao Chen, Xian Jiang, Zhikuo Liu, Juan Carlos Suárez Serrato, and Daniel Xu

NBER Working Paper No. 26336

October 2019, Revised June 2020

JEL No. D25,E22,H25

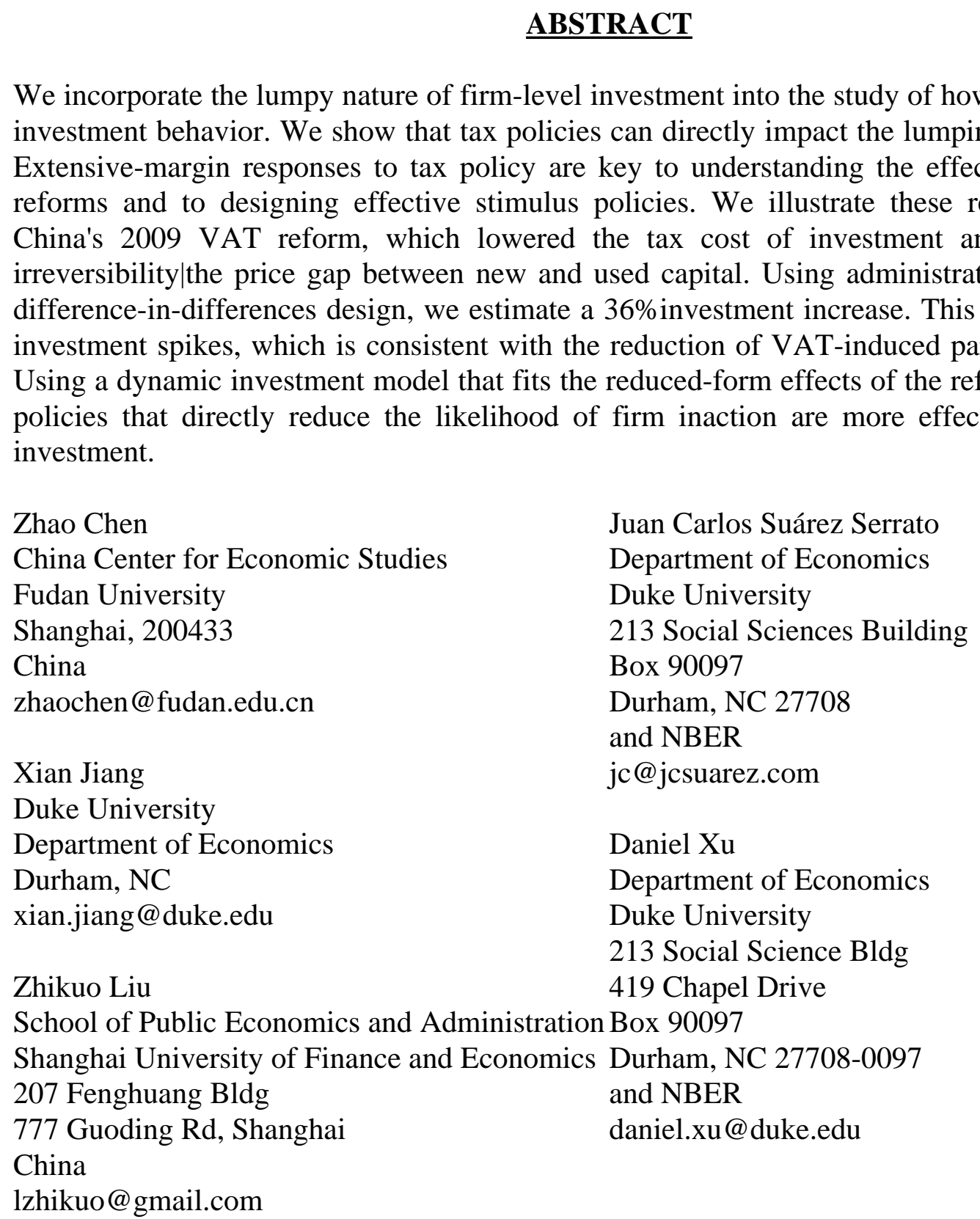


This paper improves our understanding of how tax policy affects investment behavior by incorporating the lumpy nature of investment. Lumpy investment behavior is evident in most microdata, with firms either replacing a considerable fraction of their existing capital (spikes) or not investing at all (inaction). The prevalence of lumpy investment patterns suggests that extensive-margin investment decisions - i.e., whether to invest or not-are important determinants of overall investment. It is therefore surprising that research on how tax policy impacts investment has not systematically integrated extensive-margin decisions. This paper shows that extensive-margin responses to tax policy are key to understanding the effects of different tax reforms and to designing effective stimulus policies.

We illustrate theoretically, empirically, and quantitatively that tax policy can impact extensivemargin investment decisions and that the effects of tax policy are shaped by investment frictions. Firms invest in lumpy increments because adjusting the physical stock of capital can entail fixed disruption costs and because investment is partially irreversible -i.e., the price of new capital is greater than the resale price of used capital. We integrate various tax policies into a model with these frictions. Tax policies can be a source of partial irreversibility, since input taxes and tax credits impact the wedge between the purchase and resale prices of capital. Other policies, such as income taxes and depreciation deductions, indirectly affect lumpiness by changing the after-tax value of fixed disruption costs. Different tax incentives have distinct effects on the frictions that determine whether firms undertake investment projects. As a result, policies that change the user cost of capital by the same degree can have different implications for firm investment.

Our analysis is grounded in one of the largest tax incentives for investment in recent history: China's 2009 value-added tax (VAT) reform. Understanding how tax policy impacts investment in China is of first-order importance since corporate investment comprises 30\% of China's GDP and since - as shown in Figure 1-investment in China has long surpassed investment levels in the United States and the European Union. The reform unexpectedly allowed domestic firms to deduct input VAT on purchases of new equipment. This policy change lowered the user cost of capital by $15 \%$ and reduced the wedge between the after-tax prices of new and used capital. ${ }^{1}$ We use administrative tax data to shed light on this stimulus program and to develop insights into how tax policy interacts with the frictions that generate lumpy investment.

We show that lumpy investment matters for tax policy using two sets of empirical analyses. We first use a difference-in-differences research design to document the effects of China's 2009 VAT reform. We find that affected firms increased investment relative to control firms by $36 \%$. The majority of this increase was driven by additional investment spikes, which is consistent with a reduction in the after-tax price gap between new and used capital. Second, we estimate a dynamic investment model that quantifies the interactions between investment frictions and tax policy. The

\footnotetext{
${ }^{1}$ By way of comparison, the recent tax reform in the United States lowered the user cost of capital by about $4 \%$ (Barro and Furman, 2018). The VAT reform lowered partial irreversibility since, prior to the reform, firms paid VAT on equipment but did not collect VAT on the sale of used equipment.
} 
model matches the reduced-form effects of the reform as well as the surge in investment spikes. We use the model to compare alternative tax policies and find that policies that increase the likelihood of investment spells are more effective at stimulating investment. In our empirical example, the VAT reform was more effective than an income tax cut at stimulating investment since the reduction in partial irreversibility decreased the likelihood of firm inaction. This lesson is relevant for tax policy in other countries that rely on sales taxes, VATs, and investment tax credits since such measures directly impact the extensive margin of investment.

We develop these insights in four steps. We start by embedding important tax policies - income tax, VAT, and depreciation deductions - into a standard model of dynamic investment that is rich enough to characterize our empirical setting. As in Cooper and Haltiwanger (2006), fixed costs and partial irreversibility rationalize lumpy investment patterns, and convex costs dampen investment responses to changes in taxes or productivity. We then provide intuition for how different tax policies interact with these frictions. While the VAT reform lowered the after-tax cost of capital and reduced the degree of partial irreversibility, it did not directly interact with adjustment costs. In comparison, while a corporate income tax (CIT) cut has a smaller effect on partial irreversibility, it lowers the after-tax cost of capital and affects the after-tax value of adjustment costs. Overall, the model shows that, to fully grasp how tax policy affects investment, it is necessary to account for the dual effects of tax policy on adjustment frictions and the cost of capital.

The second step of our analysis uses a novel dataset of administrative tax records from the Chinese State Administration of Tax and a difference-in-differences identification strategy to study how firms respond to the VAT reform. Since foreign firms with preferential treatment were able to deduct input VAT on equipment prior to the reform, our research design uses these foreign firms as a control group for domestic firms. We find substantial effects of the reform on firm investment. On the extensive margin, the fraction of firms investing in equipment increased by 5 percentage points, or a $10 \%$ increase. On the intensive margin, investment increased by $3.6 \%$ of the existing capital stock, for a $36 \%$ increase in investment. We then provide three pieces of evidence that these effects are driven by the impact of the reform on partial irreversibility. First, we find that the majority of the investment response was due to a surge in the number of firms that went from not investing to undertaking investment projects that were greater than $20 \%$ of their capital (investment spikes). Second, we use the fact that firms with excess VAT payments continued to face a gap between the purchase and resale prices of capital. The reform had much smaller effects on the extensive-margin response of these firms. Finally, we test whether the reform had different effects on industries that rely on specifically tailored assets. We show that, since the pre-reform price wedge induced by the VAT was less important in industries with more asset specificity, the reform leads to smaller effects on investment in these industries.

The validity of this research design rests on the assumption that, absent the reform, domestic firms would have had the same investment patterns as foreign firms. Three sets of auxiliary results suggest that foreign firms are a suitable control for domestic firms. First, we show that both sets 
of firms had similar investment trends prior to the reform. Second, the results are robust to a number of checks including using alternative measures of investment, different sample restrictions, reweighting the data to match the characteristics of foreign and domestic firms, and controlling for firm-level characteristics and other changes in tax policy. Finally, we conduct two placebo tests to further validate our identifying assumption. The first placebo test uses domestic and foreign firms that were included in a pilot program allowing firms to deduct input VAT from new investments starting in 2004. We find no evidence that the 2009 reform differentially affected foreign and domestic firms in the pilot program. This result suggests that domestic and foreign firms were not subject to time-varying shocks, including other stimulus policies implemented in response to the financial crisis, that might confound our estimates. In a second placebo test, we use the fact that the VAT reform did not impact the tax treatment of investment in structures. Because the reform did not differentially affect how foreign and domestic firms invested in structures, it is unlikely that our results are confounded by differential shocks to foreign and domestic firms. Additionally, triple-difference specifications that use these placebos as additional controls yield similar estimates of the reform. These results significantly limit the risk that our main results are a spurious feature of the data and are not driven by the tax reform.

We estimate a dynamic model of investment in the third step of our analysis. Our estimation relies on the method of simulated moments (MSM) to recover fixed and convex adjustment costs while allowing the VAT reform to influence partial irreversibility. Our model targets two sets of moments: (1) pre-reform statistics on investment patterns, such as measures of lumpiness and the autocorrelation of investment, and (2) the reduced-form estimates of the effects of the reform. We validate our model of investment by showing that it can match the reduced-form effects of an actual reform, including untargeted moments such as the effects of the reform on investment spikes. Simultaneously matching both of these sets of moments indicates that the VAT-induced price gap between used and new capital was the major source of partial irreversibility. ${ }^{2}$

The fourth and final step of our analysis uses the estimated model to simulate the effects of alternative tax policies on investment, tax revenue, and firm value. We measure the effectiveness of a given policy by comparing the tax revenue cost to the change in investment. Lowering the VAT distortion is more effective at stimulating investment than lowering the corporate income tax rate. One reason a corporate income tax cut is less effective is that a large fraction of firms are inframarginal to the tax cut - their investment is unaffected, but they benefit from the lower tax rate. In addition to having a large effect on the extensive margin of investment, policies that shrink the price gap between new and used capital — such as an investment tax credit (ITC) — only benefit firms that increase their investment. For this reason, introducing an ITC is just as effective as lowering the VAT. We also find that China's 2009 VAT reform stimulated more investment relative

\footnotetext{
${ }^{2}$ While the empirical investment literature relies on the asymmetry between the positive and negative ranges of the investment distribution to separately identify fixed costs from partial irreversibility, the lack of asset sales in tax data makes this approach infeasible. We instead use a reform that reduced the price gap between new and used capital to measure the relative importance of partial irreversibility for extensive-margin investment decisions.
} 
to lost tax revenue than a counterfactual policy that mirrors the 2017 Tax Cut and Jobs Act in the United States. $^{3}$

This paper is related to a long line of research in public finance dating to Hall and Jorgenson (1967). Recent work has revolutionized our understanding of how firms respond to taxation by exploiting credible identification strategies with administrative tax data (e.g., Yagan, 2015; Maffini, Xing and Devereux, 2016; Rao, 2016; Zwick and Mahon, 2017; Ohrn, 2018a,b; Moon, 2019). ${ }^{4}$ Papers that study how Chinese firms respond to tax incentives include Cai and Harrison (2019), Liu and Mao (2018), Chen, He and Zhang (2016), and Chen, Liu, Suárez Serrato and Xu (2019). ${ }^{5}$ The main contribution of our paper is to improve our understanding of how tax policy impacts investment by providing a coherent framework to interpret the intensive- and extensive-margin effects that have been documented in quasi-experimental studies. Deploying this framework to measure the effects of a large natural experiment using administrative tax data, we highlight the importance of investment spikes in understanding the effects of tax reforms as well as the potential for tax policy to generate partial irreversibility.

This paper also contributes to the investment literature by investigating a real-world tax reform through the lens of a workhorse model of investment (e.g., Caballero and Engel, 1999; Cooper and Haltiwanger, 2006; Gourio and Kashyap, 2007; Khan and Thomas, 2008; David and Venkateswaran, 2019; Lanteri, 2018; Winberry, 2020). Previous research in this literature has simulated the effects of tax policy changes through their effects on the after-tax cost of investment (e.g., Winberry, 2020). We highlight the importance of accounting for interactions between tax policy and the frictions that generate lumpy investment. In particular, we show that tax policies that have the same effect on the after-tax cost of capital can have different effects on firm investment. ${ }^{6}$ We also contribute to this literature by using quasi-experimental estimates of the effects of tax reform to estimate adjustment costs. As argued by Cummins, Hassett and Hubbard (1994), tax reforms generate large

\footnotetext{
${ }^{3}$ Our quantitative results are robust to alternative assumptions regarding the supply of capital goods and effects of the reform on interest rates, concomitant aggregate productivity shocks, additional sources of partial irreversibility, and interactions between income taxes, adjustment costs, and interest costs.

${ }^{4}$ Our paper is also related to classic papers that follow a model-centric estimation approach. For instance, Abel (1980), Salinger and Summers (1981), Summers (1981), and Hayashi (1982) rely on a q-theory approach for quantifying the roles of taxes on investment. Dynamic models with adjustment costs have also been considered by Auerbach (1986), Auerbach (1989), and Auerbach and Hines (1988).

${ }^{5}$ Cai and Harrison (2019) and Chen et al. (2016) use manufacturing survey data to study the effects of the pilot reform in 2004. In concurrent work, Liu and Mao (2018) use tax data to study the reduced-form effects of the rollout of the reform from 2004 to 2009 using small taxpayers as a control for large domestic firms. Using different empirical strategies, we find comparable effects of the reform on investment. Relative to Liu and Mao (2018), this paper contributes to the literature by uncovering the importance of lumpy responses to the tax reform and by providing a coherent model that synthesizes the effects of different tax policies on the intensive and extensive margins of investment.

${ }^{6}$ The focus of this paper is the interaction between tax instruments and producer-level investment behavior. Recent papers (e.g., Khan and Thomas, 2008; Bachmann, Caballero and Engel, 2013; Winberry, 2020) have clarified the conditions under which micro-level investment frictions have aggregate implications in general equilibrium. In particular, Winberry (2020) shows that lumpy investments have aggregate implications when interest-rate dynamics match the observed covariance with productivity. In Appendix F, we show that our main conclusions are robust to allowing for potential equilibrium effects on the interest rate or on the price of capital goods.
} 
and plausibly exogenous shifts in economic fundamentals and are useful in uncovering the nature of investment frictions. Our unified approach is therefore well suited to simulating the effects of potential tax reforms and comparing their effectiveness at stimulating investment.

The results of this paper have implications beyond China. First, policymakers can generate partial irreversibility through indirect taxation. This can occur when VATs do not allow for the deductibility of investment or when businesses pay indirect taxes on investment goods (e.g., Desai, Foley and Hines, 2004). In the United States, Cline, Mikesell, Neubig and Phillips (2005) document that businesses pay over $\$ 100$ billion in state sales taxes on inputs, including investment purchases. Second, VATs can generate partial irreversibility when credits are not refundable. Our reducedform results show that firms with excess VAT credits are subject to partial irreversibility after the reform. While China started refunding excess VAT credits in 2019 (Ministry of Finance, 2019), excess credits are not refundable in 24 other countries (EY, 2017). Finally, interactions between different tax policies influence the effectiveness of different forms of stimulus. For instance, a corporate income tax cut can be more effective at stimulating investment when other policies, such as an investment tax credits (e.g., Chirinko and Wilson, 2008), are simultaneously used to lower the price gap between new and used capital.

The paper is organized as follows. Section 1 develops the intuition for how tax policies interact with firm frictions and culminates by detailing an empirical model of investment. Section 2 discusses China's 2009 VAT reform. Section 3 describes the administrative tax data, and Section 4 documents the reduced-form effects of the reform. Section 5 estimates the model, Section 6 simulates the effects of potential tax reforms, and Section 7 concludes.

\section{Modeling Tax Policy and Lumpy Investment}

Empirical models of investment use adjustment costs to rationalize two empirical features of investment data. First, the observed pattern of infrequent and lumpy investment suggests firms face fixed costs and partial irreversibility. Second, the sluggish response of investment to changes in economic fundamentals suggests that investment is subject to convex costs of adjustment. We first characterize how these frictions affect the effectiveness of different tax policies in a simple, static model. We then describe a dynamic investment model and show that the intuition from the static model carries over to the dynamic world. Appendix A presents detailed derivations.

\section{$1.1 \quad$ Theoretical Motivation}

Consider a firm with preexisting capital $K_{0}$, productivity $A$, and profit function $A^{1-\theta} K^{\theta}$, where $\theta<1$ is the curvature of the profit function. The firm pays a corporate tax rate $\tau$ on profits. We model the after-tax price of capital $p=p_{k}(1+\nu)\left(1-\tau p_{v}\right)$, where $p_{k}$ is the capital goods price, $\nu$ is any form of sales tax related to capital purchase, and $p_{v} \leq 1$ is the discounted present value of 
depreciation deductions. ${ }^{7}$ Absent additional frictions, the firm solves the problem:

$$
\max _{K}(1-\tau) A^{1-\theta} K^{\theta}-p\left(K-K_{0}\right) \Longrightarrow K^{*}=A[\frac{1}{\theta} \underbrace{\frac{p_{k}(1+\nu)\left(1-\tau p_{v}\right)}{(1-\tau)}}_{\text {UCC }}]^{\frac{-1}{1-\theta}} .
$$

Equation 1 implies that the firm will adjust its capital in response to all changes in taxes or productivity. There is no inaction or scope for an extensive-margin response. ${ }^{8}$ The user cost of capital (UCC) is given by $\frac{p_{k}(1+\nu)\left(1-\tau p_{v}\right)}{(1-\tau)}$. The symmetric effect of $p_{k}$ and the tax term of the UCC $\frac{(1+\nu)\left(1-\tau p_{v}\right)}{(1-\tau)}$ is one reason the empirical public finance literature estimates the user cost elasticity of investment. In this model, this elasticity is governed by the curvature of the profit function and equals $\frac{-1}{1-\theta} \cdot{ }^{9}$

\section{Partial Irreversibility}

Partial irreversibility occurs when firms face different prices to purchase and sell equipment. This distortion can arise from imperfections in the market for used capital or from tax policies. For instance, sales taxes on equipment purchases increase partial irreversibility and have been shown to affect the investment of US firms (e.g., Desai et al., 2004). On the other hand, investment tax credits at the state level in the US (e.g., Chirinko and Wilson, 2008) decrease partial irreversibility. In the case of China, the pre-2009 VAT system increased the purchase price of capital by a factor of $(1+\nu)$, where $\nu$ is the VAT rate. Firms selling used capital could not charge the VAT rate. The effective after-tax purchase price is then $p^{b}=p_{k}\left(1+\nu-\tau(1+\nu) p_{v}\right)$ and the sales price is $p^{s}=p_{k}\left(1-\tau(1+\nu) p_{v}\right)$. $^{10}$

Partial irreversibility generates inaction - a range of productivity in which firms do not adjust their capital stock in response to small changes in economic fundamentals. While firms usually set the after-tax marginal product of capital (MPK) equal to the price of capital, firms do not adjust their capital when the MPK of their existing capital falls in the range $\left[p^{s}, p^{b}\right]$. The dashed line in Panel A of Figure 2 shows how the MPK increases with productivity. The two horizontal lines denote $p^{b}$ and $p^{s}$. The inaction region is the range of productivity where the MPK falls between

\footnotetext{
${ }^{7} p_{v}$ is determined by the tax depreciation schedule of capital. We provide more details of how the tax depreciation schedule maps into $p_{v}$ in the dynamic model. While this static model abstracts away from how real depreciation impacts investment, this important force is present in our dynamic model, and we estimate the rate of depreciation in our structural model in Section 5.

${ }^{8}$ By an extensive-margin response, we refer to a firm's decision to invest in a given year relative to a counterfactual of not investing. Our empirical analysis focuses on a balanced panel of existing firms, and we do not study firm entry as part of a broader extensive-margin response.

${ }^{9}$ As an example, when firms face a downward-sloping residual demand curve, assuming $\theta=0.75$ implies a markup excluding capital costs of $25 \%$ and results in $\frac{-1}{1-\theta}=4$.

${ }^{10}$ Note that the VAT also increases the value of depreciation deductions.
} 
these two lines and is given by:

$$
[\underline{A}, \bar{A}] \equiv\left[\left(\frac{p^{s}}{\theta(1-\tau)}\right)^{\frac{1}{1-\theta}} K_{0},\left(\frac{p^{b}}{\theta(1-\tau)}\right)^{\frac{1}{1-\theta}} K_{0}\right]
$$

Panel B of Figure 2 shows how $p^{b}, p^{s}$, and the inaction region affect the firm's policy function-the relation between productivity and capital.

To see how tax policies influence the inaction region, note that:

$$
\bar{A}-\underline{A}=\left(\frac{\mathrm{UCC}}{\theta}\right)^{\frac{1}{1-\theta}}\left[1-\left(\frac{\frac{1}{1+\nu}-\tau p_{v}}{1-\tau p_{v}}\right)^{\frac{1}{1-\theta}}\right] K_{0}
$$

This formulation makes it clear that the UCC is not a sufficient statistic to capture the extensivemargin effects of tax policy changes. To see this, consider two policies that lower the UCC by the same amount by either decreasing $\nu$ or increasing $p_{v}$. A reduction in $\nu$ will narrow the inaction

region both by lowering the UCC and by closing the price gap $\left[1-\left(\frac{\frac{1}{1+\nu}-\tau p_{v}}{1-\tau p_{v}}\right)^{\frac{1}{1-\theta}}\right]$. In contrast, increasing $p_{v}$ has two countervailing effects on the inaction region. While increasing $p_{v}$ lowers the UCC, this change also widens the price gap. For this reason, we would expect to see smaller extensive-margin responses from policies that increase $p_{v}$ - such as bonus depreciation-than from policies that lower $\nu .^{11}$

\section{Fixed Costs}

In addition to partial irreversibility, fixed costs also generate inaction. Following the literature (e.g., Caballero and Engel, 1999; Cooper and Haltiwanger, 2006), we interpret fixed costs as technological constraints, including production disruptions and short-run capacity limits that firms face when they replace machinery. We therefore assume that the firm has to pay a non-tax-deductible fraction $\xi$ of its desired capital stock $\left(K^{*}\right)$ to adjust its capital stock. To highlight the role of fixed costs, we abstract from partial irreversibility by assuming that $p^{s}=p^{b}=p_{k}(1+\nu-\tau(1+\nu))$.

A firm decides to adjust its capital if its profits after making the adjustment, $(1-\tau) A^{1-\theta} K^{* \theta}-$ $p\left(K^{*}-K_{0}\right)-\xi K^{*}$, are greater than the profits from inaction, $(1-\tau) A^{1-\theta} K_{0}^{\theta}$. Comparing the relative profit levels from these two alternatives, we have:

$$
\overbrace{\text { Slope }}^{\overbrace{\left[\frac{(1-\theta)}{\theta} \mathrm{UCC}-\frac{\xi}{1-\tau}\right]\left[\frac{\theta}{\mathrm{UCC}}\right]^{1 /(1-\theta)}}^{\text {Profit conditional on adjusting to optimal capital } K^{*}}+\underbrace{\mathrm{UCC} K_{0}}_{\text {Intercept }}}=\overbrace{K_{K_{0}^{\theta} A^{1-\theta}}}^{\text {Profit using initial capital } K_{0}}
$$

\footnotetext{
${ }^{11} \mathrm{~A}$ similar argument shows that changes in $\nu$ and $\tau$ that affect the UCC by the same amount generally have different effects on the inaction region. In the range of policy parameters that we study, a cut in $\nu$ has larger extensive-margin effects than a cut in $\tau$.
} 
The inaction region is characterized by the two values $\underline{A}$ and $\bar{A}$ that satisfy this indifference condition. The solid black line in Panel A of Figure 3 plots the after-tax profit in the case of no adjustment costs. The fixed cost $\xi$ flattens the slope and rotates this line clockwise (shown by the dot-dashed line). The inaction region $[\underline{A}, \bar{A}]$ is defined by the intersection of this rotated line and the curved profit line (in dashes) that holds capital at the initial level. The optimal profit with fixed costs is the red envelope of these two lines. Panel B shows how fixed costs generate inaction in capital adjustment.

Equation 2 can be used to illustrate the dual effects of tax policy on the cost of capital and adjustment frictions. Consider first a policy that reduces the UCC through changes in $p_{v}$ or $\nu$. These policies would shrink the inaction region by lowering the intercept and increasing the slope. However, a cut in $\tau$ that lowers the UCC by the same amount as changes in $p_{v}$ or $\nu$ will further increase the slope by reducing the after-tax value of the fixed cost. This discussion shows that, even without partial irreversibility, the UCC is not a sufficient statistic to gauge the effects of tax policy. Finally, because fixed costs and partial irreversibility have different interactions with tax policies, measuring the relative importance of these frictions is crucial for understanding the effects of tax policy.

\section{Convex Costs}

We now introduce convex adjustment costs and show how they help dampen the response of investment to changes in tax policy. While convex costs directly impact the intensive margin of investment, properly accounting for this mechanism is crucial to quantifying forces that affect the extensive margin. We assume that firms pay a non-tax-deductible convex cost, $D(K)$, to adjust their capital. The firm's optimal capital level is now:

$$
K^{*}=A\left[\frac{1}{\theta}\left(\mathrm{UCC}+\frac{D^{\prime}(K)}{1-\tau}\right)\right]^{\frac{-1}{1-\theta}}
$$

where the total marginal cost of investment is the UCC plus the marginal convex cost, $\frac{D^{\prime}(K)}{1-\tau}$. Since $\tau$ enters separately from the UCC in this expression, the latter is not a sufficient statistic for the effects of tax policy on investment. ${ }^{12}$

Overall, these simple models yield two insights. First, the models clarify how investment frictions help match empirical investment patterns. Convex costs help match the sluggish response of investment to tax changes. Fixed costs and partial irreversibility generate lumpy investment. Together, these frictions yield coherent interpretations of the intensive- and extensive-margin investment responses to tax changes that have been documented in empirical studies.

\footnotetext{
${ }^{12}$ In Appendix A.1, we formally show that the UCC is not a sufficient statistic when at least a portion of the convex costs are not tax deductible. In Section 6 , we show that our quantitative results are robust to assuming that adjustment costs are tax deductible.
} 
Second, these models show that accounting for interactions between tax policies and the frictions that generate lumpy investment is crucial to characterizing the effects of tax policy on investment. In particular, changes in the UCC are not sufficient statistics for tax policy. These static models suggest that, holding changes in the UCC constant, increasing $p_{v}$ through accelerated depreciation has the smallest impact on extensive margin decisions. While the effects of cuts to $\tau$ and $\nu$ are theoretically ambiguous, our models suggest that cuts to $\nu$ have larger effects on the extensive margin when partial irreversibility is a more important driver of inaction than fixed adjustment costs. This result highlights the importance of quantitatively measuring the relative magnitudes of these two frictions. The fact that tax policy can directly influence firms' extensive-margin investment decisions should be taken into account when modeling the effects of tax policy changes.

\subsection{A Dynamic Model of Tax Policy and Lumpy Investment}

We now incorporate how investment frictions interact with tax policy in a dynamic model built on Cooper and Haltiwanger (2006) that is rich enough to characterize our empirical setting. ${ }^{13}$

\section{Pre-Tax Profit Function}

Firms have a profit function given by:

$$
\Pi\left(K, A^{\Pi}\right)=\left(A^{\Pi}\right)^{1-\theta} K^{\theta}
$$

where $K$ is the predetermined capital stock and $A^{\Pi}$ is a profit shock that is realized at the beginning of the period. ${ }^{14} a_{i t} \equiv \log \left(A_{i t}^{\Pi}\right)$ denotes a firm's log profitability, which has three components:

$$
a_{i t}=b_{t}+\omega_{i}+\varepsilon_{i t},
$$

where $b_{t}$ is an aggregate shock, $\omega_{i}$ captures firm-specific permanent heterogeneity, and $\varepsilon_{i t}$ is an idiosyncratic transitory shock. Firms draw their permanent productivity $\omega_{i}$ from a normal distribution. The aggregate shock $b_{t}$ and the transitory shock $\varepsilon_{i t}$ evolve over time following $\operatorname{AR}(1)$ processes.

\footnotetext{
${ }^{13}$ To focus on the role of adjustment costs and lumpy investment, we abstract from the role of financial frictions. Combining financial frictions and lumpy investment raises additional modeling and identification challenges. Recent models that focus on financial frictions but abstract from lumpy investment include Hennesy and Whited (2007); Arellano, Bai and Zhang (2012); Ottonello and Winberry (2019).

${ }^{14}$ We view this as a reduced-form way to model the profit function, but it is easy to microfound it as the result of a static profit-optimization problem. We give an example using a decreasing-returns-to-scale (DRTS) production function and competitive final good market in Appendix A.2. An alternative is to assume a monopolistic competitive environment with constant-returns-to-scale (CRTS) technology.
} 


\section{Taxes}

As in the static model, firms pay the VAT rate $\nu$ on purchases of new equipment. Consistent with the Chinese institutional setting, we assume that new capital purchases cannot be deducted from output VAT. Firms pay the CIT at rate $\tau$ on profits and depreciate a fixed fraction $\hat{\delta}$ of the end-ofyear book value of the capital stock in each period. We summarize the impact of the depreciation schedule on the effective capital purchase price with the sufficient statistic $p_{v}$ : the present discounted value of depreciation deductions. ${ }^{15}$ The depreciation schedule interacts with both the CIT and the VAT since depreciation is deductible from the CIT base and the VAT affects the book value of capital.

\section{Adjustment Costs}

Firms face three types of adjustment frictions: a convex adjustment cost, a fixed disruption cost, and partial irreversibilty. We assume that the only source of irreversibility is the non-deductible VAT on equipment purchases, so the resale price is set to one. ${ }^{16}$ Firms incur a fixed disruption cost $\xi K^{*}$ when adjusting the capital stock. $\xi$ is assumed to be independent and identically distributed (i.i.d.) across firms and over time and is drawn from the distribution $G(\xi) .{ }^{17}$ Finally, the convex cost follows the quadratic form $\frac{\gamma}{2}\left(\frac{I}{K}\right)^{2} K$.

\section{Normalization and Recursive Formulation}

We normalize the firm problem relative to a given permanent productivity by defining $k=K / \exp (\omega)$. This normalization reduces the state space to $(k, b, \varepsilon, \xi) .{ }^{18}$ In any given period, the firm's value is the maximum of the value from buying capital, selling capital, or inaction:

$$
v(k, b, \varepsilon, \xi)=\max \left\{v^{b}(k, b, \varepsilon, \xi), v^{s}(k, b, \varepsilon, \xi), v^{i}(k, b, \varepsilon, \xi)\right\}
$$

\footnotetext{
${ }^{15}$ By abstracting from the depreciation schedule, this assumption allows us to study the firm's problem recursively. $p_{v}=\hat{\delta}+(1-\hat{\delta}) \beta \mathbb{E}\left[p_{v}^{\prime}\right]$. Assuming a fixed and exogenous real interest rate $r, \beta \mathbb{E}\left[p_{v}^{\prime}\right]=\frac{p_{v}}{1+r}$. This formulation builds on arguments in Winberry (2020). We show that this result holds in our setting in Appendix A.3.2.

${ }^{16}$ Partial irreversibility arises naturally from the fact that firms need to pay VAT to sellers when purchasing capital but do not retain VAT payment when selling capital. Section 6 shows our results are robust to allowing for additional sources of partial irreversibility.

${ }^{17}$ We represent the units of the fixed disruption cost in terms of the "desired capital level" $K^{*}$, as in the frictionless benchmark in Equation 1. In the dynamic setting, $K^{*}=\mathbb{E}\left[A^{\prime} \mid A\right]\left[\frac{1}{\theta} \frac{p_{k}(1+\nu)\left(1-\tau p_{v}\right)}{1-\tau}\right]^{-1 /(1-\theta)}$ with $p_{k}=r+\delta$, where $r$ is the interest rate defined by $r=1 / \beta-1$, and $\delta$ is the economic depreciation rate.

${ }^{18}$ This normalization allows us to account for firm-level permanent heterogeneity in firm-level productivity or unmodeled frictions (see, e.g., David and Venkateswaran, 2019). This result follows from the fact that the profit function (Equation (3)) and the costs of investment are homogeneous of degree one in the pair ( $K, A)$ and thus on $(K, \exp (\omega))$. The value function is also homogeneous of degree one in the pair $(K, \exp (\omega))$. See Appendix A.3.3 for additional details.
} 
where

$$
\begin{aligned}
& v^{b}(k, b, \varepsilon, \xi)=\max _{i>0}(1-\tau) \pi(k, b, \varepsilon)-\left[\left[1+\nu-\tau p_{v}(1+\nu)\right] i+\frac{\gamma}{2}\left(\frac{i}{k}\right)^{2} k+\xi k^{*}\right]+\beta \mathbb{E}\left[v^{0}\left(k^{\prime}, b^{\prime}, \varepsilon^{\prime}\right) \mid b, \varepsilon\right] \\
& v^{s}(k, b, \varepsilon, \xi)=\max _{i<0}(1-\tau) \pi(k, b, \varepsilon)-\left[\left[1-\tau p_{v}(1+\nu)\right] i+\frac{\gamma}{2}\left(\frac{i}{k}\right)^{2} k+\xi k^{*}\right]+\beta \mathbb{E}\left[v^{0}\left(k^{\prime}, b^{\prime}, \varepsilon^{\prime}\right) \mid b, \varepsilon\right] \\
& v^{i}(k, b, \varepsilon, \xi)=(1-\tau) \pi(k, b, \varepsilon)+\beta \mathbb{E}\left[v^{0}\left(k(1-\delta), b^{\prime}, \varepsilon^{\prime}\right) \mid b, \varepsilon\right]
\end{aligned}
$$

where $k^{\prime}=(1-\delta) k+i, \delta$ is the economic rate of depreciation, and where the ex ante value function (before the fixed cost draw is realized) is given by:

$$
v^{0}(k, b, \varepsilon)=\int_{0}^{\bar{\xi}} v(k, b, \varepsilon, \xi) d G(\xi) .
$$

$v^{b}(k, b, \varepsilon, \xi)$ is the value function conditional on investing. The costs of investing include convex and fixed adjustment costs, as well as the VAT-inclusive price of capital $(1+\nu)$ minus depreciation deductions $\tau p_{v}(1+\nu)$. When the firm decides to disinvest, the value function $v^{s}(k, b, \varepsilon, \xi)$ differs by not including $\nu$ in the resale price. This difference is the source of partial irreversibility. In the last case, that of inaction, the firm collects profits and transitions to the next period with depreciated capital. Notice that our model embeds a "time-to-build" assumption since investment in this period does not affect current profits.

\section{Implications for Policy Reform}

While it is not possible to analytically characterize the effects of tax policy in the dynamic model, we can solve the model numerically. This allows us to characterize how different policies affect the investment policy function and to confirm that many of the lessons from the static model are applicable in the dynamic setting.

Figure 4 plots the policy function against the firm's transitory productivity shock to illustrate how various policy reforms affect the firm's investment decisions. Panel A plots the pre-reform baseline. The dotted line is the firm's optimal capital choice in a frictionless environment without adjustment costs. In this case, the optimal capital choice is log-linear in the firm's transitory productivity shock. The slope is determined by the return-to-capital parameter $\theta$ and the persistence of the idiosyncratic shock $\varepsilon$.

The dashed line in Figure 4 plots the optimal policy in the presence of all investment frictions. Both the partial irreversibility generated from the VAT and the fixed investment cost create an inaction region where firms do not respond to small productivity shocks. When the productivity shocks are large enough, firms adjust their capital. However, the convex adjustment cost and partial irreversibility prevent firms from directly adjusting to the optimal capital level, which gives 
the policy function a flatter slope with respect to productivity shocks.

Panels B-D compare the effects of different tax policies on the firm's policy function. For comparability, we consider three policies that have the same impact on the tax term of the UCC. The red solid line in Panel B of Figure 4 shows a VAT cut from $17 \%$ to $12.9 \%$. ${ }^{19}$ This VAT cut reduces the asymmetry between the purchase and sale price of capital. This change shrinks the inaction region and allows firms to adjust their capital under more modest productivity shocks. The reform generates extensive-margin responses from firms with productivity shocks that fall outside of the red inaction region but that would otherwise be inside the black dashed inaction region. In addition to changing which firms respond to productivity shocks, a VAT cut directly reduces the UCC, which also affects investment along the intensive margin. The joint effects of reducing the UCC and narrowing the inaction region are key building blocks for understanding the effectiveness of the VAT reform on investment.

In Panel C, we report the policy function following a CIT cut. To match the UCC effect of the small VAT cut in Panel B, we consider the effect of reducing $\tau$ from the average effective rate in our data from $15.4 \%$ to $0 \%$. Based on the insights from our static model, we would expect that a CIT cut would also have a large effect on the inaction region if fixed costs were the primary driver of inaction. Relative to Panel B, we find that the CIT cut has a smaller effect on the inaction region, primarily driven by the lack of response by firms with low productivity shocks. Whether a cut in $\tau$ or $\nu$ has a larger effect on the likelihood that firms undertake investment projects is ultimately an empirical question, which motivates the structural estimation of Section 5.

Panel D reports the effects of a policy of bonus depreciation - which accelerates the timing of depreciation deductions and increases the value of $p_{v}$. By shifting the red line to the left, this reform affects the investment decisions of firms with low and high productivity shocks. Consistent with our theoretical insight, the inaction region does not narrow considerably, and a significant fraction of firms do not respond to this incentive.

While these reforms have similar effects on the UCC, the fiscal effectiveness of different policies is partly driven by extensive-margin responses. Because all firms - even those in the inaction regionbenefit from a CIT cut, the government collects less revenue from a large fraction of firms that do not undertake new investment projects. In contrast, only firms that invest benefit from a VAT cut or from bonus depreciation. Because the fiscal costs of all these policies depend on the effects of investment on future tax revenue, the degree to which different policies stimulate firms to undertake investment projects also shapes the fiscal effectiveness of different policies.

Figure 4 shows that different tax reforms have distinct interactions with adjustment costs. These interactions are the source of the different intensive- and extensive-margin responses documented in empirical studies. While the red lines in Figure 4 compare reforms with similar effects on the UCC, the blue line in Panel B shows the effects of the actual VAT reform. This figure shows that the

\footnotetext{
${ }^{19}$ For simplicity, we assume that, after the reform, firms use the post-reform VAT rate when calculating the present value of their depreciation deductions.
} 
VAT reform would lead to a more substantial reduction in the inaction region than the elimination of the corporate income tax. This figure also shows how the VAT reform - which eliminated the source of partial irreversibility in our model - allows us to pin down the importance of fixed costs for extensive-margin decisions. In Section 5, we estimate an empirical version of this model that is consistent with the reduced-form effects of the reform to quantitatively compare the effects of alternative tax policies. Based on this discussion, an important test that our model correctly measures the relative importance of fixed costs and partial irreversibility is whether it matches the extensive-margin effects of China's VAT reform, including spikes in investment.

\section{Policy Background: China's 2009 VAT Reform}

China's 2009 reform was one of the largest tax incentives for investment in recent history. This section describes the reform and how it generated quasi-experimental variation in the after-tax cost of investment.

The VAT is the largest source of tax revenue in China. In 2016, VAT revenues comprised $39 \%$ of overall tax revenue. By comparison, corporate and personal income taxes accounted for $22 \%$ and $8 \%$ of tax revenue, respectively (NBS China, 2018). Note that China's reliance on the VAT for tax revenues mirrors much of the developed and developing world. China has a standard VAT rate of $17 \%$, which applies to the majority of sales. $^{20}$

\section{The Reform as a Natural Experiment}

One of the purported benefits of the VAT is that it does not distort the choice of production inputs - that is, it preserves "production efficiency." In practice, however, VATs can distort input choices depending on how they are implemented (Ebrill, Keen, Bodin and Summers, 2001). Before 2004, China's "production-based" VAT allowed firms to offset output VAT on sales with VAT paid on inputs such as materials and factory expenses. In contrast, firms were not allowed to deduct the VAT on fixed investment from their VAT base. This lack of deductibility discouraged investment, which works against the production efficiency of the VAT. To correct this distortion, China launched a reform to transition to a "consumption-based" VAT that allows for the deductibility of investment. Because this reform was part of long-term central government plans dating to 2003, firms deemed the chance of policy reversal to be extremely low. ${ }^{21}$

The Chinese government experimented with this transition starting in 2004. The reform was first piloted on firms in selected industries in Northeastern China. ${ }^{22}$ As with most other reforms in China,

\footnotetext{
${ }^{20}$ The VAT is calculated using a credit-invoice method. Exports are zero-rated and some selected goods face a lower rate of $13 \%$. Most of the goods affected by the reform face a $17 \%$ rate.

${ }^{21}$ The Chinese government announced the gradual transition from the production-based VAT to consumptionbased one at the Third Plenary Session in October 2003. Plenary sessions are among the highest-level government meetings. Decisions made at these meetings are meant to be permanent and are very rarely revoked.

${ }^{22}$ The initial provinces included Heilongjiang, Jilin, Liaoning, and the city of Dalian. From 2004 to 2008 , the pilot
} 
the reform was designed to follow a slow rollout to allow for trial and error. However, the government unexpectedly announced on December 19, 2008, that the reform would be extended nationwide in 2009. This announcement broke with existing expansion plans. Prior to this announcement, authorities had last announced on July 30, 2008, that the rollout of the program would continue in two additional provinces. Starting on January 1, 2009, all firms were able to deduct the input VAT on equipment from the VAT on sales. ${ }^{23}$

The reform was an unexpected and permanent change to firms' after-tax cost of investment. Because the reform was unexpected, it is unlikely that firms delayed their investment plans in anticipation of the reform. Because the reform was permanent, the effects we measure are likely not due to other forms of inter-temporal substitution.

The reform generated a natural experiment since it had no effect on the after-tax cost of investment for a group of foreign firms. Specifically, foreign firms in industries categorized by the government as encouraged had previously been allowed to deduct equipment purchases from VAT on sales. ${ }^{24}$ Our research strategy uses foreign firms in encouraged industries as a control group for domestic firms. The identifying assumption behind this strategy is that treated and control firms are not subject to differential shocks in this time period.

One set of potential concerns is related to the fact that the Chinese government implemented a broad stimulus package in responses to the financial crisis, which was colloquially known as the 4 trillion yuan package. Through this program, the central government provided low-cost credit through the local financing vehicles of regional governments. As Bai, Hsieh and Song (2016) show, these loans were used for railways, roads and other infrastructure (38\%), reconstruction following the Wenchuan earthquake (25\%), affordable housing (10\%), and social welfare projects $(27 \%)$. Importantly, these loans did not target the manufacturing sector. In contrast, the 2009 VAT reform - which was also part of this stimulus package - directly affected the manufacturing sector. For these reasons, we do not expect that other aspects of the stimulus package would confound the effects of the VAT reform.

Nevertheless, we conduct a number of checks to ensure that our results are driven by the VAT reform and not by other aspects of the stimulus package that may differentially affect foreign and domestic firms. First, because the credit provision was channelled through regional governments, we

was extended to Inner Mongolia and to areas affected by earthquakes in the province of Wenchuan. Appendix B documents the legislative background and timeline for the reform from 2004 through 2009. Cai and Harrison (2019) and Chen et al. (2016) study the effects of the pilot reform.

${ }^{23}$ Equipment includes machinery, mechanical apparatus, means of transportation, and other equipment, tools, and fixtures related to production and business operations that are used for over 12 months. Purchased and self-made housing, buildings, and other real estate were not included in the reform.

${ }^{24}$ Qualified foreign firms were able to deduct input VAT on purchases of equipment starting in 1999. Starting on April 1, 2002, the government classified foreign investment projects as encouraged, allowed, restricted or prohibited. The Catalogue for the Guidance of Foreign Investment Industries lists the encouraged, restricted and prohibited projects. If a foreign project is not included in the previous three categories in the Catalogue, it is considered as falling within the allowed category. Additionally, firms participating in the Midwest Advantageous Project list also qualified for preferential treatment. As a robustness check, we also use all foreign firms as controls, and we find similar results. This suggests that selection into the encouraged category is not central for our results. 
control for province-by-year fixed effects in our baseline specifications. Second, because Cong, Gao, Ponticelli and Yang (2019) show that the credit expansion disproportionately benefited state-owned enterprises (SOEs), we show that our results are robust to excluding SOEs or listed firms. Finally, we conduct two sets of placebo tests to show that we are capturing the effects of the VAT reform. Because the reform did not impact the investment incentives of domestic firms that were part of the 2004 pilot, we would not expect investment in these firms to be affected by the reform. Similarly, we leverage the fact that, apart from minor affiliated structures, the VAT reform did not change the tax treatment of investment in major structures. We find that the 2009 reform did not significantly impact investment in pilot firms or on major structures. Additionally, we obtain similar results in triple-difference analyses relative to these placebos. We provide more details behind this identifying variation in Section 4, where we also discuss different strategies that support the assumption that foreign firms' investment is a suitable counterfactual for domestic firms' investment. ${ }^{25}$

\section{The VAT and the After-Tax Cost of Investment}

To see how the reform affected the after-tax cost of investment, consider a domestic firm purchasing equipment at a price of 1,000 RMB. Table 1 shows that, prior to the reform, the VAT-included cost would be 1,170 RMB, since the firm would pay a 17\% VAT on the purchase. The asset generates depreciation deductions according to Chinese accounting standards, which have a discounted present value of $984 \mathrm{RMB}^{26}$ At a corporate income tax rate of $25 \%$, these deductions reduce the firm's corporate income tax obligations by $237 \mathrm{RMB}$. The after-tax cost of the equipment purchase is therefore 932 RMB.

The reform modifies this calculation in two ways. First, the firm's direct cost of investment decreases by 170 RMB, since the VAT paid on the equipment is deducted from the VAT on sales. Second, depreciation deductions only lower corporate income tax obligations by 202.7 RMB since the book value no longer includes the VAT payment. Because the direct effect is larger than the effect on depreciation deductions, the after-tax cost of investment drops to 797.3 RMB. In total, the reform lowered the after-tax cost of investment by close to $15 \% .^{27}$

The results of Table 1 can also be expressed by extending the framework of Hall and Jorgenson (1967) to include the effect of the VAT:

$$
\mathrm{TUCC}=(1+\nu) \frac{1-\tau p_{v}}{1-\tau}
$$

\footnotetext{
${ }^{25}$ An alternative research strategy would be to use small-scale taxpayers as controls since the reform only targeted general taxpayers (as in Liu and Mao, 2018). We focus on large firms since they conduct over $99 \%$ of overall investment in China. In general, we avoid issues related to selection into VAT by excluding small-scale taxpayers from the analysis. Because small-scale taxpayers only constitute $0.58 \%$ of the data, we do not expect to find significantly different results by including these observations.

${ }^{26}$ This calculation assumes a discount rate of $5 \%$. According to Chinese accounting standards, the book value of the asset would be depreciated over 10 years using the straight-line depreciation method.

${ }^{27}$ Equivalently, the non-deductibility of investment purchases (prior to the reform) raised the after-tax cost of investment by $17 \%$, relative to the post-reform value.
} 
where TUCC is the tax component of the user cost of capital, which depends on the VAT rate $\nu$, the CIT rate $\tau$, and the present value of depreciation deductions $p_{v}$. As in Table 1 , the VAT has a direct effect on the purchase price of equipment, $(1+\nu)$, and an indirect effect on the value of depreciation deductions, $(1+\nu) \tau p_{v}$.

While Equation 5 is not a sufficient statistic for tax policy, we can use it to compare the VAT reform to potential policies and recent reforms. One approach to lowering the TUCC is to accelerate the depreciation schedule with the goal of increasing $p_{v}$. However, setting $p_{v}=1$ through a policy of expensing (or 100\% bonus depreciation) only lowers the TUCC by $6 \%$. Recent bonus depreciation policies in the US decreased the TUCC by 2.4\%-3.8\% (Zwick and Mahon, 2017). Alternatively, consider the effects of changing the corporate income tax. Eliminating the income tax would only lower the TUCC by $6 \%$. Barro and Furman (2018) calibrate that the recent US tax reform reduced the average TUCC by 4\%. Finally, consider that undoing the effect of the VAT distortion on the TUCC would require an investment tax credit (ITC) of $13.6 \%$. This rate is greater than the last federal ITC in the US (the 8\% ITC was eliminated in 1986, Cummins et al., 1994) as well as current state-level ITCs (which average 4\%, Chirinko and Wilson, 2008). These calculations give context to the claim that the VAT reform comprised one of the largest incentives for investment in history. They also highlight the importance of studying the effects of indirect taxes on investment (e.g., Desai et al., 2004; Cline et al., 2005).

One potential concern with our identification strategy is that other reforms may also affect the after-tax cost of investment of foreign and domestic firms. In particular, the VAT reform occurred shortly after a reform of the corporate income tax system in 2008. While this reform harmonized the statutory income tax for foreign and domestic corporations, it had almost no effect on the TUCC of foreign and domestic firms. We observe almost no change in the TUCC of foreign and domestic firms before 2008. In 2009, we see that the VAT reform lowered the TUCC of domestic firms by $15 \%{ }^{28}$ The fact that the TUCC is not affected by the CIT reform is reassuring for our analysis focused on the VAT reform. In addition, we report robustness checks that control for firms' CIT rates in our empirical analysis.

Finally, we note that these calculations ignore a practical and important aspect of how the VAT is administered. Specifically, countries differ in how they process excess VAT credits. Ideally, tax authorities would automatically refund excess credits to firms. In China, as in many other countries (EY, 2017), firms can carry over credits to future tax periods. The degree to which firms are able to claim these credits varies in practice, however, and firms may view excess credits as completely foregone. For this reason, firms with excess VAT credits may still view investment as partially irreversible even after the reform. In our empirical analysis in Section 4, we test whether the lack of refundability of excess VAT payments hampers the effects of the reform.

\footnotetext{
${ }^{28}$ Table F.1 shows these calculations by year and ownership. We implement Equation 5 using firms' effective tax rates. We also assume $r=5.26 \%$, which implies $p_{v}=80 \%$. The TUCC for foreign firms increases from 1.023 to 1.035 between 2007 and 2009, a 1\% difference. In contrast, the TUCC of domestic firms drops from 1.22 to 1.042.
} 


\section{Administrative Data from Corporate Tax Returns}

The main dataset we use comes from the administrative tax records of the Chinese State Administration of Tax (SAT) from 2007 to 2011. The sampling of our dataset ensures that large firms are included every year and that smaller firms are included on a rotating basis. This dataset contains detailed information on VAT payments and investment in fixed assets. We restrict our analysis to firms with non-negative values of fixed assets for production and to firms that do not change ownership type in our sample. Importantly, these data directly measure investment and separate investments in buildings and structures, which are not part of the reform, from other types of investment. Finally, the dataset includes a flag that identifies firms that were part of the pilot program as of 2007. Appendix C provides additional details on our data sources.

Table 2 reports summary statistics of the firms in our sample, where we winsorize all variables at the $1 \%$ level. Our sample includes data on close to 315,000 firm-year observations. Because our main analysis relies on a balanced panel of firms that stay in the data for all five years and that have non-missing investment in all years, the number of observations used in our estimations is smaller. For robustness, we compare our results with a sample that also includes firms with missing investment spells. Average total investment is 4.7 million RMB. The policy we study affected the after-tax cost of equipment investment, which constitutes $67 \%$ of total investment. Table 2 shows that, while foreign firms invest more on average, the average investment rate (equipment investment relative to the stock of fixed assets) is $10 \%$ for both domestic and foreign firms.

As in many other countries, investment data in China is lumpy. Panel A of Figure 5 shows the distribution of investment rates and shows that $49 \%$ of firms do not invest in a given year. In addition, $17 \%$ of firms replace more than $20 \%$ of their capital stock in a given year. These lumpy data patterns suggest that investment decisions are subject to fixed costs or partial irreversibility and motivate our study of how taxes affect lumpy investment decisions. By way of comparison, Zwick and Mahon (2017) report that $34 \%$ of firms in the US replace less than $1 \%$ of their capital and that $16 \%$ of firms replace more than $20 \% .^{29}$ As in other settings that rely on tax data to measure investment, we do not observe equipment sales. ${ }^{30}$

Panel B of Figure 5 shows that, despite the large number of firms that do not invest in a given year, the investment rate has a serial correlation of 0.20 . The positive correlation suggests firm investment is also subject to convex adjustment costs. The comparable number for the US is 0.40 (Zwick and Mahon, 2017), which reflects a lower likelihood of inaction.

Table 2 also reports data on firm sales, fixed assets, cash flow, and debt for both domestic

\footnotetext{
${ }^{29}$ Similarly, Levinsohn and Petrin (2003) report that about $60 \%$ of Chilean firms replace less than $1 \%$ of their capital. Additional data for the US can be found in Cooper and Haltiwanger (2006). Since we use firm-level tax data as opposed to plant-level data, the statistics from Zwick and Mahon (2017) are more comparable to our setting.

${ }^{30}$ One concern is that this limits us from studying the role of partial irreversibility. However, as we discuss in Section 1, the VAT reform reduced partial irreversibility by decreasing the gap between the purchase and resale price of equipment. We use the fact that this change in partial irreversibility impacts the fraction of firms that make large investment decisions to quantify the role of partial irreversibility in lumpy investment decisions.
} 
and foreign firms. We use these variables as controls in some specifications. Since these variables show that foreign firms are larger than domestic firms, we follow Yagan (2015) by showing that our results are robust to reweighting our data to match the distribution of firm characteristics between domestic and foreign firms. Specifically, we first estimate a propensity score model that controls for firm industry, region, exporting status, sales, and interaction terms between these variables. We then generate estimation weights following DiNardo, Fortin and Lemieux (1996). As we show in Figure F.2, this inverse probability weighting (IPW) method ensures that our treatment and control groups are comparable (see Appendix D.1 for details).

We complement these tax data with two additional datasets. First, we use data on foreign direct investment records from the Ministry of Commerce (MOC). This dataset contains information on the type of foreign firms: encouraged, restricted, or whether the project is considered advantageous

under the Midwest program. We merge this dataset with our main dataset from SAT to identify the foreign firms that enjoyed the preferential VAT prior to the reform. Second, we merge our tax return data with survey responses from the Chinese Annual Survey of Manufacturing (ASM) from 2005 to 2007. This merge allows us to confirm that foreign and domestic firms have similar investment trends for a longer period of time.

Finally, we discuss the role of SOEs in the Chinese economy. SOEs make up $8.4 \%$ of all firms, account for $4 \%$ of large manufacturing firms (those with sales above 5 million RMB), and have an investment rate of $11 \%$, which is similar to other firms. In our estimation sample, SOEs account for $3 \%$ of observations and $5.2 \%$ of total investment in equipment. Our empirical results are robust to excluding SOEs.

\section{Reduced-Form Effects of China's VAT Reform}

We now estimate the reduced-form effects of the reform on investment. Our main results rely on a difference-in-differences research strategy that exploits the different policy treatments of domestic and foreign firms prior to the reform. As detailed in Section 2, most domestic firms were not able to deduct input VAT on equipment before 2009. In contrast, foreign firms in encouraged sectors enjoyed preferential treatment that allowed them to deduct equipment from VAT. For this reason, the reform significantly reduced the investment cost for domestic firms, but it did not affect foreign firms. We then show that our main results are robust to a number of checks and to two alternative triple-differences strategies that rely on pilot firms and investment in non-eligible structures as additional controls. Finally, we provide evidence that interactions between tax policy and partial irreversibility were important drivers of the effects of the reform. 


\subsection{Estimation Strategy and Baseline Results}

We begin our analysis by estimating the following difference-in-differences specification:

$$
Y_{i j t}=G_{i} \gamma_{t}+\mu_{i}+\delta_{j t}+X_{i t}^{\prime} \beta+\varepsilon_{i j t}
$$

where $Y_{i j t}$ is a firm-level measure of investment for firm $i$ in industry $j$ in year $t .^{31}$ We measure extensive-margin responses with the fraction of firms with positive investment and intensive-margin responses with the investment rate. $G_{i}$ is an indicator for treatment that takes a value of 1 for domestic firms and 0 for foreign firms. ${ }^{32}$ The parameters of interest $-\gamma_{t}$-measure whether domestic and foreign firms have different trends prior to the reform as well as how investment in domestic firms is affected by the reform. $\mu_{i}$ is a firm fixed effect that controls for firm-specific unobservables. Industry-year fixed effects $\delta_{j t}$ control for industry-specific trends, which rule out the possibility that our results are driven by differential growth rates across industries. In some specifications, we also include province-year fixed effects. These fixed effects assuage concerns that differential growth rates across provinces - e.g., due to differential concentrations of foreign and domestic firms - impact our results. Finally, we also show that our results are robust to including firm-level controls, $X_{i t}$, which include lagged cash-flow measures and corporate income tax rates, as well as quartic expansions of sales, firm age, and profit margin. We cluster standard errors at the firm level.

The key identifying assumption is that no other unobserved ownership-year-specific shocks coincide with the reform. We first show graphical evidence that domestic and foreign firms had similar investment trends before the reform. Figure 6 plots investment trends from 2005 to 2011. Panel A plots the fraction of firms investing in any given year and shows that domestic and foreign firms had similar trends prior to the reform. Panel B plots the same figure for the investment rate. ${ }^{33}$ Panels C and D report the coefficients $\gamma_{t}$ in Equation 6 and show that the parallel trends observed in Panels A and B result in statistically insignificant estimates before 2009. These parallel trends are consistent with our assumption that domestic and foreign firms would have had the same investment patterns absent the reform. After the reform, however, we see that domestic firms are more likely to invest (Panels A and $\mathrm{C}$ ) and that their overall investment rate is also higher (Panels B and D). ${ }^{34}$

To quantify the effects of the reform, Table 3 provides estimates of the following difference-in-

\footnotetext{
${ }^{31}$ We use CIC (Chinese Industrial Classification) codes, which are comparable to 3-digit NAICS (North American Industry Classification System) codes.

${ }^{32}$ Our main specification only includes foreign firms with preferential treatment and excludes domestic firms in the pilot program.

${ }^{33}$ To create this figure, we use tax data that has information on equipment investment for years 2007 to 2011 as well as total investment data in the ASM from 2005 to 2006. Since the ASM only reports total investment, this figure assumes that firms invest in equipment and other assets proportionately. Finally, we normalize investment outcomes to domestic levels in 2008.

${ }^{34}$ We report the coefficients in Figure 6 in Table F.3. Table F.4 shows that these results are robust to the same robustness checks performed in our difference-in-differences analysis.
} 
differences regression using our tax data:

$$
Y_{i j t}=\gamma G_{i} \times \text { Post }_{t}+\mu_{i}+\delta_{j t}+X_{i t}^{\prime} \beta+\varepsilon_{i j t}
$$

The first three columns in Panel A show that the reform increased the fraction of domestic firms reporting positive investment by close to 5 percentage points. This result lines up very well with the visual evidence in Figure 6. Relative to a base participation of $50 \%$, this increase represents a $10 \%$ increase in the fraction of firms with positive investment. Given this large effect on the extensive margin of investment, it is crucial to have a model that accounts for firms' decisions to undertake new investment projects. These columns also show that this result is robust to including industry-by-year and province-by-year fixed effects.

The last three columns of Panel A report average effects of the reform on the investment rate. These columns show that, relative to foreign firms with preferential treatment, domestic firms increased investment by about $3.6 \%$ of the capital stock. Relative to an average investment rate of $10 \%$, the estimate from Table 3 represents a $36 \%$ increase in investment and implies a user-cost elasticity of $2.4\left(\approx \frac{36 \%}{15 \%}\right) \cdot{ }^{35}$

\subsection{Robustness Checks}

Panel B of Table 3 shows that these results are robust to the set of firms used in our estimation. First, columns (1) and (4) show that our results are robust to weighting observations to ensure that foreign and domestic firms have similar observable characteristics. ${ }^{36}$ The remaining columns of Panel B show that our results are robust to including observations missing investment spells (Unbalanced) or to using all foreign firms (and not just those in preferential industries) as controls.

Panel C further shows that our results are robust to the set of firms used in our estimation. Since foreign firms are also more export intensive, one concern is that they are more severely affected by the financial crisis. Columns (1) and (4) show that we obtain similar estimates when we restrict the sample to non-exporters. Another concern is that SOEs differentially benefited from the stimulus program. Columns (2) and (4) show that we find very similar effects when we exclude SOEs from the estimation. Finally, our estimates are robust to also excluding publicly listed firms, as we show in columns (3) and (6).

Panel D of Table 3 shows that our estimates are also robust to controlling for firm-level characteristics. Columns (1) and (4) include a measure of lagged cash flow, and columns (2) and (5)

\footnotetext{
${ }^{35}$ In Appendix D, we also calculate the semi-elasticity of investment with respect to the TUCC. Using the reform as an instrument for the change in the TUCC, we estimate a semi-elasticity of 0.19 . This estimate is significantly lower than the recent estimate of 1.6 for the US (Zwick and Mahon, 2017) and the range of [0.5, 1] used by Hassett and Hubbard (2002) to summarize previous studies. One possibility is that recent estimates using variation from bonus depreciation find larger effects due to interactions with liquidity constraints. In contrast, the VAT reform does not impact the timing of firms' cash-flow obligations. In Appendix D.4, we show that firms in industries with higher external finance dependence do not see larger increases in investment.

${ }^{36}$ We describe this inverse-probability weighting (IPW) strategy in Section 3. See Appendix D.1 for more details.
} 
control for quartics in sales, firm age, and profit margin. Finally, columns (3) and (6) show that our results are robust to controlling for changes in the corporate income tax rate. As we discuss in Section 2, while a 2008 reform changed the statutory CIT for foreign and domestic firms, the reform had very small effects on firms' effective tax rates. These columns show that controlling for this policy change does not affect our main estimate. ${ }^{37}$ This panel shows that firm-level characteristics and other observable policies are not driving our results. By including these controls, we also limit the number of potential unobservable shocks that can challenge our identifying assumption.

The last panel in Table 3 shows that our results are robust to how we measure investment outcomes. Columns (1)-(3) now report the effects of the reform on the logarithm of investment. Precisely because lumpy investment patterns imply that firms will have zero investment in many years, using the logarithm of investment limits the number of observations in our regressions. Nonetheless, we find similar estimates in this selected sample. Specifically, we find that investment increases by 40\%-45\%, which is close to the 36\%-38\% increase implied by columns (4)-(6) in Panel A. Finally, columns (4)-(6) of Panel E report effects on the inverse hyperbolic sine (IHS) of investment, i.e., $\log \left(I+\sqrt{1+I^{2}}\right)$. The IHS has the advantage that it can deal with zero values of investment, and it also approximates the logarithm for large values of investment. These estimates imply larger effects than the log specification, with increases of $63 \%-72 \%$. However, because the derivative of the IHS is greater near zero, these estimates place considerable weight on extensive-margin responses. These results show that the conclusion that the reform led to significant increases in investment by domestic firms does not rely on how we measure investment outcomes.

As a final robustness check, we consider whether firms could avoid or evade the VAT on equipment. It is unlikely that firms could evade this tax since China's VAT system with third-party reporting makes it likely that firms would get caught misreporting, especially when it comes to a large purchase, such as production equipment. One potential worry is that firms could avoid paying this tax by leasing instead of owning equipment. To explore this possibility, we estimate the effects of the reform on a measure of capital utilization that includes changes in leased equipment and investment. Table F.6 reports the results of these estimates and finds similar estimates to those of Panel A of Table 3. This result suggests that evasion and avoidance are not important concerns for the interpretation of our reduced-form results.

\subsection{Placebo Tests and Triple-Differences Analyses}

To further explore our identifying assumption, we conduct two sets of placebo tests on firms and types of investment that were not affected by the reform. We first compare foreign firms and domestic firms that were part of the pilot reform in 2004. Since these firms were already able to deduct equipment purchases from the VAT, the reform should not have affected their investment decisions. Columns (2) and (5) of Table 4 report the results of this placebo test. These results show

\footnotetext{
${ }^{37}$ This result is also visible in Figure 6, since there is no change in investment patterns in 2008.
} 
that foreign and domestic firms in the pilot had statistically indistinguishable investment patterns. Moreover, these null effects are precisely estimated and can rule out our main effects in columns (1) and (4). These results shows that foreign and domestic firms did not face differential shocks at the time of the reform.

Our second placebo test uses the fact that the tax treatment of investment in structures was not affected by the reform. Column (3) of Table 4 estimates the extensive-margin effect of the reform on structures. ${ }^{38}$ We find small effects on the extensive margin that are less than half of those on equipment investment. These results suggest firms may need to retrofit existing structures through minor investments to accommodate new equipment. Consistent with this conjecture, column (6) of Table 4 finds no impact on the intensive margin of investment in structures. These results show that foreign and domestic firms had similar investment patterns in assets that were not affected by the reform.

We now expand our specification in Equation 7 by including our two placebo groups as additional controls. The advantage of these triple difference specifications is that - by absorbing time-varying shocks - they ensure that the effects of the reform are not confounded by shocks that specifically affect foreign or domestic firms. Columns (2) and (3) of Table 5 report our triple-difference estimates on the extensive margin of investment. Relative to pilot firms and investment in structures, we find effects on equipment investment that are in the range of those in Table 3. Columns (5) and (6) also show that we obtain very similar estimates on the intensive margin as in our baseline differencein-differences specification. Taken together with the two placebo tests, these results support our identifying assumption that foreign and domestic firms did not face differential shocks that would confound the effects of the reform.

\subsection{Tax Policy and Partial Irreversibility}

We now provide three pieces of evidence that the effects of the VAT reform were driven by interactions between tax policy and partial irreversibility. First, we show that, consistent with the predictions of our model in Section 1, the VAT reform led to an increase in investment spikes. Second, we show that firms with excess VAT credits did not experience a reduction in partial irreversibility and therefore have smaller increases in investment. Finally, we explore heterogeneous effects across industries with different degrees of partial irreversibility.

\section{Investment Spikes}

We now show that the majority of the investment increase was due to the stimulus of additional investment spikes. We follow the literature (e.g., Cooper and Haltiwanger, 2006; Gourio and Kashyap,

\footnotetext{
${ }^{38}$ To focus on major investment in structures and exclude minor investments in affiliated facilities to buildings (e.g., pipes and elevators), we define the extensive margin of investment on structures in Table 4 as expansions of the capital stock by more than 1\%. Table F.7 shows that our results are robust to using different thresholds to define the extensive margin.
} 
2007) in defining investment spikes as events when the investment rate is greater than $20 \%$. We generate three new measures of investment responses to measure the importance of spikes. First, we define a dummy variable that takes the value of 1 when the investment rate is greater than $20 \%$ (i.e., $D_{i t}^{\text {spike }}=\mathbb{1}\left\{I K_{i t} \geq 0.2\right\}$ ) to capture the effect of the reform on the likelihood of an investment spike. Second, we define the spike investment rate as the product of the investment rate and the investment spike dummy, i.e., $I K_{i t}^{\text {spike }}=I K_{i t} \times \mathbb{1}\left\{I K_{i t} \geq 0.2\right\}$. Finally, we also consider the non-spike investment rate, i.e., $I K_{i t}^{\text {non-spike }}=I K_{i t} \times \mathbb{1}\left\{I K_{i t}<0.2\right\}$.

Table 6 reports difference-in-differences estimates of the effects of the reform on these outcomes. Columns (1)-(3) show that the fraction of firms undergoing investment spikes increased by 7.3 percentage points, which is greater than the effect on the likelihood that firms report positive investment (4.6 percentage points). This effect increases the spike rate from $16.6 \%$ to $23.9 \%$. Columns (4)-(6) report effects on the spike investment rate and columns (7)-(9) report effects on the non-spike investment rate. Algebraically, the sum of the effects on the spike and non-spike investment rates add up to the total effect in Panel A of Table 3 (columns (4)-(6)). Comparing the spike investment rate to the total effect, we find that the $23.9 \%$ of firms with a spike are responsible for $86 \%-92 \%\left(\approx \frac{0.031}{0.036}-\frac{0.035}{0.038}\right)$ of the effect on the investment rate. These results further show the importance of accounting for extensive-margin responses when studying the effects of tax policy on investment behavior.

\section{Excess VAT Payments and Partial Irreversibility}

While the reform allowed domestic firms to deduct VAT payments on equipment, firms with excess VAT payments did not receive refunds from the government. This feature allows for an additional test of the role of partial irreversibility, since firms with excess VAT payments that decide to invest would face a higher purchase price. ${ }^{39}$ We define a firm to be in a positive tax position if it has a positive potential VAT credit, defined by an excess VAT credit ignoring the input credit from investment. ${ }^{40}$ After the reform, $13.38 \%$ of domestic firms have a positive tax position.

Table 7 reports heterogeneous effects of the reform on investment by tax position. Columns (1) and (4) show the results for all firms, ${ }^{41}$ columns (2) and (5) for firms without a positive VAT credit, and columns (3) and (6) for firms with a positive VAT credit. These results show that investment responses, especially at the extensive margin, are driven by firms without excess VAT credits. Firms that will not recover the VAT payment on equipment in this period are still subject to tax-driven partial irreversibility and display much smaller investment effects. ${ }^{42}$

\footnotetext{
${ }^{39}$ In theory, firms could carry excess credits forward. However, even if firms are able to use these credits in the future, the interest cost of carrying the credits forward impacts the partial irreversibility of investment.

${ }^{40}$ Specifically, the potential VAT credit equals InputVAT $i t-$ OutputVAT $_{i t}+$ Credit $_{i, t-1}$ for domestic firms prior the reform. For foreign firms prior to the reform or all firms after the reform, the potential VAT credit equals InputVAT $_{i t}-$ OutputVAT $_{i t}+$ Credit $_{i, t-1}-17 \% \times I_{i t}$.

${ }^{41}$ The numbers of observations for columns (1) and (4) are different from the baseline results in Table 3 because this table restricts the sample to a balanced panel of firms with a non-missing tax position.

${ }^{42}$ While this is an important result for the study of tax administration (e.g., Ebrill et al., 2001), we do not model
} 


\section{Heterogeneous Response by Redeployability}

To further shed light on the role of irreversibility, we now explore whether the reform had heterogeneous effects depending on non-tax sources of partial irreversibility. Intuitively, firms that use assets that are specifically tailored to their needs are likely to face additional partial irreversibility. Eliminating tax-driven sources of partial irreversibility would then have smaller effects on firms in industries with high asset specificity.

To measure the importance of irreversibility, we use an industry-level index of asset redeployability developed by Kim and Kung (2017). The index takes into account the industry's asset composition as well as how each asset is used within and across industries. ${ }^{43}$ Industries with higher redeployability are less likely to face additional (non-tax) partial irreversibility. To test this hypothesis, we add an interaction with the redeployability index to our difference-in-differences regression. Table 8 reports the results of this analysis, where we normalize the redeployability index to have a zero mean and unit standard deviation. This table shows that industries with redeployability that is one standard deviation higher than average see larger increases in the fraction of firms investing in equipment (i.e., the extensive margin), the fraction of firms replacing more than $20 \%$ of their capital stock (i.e., investment spikes), and the investment rate (i.e., the intensive margin). These results further confirm the importance of considering the interactions between tax policy and partial irreversibility.

Overall, the results of this section show that China's 2009 VAT reform had a large effect on the investment of domestic firms. Relative to the magnitude of the reform, however, the estimates imply elasticities in the lower range of the previous literature (Hassett and Hubbard, 2002). Moreover, we find that spikes in investment account for the majority of the investment response to the reform. While these estimates evaluate the current reform, the results from Section 1 suggest that the estimated effects are not sufficient to evaluate the effects of other reforms.

\section{$5 \quad$ Estimating a Dynamic Investment Model}

The previous section provides evidence that taxes interact with investment frictions. To quantify the importance of these interactions and to study the fiscal effectiveness of alternative policy tools, we now estimate the dynamic model of investment outlined in Section 1. We estimate this model in two steps. First, we use the dynamic panel data model of Blundell and Bond (2000) to estimate the parameters that govern firms' static profit functions and productivity processes. Second, we estimate adjustment frictions using a simulated method of moments approach that targets prereform investment statistics as well as the reduced-form effects estimated in Section 4. By showing

the refundability of VAT payments in our baseline structural model. We find similar effects when we include the tax position as a feature of the structural model.

${ }^{43}$ For example, printing - which relies on customized machines - has a lower redeployability index, while leather manufacturing has a higher index. 
that our model can reproduce the effects of an actual reform, we ensure that the model predicts reasonable investment responses to tax changes.

\subsection{Estimating the Profit Function and Decomposing Productivity}

Recall that our model of firm profit (Equations 3-4) implies:

$$
\pi_{i t}=\theta k_{i t}+(1-\theta) a_{i t}=\theta k_{i t}+(1-\theta)\left(b_{t}+\omega_{i}+\varepsilon_{i t}\right),
$$

where $\pi_{i t}$ is $\log$ profit and $k_{i t}$ is $\log$ capital. The profitability term $a_{i t}$ is composed of an aggregate term $b_{t}$, an idiosyncratic transitory shock $\varepsilon_{i t}$, and a firm-specific permanent term $\omega_{i}$. $\omega_{i}$ captures unobserved firm-level heterogeneity as well as unmodeled frictions. ${ }^{44} \varepsilon_{i t}$ follows an $\operatorname{AR}(1)$ process with persistence and standard deviation $\left(\rho_{\varepsilon}, \sigma_{\varepsilon}\right)$. $b_{t}$ also follows an $\operatorname{AR}(1)$ process with parameters $\left(\rho_{b}, \sigma_{b}\right) \cdot \omega_{i}$ is normally distributed with mean zero and standard deviation $\sigma_{\omega}$. The main parameters of this equation are the curvature of the profit function, $\theta$, and the parameters governing productivity $\left(\rho_{\varepsilon}, \sigma_{\varepsilon}, \rho_{b}, \sigma_{b}, \sigma_{\omega}\right)$.

Two sets of challenges prevent us from estimating Equation (8) directly. First, it is hard to measure economic profit using accounting data. To overcome this issue, we follow Cooper and Haltiwanger (2006) by assuming that profits are proportional to revenue. ${ }^{45}$

A second set of concerns with Equation (8) is that capital may be measured with error and that it may also be correlated with productivity. We address these concerns by using the system GMM estimator of Blundell and Bond (2000). This estimator uses the assumption that the idiosyncratic productivity term $\varepsilon_{i t}$ is an $\mathrm{AR}(1)$ process to rewrite Equation (8) in a more favorable form. Specifically, using the fact that $\varepsilon_{i t}=\rho_{\varepsilon} \varepsilon_{i, t-1}+e_{i t}$, where $e_{i t}$ is an innovation term independently and identically distributed across firms and over time, and that $\varepsilon_{i, t-1}$ can be expressed as a function of lagged capital and revenue, we obtain the following equation:

$$
r_{i t}=\rho_{\varepsilon} r_{i, t-1}+\theta k_{i t}-\rho_{\varepsilon} \theta k_{i, t-1}+b_{t}^{*}+\omega_{i}^{*}+m_{i, t}-\rho_{\varepsilon} m_{i, t-1}+(1-\theta) e_{i t}
$$

where we replaced $\pi_{i t}$ with $r_{i t}$ (log-revenue), where $m_{i t}$ is a classical measurement error (or an unexpected optimization error), and where $b_{t}^{*}$ and $\omega_{i}^{*}$ are year and firm-level fixed effects. ${ }^{46}$ We can

\footnotetext{
${ }^{44}$ As in Hsieh and Klenow (2009), firms may face different wedges that impact effective prices. Section 5.2 augments our model to account for heterogeneity in $\omega_{i}$ in firms' dynamic investment decisions.

${ }^{45}$ Appendix A.2 gives examples where this assumption holds either with a DRTS production function and perfect competition or with constant-elasticity-of-substitution (CES) demand and monopolistic competition - two cases that are commonly analyzed in the macro investment literature. In addition, without loss of generality, we can also decompose revenue shocks as $a_{i t}^{R}=b_{t}+\omega_{i}+\varepsilon_{i t}$. When logarithms are taken, the profit and revenue shocks differ by a constant, which implies that $a_{i t}^{R}$ and $a_{i t}$ have the same persistence and variance.

${ }^{46}$ This follows from writing Equation (8) in terms of revenue $\left(r_{i t}=\theta k_{i t}+(1-\theta) b_{t}+(1-\theta) \omega_{i}+(1-\theta) \varepsilon_{i t}+m_{i t}\right)$, replacing $\varepsilon_{i t}$ with $\rho_{\varepsilon} \varepsilon_{i, t-1}+e_{i t}$, then replacing $\varepsilon_{i, t-1}$ with $\left(r_{i t-1}-\theta k_{i t-1}\right) /(1-\theta)-b_{t-1}-(1-\theta) \omega_{i}-m_{i t-1} /(1-\theta)$, and finally setting $b_{t}^{*}=(1-\theta) b_{t}-\rho_{\varepsilon}(1-\theta) b_{t-1}$ and $\omega_{i}^{*}=(1-\theta)\left(1-\rho_{\varepsilon}\right) \omega_{i}$. See Appendix E for more details.
} 
then write this equation in first differences to obtain:

$$
\Delta r_{i t}=\rho_{\varepsilon} \Delta r_{i, t-1}+\theta \Delta k_{i t}-\rho_{\varepsilon} \theta \Delta k_{i, t-1}+\Delta b_{t}^{*}+\Delta m_{i, t}-\rho_{\varepsilon} \Delta m_{i, t-1}+(1-\theta) \Delta e_{i t}
$$

To avoid problems arising from endogenous capital, we instrument this equation using lagged revenue $r_{i t-s}$ and capital $k_{i t-s}, s \geq 3$. Finally, to avoid potential problems of weak instruments, we use the system GMM estimator of Blundell and Bond (2000), which jointly estimates Equation (9) using changes in lagged revenue $\Delta r_{i t-s}$ and capital $\Delta k_{i t-s}, s \geq 2$ as additional instruments. ${ }^{47}$

Panel B of Table 9 reports the results of this estimation. This procedure delivers an estimate of $\theta=0.734$. To better understand how $\theta$ affects the curvature of the profit function, we compute the implied markup in a simple model of monopolistic competition. Our estimate of $\theta$ yields a markup of 1.224, which is comparable to values used in the literature. ${ }^{48}$ We use this estimate of $\theta$ to compute firm-level productivity $\hat{a}_{i t}=r_{i t}-\hat{\theta} k_{i t}$.

The system GMM estimator also delivers an estimate of the persistence coefficient $\rho_{\varepsilon}$ of $0.860 .{ }^{49}$ We then recover the distributions of $b_{t}, \omega_{i}$, and $\varepsilon_{i t}$ by decomposing the variance of the estimated productivity $\hat{a}_{i t}$ - see Appendix E.3 for more details. Due to the short panel nature of our data, aggregate shocks play a relatively small role. Our estimate of the standard deviation of aggregate shocks $\sigma_{b}$ is 0.010 , and the estimate of its persistence $\rho_{b}$ is 0.009 . Nonetheless, including aggregate productivity shocks in our framework allows us to consider counterfactual scenarios where changes to tax policy coincide with shocks to aggregate productivity. We estimate that the standard deviation of transitory shocks $\sigma_{\varepsilon}$ equals 0.529 and that the permanent heterogeneity term has a standard deviation of $\sigma_{\omega}=0.854$. As a result, a large fraction of the dispersion in profitability comes from permanent heterogeneity across firms. ${ }^{50}$ However, despite the fact that the distributions of the capital stock and firm size depend on permanent heterogeneity, investment dynamics are mostly determined by transitory shocks.

\subsection{Estimating Adjustment Costs}

We now estimate the adjustments costs of investment using the method of simulated moments (MSM). This approach simulates the investment decisions of a large number of firms by numerically solving the dynamic investment model in Section 1 subject to the profit function and productivity

\footnotetext{
${ }^{47}$ The exclusion restriction is that $\Delta e_{i t}$ is uncorrelated with the twice-lagged values of revenue and capital and that $e_{i t}$ is uncorrelated with the twice-lagged changes in revenue and capital.

${ }^{48}$ We show this in Appendix E.2 by assuming that the firm has a CRTS production function and faces CES demand. In this case, the markup excluding the capital cost is constant and equals $\frac{1}{\theta} \frac{\alpha(1-\sigma)}{(1-\alpha)(1-\sigma)+\sigma}+1$, where $\alpha$ is the share of capital in value added and $\sigma$ is the share of materials. Assuming $\alpha=0.5$ (Bai, Hsieh, Qian et al., 2006) and $\sigma=0.7$ (Jones, 2011), the implied markup is 1.224. For comparison, the ratio of total sales to major business costs in the data is 1.223 .

${ }^{49}$ Cooper and Haltiwanger (2006) estimate a value of 0.85 , and Winberry (2020) fixes this parameter at 0.9 .

${ }^{50}$ As in David and Venkateswaran (2019), accounting for permanent heterogeneity is important when estimating investment models with adjustment costs.
} 
shocks estimated in the previous section. We simulate these firms until the distribution reaches the steady state. We then measure key investment statistics in the simulated data, and we also simulate a VAT reform mirroring the difference-in-differences research design of Section $4 .{ }^{51}$ Finally, the estimated adjustment cost parameters are those that best reconcile the simulated data with the actual data.

Before we detail the MSM estimator, we first discuss three sets of fixed parameters. First, we set the discount factor $\beta$ to 0.95 . Second, we set the CIT rate to the average effective rate in the data, $15.4 \%$, and we set the VAT rate to $17 \%$ - the statutory rate before the reform. Third, we set the present value of depreciation deductions $p_{v}$ to $0.803 .^{52}$

We estimate two models that differ by the distribution of fixed costs. The first model is based on Cooper and Haltiwanger (2006) and assumes a degenerate distribution $G(\xi)$ with a single mass point at $\bar{\xi}$. The second model assumes that $\xi$ is drawn from a uniform distribution over the interval $[0, \bar{\xi}]$, as in Caballero and Engel (1999); Khan and Thomas (2008); Winberry (2020). We estimate three parameters for each model: the economic rate of depreciation $\delta$, the convex adjustment cost parameter $\gamma$, and the parameter of the fixed cost distribution $\bar{\xi}$.

We now form the criterion function for the MSM estimator. Denote $\phi=\{\delta, \gamma, \bar{\xi}\}, \hat{m}$ as the data moments and $m(\phi)$ as the simulated moments. The estimate $\hat{\phi}$ minimizes the criterion function:

$$
g(\phi)=[\hat{m}-m(\phi)]^{\prime} W[\hat{m}-m(\phi)]
$$

We include two sets of moments in $\hat{m}$ :

1) The first set of moments $\left(m^{A}\right)$ is based on pre-reform stationary moments (as in Figure 5):

(a) the mean and the standard deviation of the investment rate;

(b) the empirical distribution of the investment rate, defined by the fraction of firms with an investment rate below 10\%, 20\% (i.e., 1-spike rate), and 30\%; and

(c) the 1-year autocorrelation of the investment rate.

These moments are widely used to identify adjustment costs in the investment literature. ${ }^{53}$ As in other settings that rely on tax data (e.g., Zwick and Mahon, 2017; Winberry, 2020), we do not observe equipment sales. Since asset sales are often used to disentangle the roles of fixed costs and partial irreversibility (e.g., Cooper and Haltiwanger, 2006), a potential concern is

\footnotetext{
${ }^{51}$ We simulate two sets of 10,000 firms for the simulated difference-in-differences: a set of treatment firms that experience a drop in the VAT rate from $\nu=17 \%$ to zero and a set of control firms unaffected by the reform. We assume the reform is unexpected and permanent and occurs at the initial steady state. To match our empirical analysis, the simulated difference-in-differences measure effects on investment over a three-year period.

${ }^{52}$ This value follows from using an interest rate $r=5.26 \%(=1 / \beta-1)$ to depreciate deductions using a straight-line depreciation rule over a 10-year period.

${ }^{53}$ For example, among other moments, Cooper and Haltiwanger (2006) use the spike rate and the autocorrelation coefficient; Winberry (2020) uses the standard deviation of the investment rate and the spike rate; and Clementi and Palazzo (2016) use the standard deviation and autocorrelation of the investment rate.
} 
that excluding sales data will impact our estimates of fixed costs. Because China's 2009 VAT reform reduced partial irreversibility by lowering the purchase price of equipment, we use the effects of the reform on the intensive and extensive margins of investment to overcome this concern.

2) The second set of moments $\left(m^{B}\right)$ is based on the difference-in-difference (DID) estimates reported in Table 3:

(a) the DID estimate of the effect of the reform on the investment rate; and

(b) the DID estimate of the effect of the reform on the fraction of firms with positive investment.

We use these reduced-form moments to validate our adjustment-cost estimates based on the moments in $m^{A}$ and as a way to provide overidentifying restrictions.

To compute the simulated moments, $m(\phi)$, we simulate the investment statistics for each value of $\phi$. Similarly, we mirror the actual reform by measuring the effects of a simulated VAT reform for three years after the tax change.

We use the identity weighting matrix in our estimation. This allows the estimate $\hat{\phi}$ to be informed by both $m^{A}$ and $m^{B} .{ }^{54}$

\section{Identification}

We briefly discuss the identification of the model parameters since they follow standard arguments in the investment literature. The first set of stationary moments $\left(m^{A}\right)$ is sufficient to identify the three structural parameters. The economic depreciation rate $\delta$ is closely tied to the average investment rate.

The convex adjustment cost $\gamma$ affects investment moments through two channels. First, a higher $\gamma$ increases the serial correlation of investment by incentivizing firms to smooth investment over time. It also decreases the likelihood of an investment spike. Second, a higher $\gamma$ lowers firms' steadystate capital levels and - by increasing the relative importance of fixed costs - leads to less frequent investment spells. When $\gamma$ is sufficiently large, the second channel dominates and a higher $\gamma$ leads to a smaller serial correlation of investment (see Figure F.4). In contrast, a higher $\bar{\xi}$ increases the fraction of firms with lumpy investment as well as the standard deviation of the investment rate. At the same time, a higher $\bar{\xi}$ also reduces the serial correlation of investment.

One concern is that additional sources of partial irreversibility may bias our estimates of $\gamma$ and $\bar{\xi}$ that only rely on the moments in $m^{A}$. The reduced-form moments $m^{B}$ help assuage this

\footnotetext{
${ }^{54}$ Models that rely on $m^{A}$ moments result in similar estimates when $W$ is the identity matrix or when we use the bootstrapped variance-covariance matrix of the moments. While the moments $m^{B}$ are precisely estimated (with t-stats around 4 or 8 ), the cross-sectional moments in $m^{A}$ have very small variances (with t-stats between 100-500). For this reason, models that weight $m^{A}$ and $m^{B}$ using the variance-covariance matrix give very little weight to the moments in $m^{B}$.
} 
concern. As we discuss in Section $1, \gamma$ and $\bar{\xi}$ both lower the effect of a VAT cut on the investment rate. In addition, a lower $\bar{\xi}$ would increase the effect of the reform on the extensive margin. By simultaneously matching a reform that eliminated an important source of partial irreversibility, these moments help us evaluate the robustness of our estimates.

As a complement to this discussion, we conduct a systematic analysis of how these moments affect $(\hat{\delta}, \hat{\gamma}, \hat{\bar{\xi}})$ in Appendix E.4 by calculating the sensitivity measure proposed by Andrews, Gentzkow and Shapiro (2017).

\section{Estimates of Adjustment Costs}

Table 10 reports estimates of the adjustment $\operatorname{costs} \gamma$ and $\bar{\xi}$ and the depreciation rate $\delta$ and compares the data moments with the simulated moments. The second row reports estimates from a model that only uses the pre-reform stationary statistics $m^{A}$ as target moments and where $\xi$ is fixed at a single value. While this model does a relatively good job of matching the spike rate and the average investment rate, it overpredicts the fraction of firms with an investment rate below $10 \%$ as well as the standard deviation of the investment rate. The low convex cost and high fixed cost in this model result in a "bang-bang" investment function where firms either do not invest at all or replace more than $30 \%$ of their capital. Notably, there are no firms with investment rates in the 10\%-30\% range. As a consequence, the model predicts that the VAT reform would have increased both the fraction of firms investing and the investment rate by 15 percentage points. These effects are 3-4 times larger than our reduced-form estimates.

The third row of Table 10 reports estimates of a model that only targets pre-reform stationary statistics $m^{A}$ and that allows $\xi$ to be i.i.d. with a uniform distribution. The estimate of $\bar{\xi}$ implies a larger upper bound for the fixed costs, and we also estimate a larger value of $\gamma$ relative to the first model. The randomness of the fixed cost lowers the serial correlation of investment and results in an overall better match of the whole investment rate distribution. In particular, the model implies that $14 \%$ of firms have investment rates between $10 \%$ and $30 \%$ (relative to $17 \%$ in the data). ${ }^{55}$ One potential concern is that the lack of data on equipment sales makes it hard to estimate fixed costs separately from the role of partial irreversibility. Because the VAT reform decreased partial irreversibility by lowering the price of new equipment, we can validate our baseline model estimates using the reduced-form effects of the reform. While this model does not target the difference-indifferences estimates, it does a relatively good job of matching the effects of the reform. The model predicts slightly smaller increases in the fraction of firms investing (3 percentage points) and in the investment rate (2.8 percentage points) than those measured in the data.

The fourth row of Table 10 reports estimates of a model that targets both $m^{A}$ and $m^{B}$. This model results in very similar estimates of the structural parameters. However, the small changes in the estimates result in an improved fit of the standard deviation and the serial correlation of

\footnotetext{
${ }^{55}$ Baley and Blanco (2019) show that it is important to match cross-sectional investment patterns to characterize the role of lumpy investment in aggregate impulse response functions to a policy reform.
} 
investment. Not surprisingly, the model results in a slightly better fit of the moments $m^{B}$. ${ }^{56}$ The model predicts an increase of 4.2 percentage points in the fraction of firms investing and an increase of 3.3 percentage points in the investment rate. It is worth noting that the last two models have slightly lower average investment rates. Overall, relative to the average investment rate, the last two models predict that the VAT reform would increase investment by 35\%-40\%, which is remarkably close to our reduced-form estimates.

As we discuss in Section 4, the majority of the increase in the investment rate following the reform was due to additional investment spikes. We use the estimated effect of the reform on investment spikes as additional overidentifying moments. Table F.11 reports that the model predicts a 6.4-percentage-point increase in the likelihood of an investment spike (relative to a measured 7.3 percentage points). Similarly, the model predicts an increase in the spike investment rate of 3.6 percentage points (relative to a measured 3.5 percentage points). These results show that our model is able to quantitatively match the empirical finding that the extensive margins of investment are key determinants of the effects of the VAT reform. Moreover, because the effects of tax policy depend on the relative magnitudes of fixed costs and partial irreversibility, this overidentification check is evidence that our estimated model properly captures the importance of these frictions.

Finally, we now consider the economic magnitude of the estimated adjustment costs. The estimated convex cost parameter $\hat{\gamma}$ is 1.432. Given the model's average investment rate of $8 \%$, the convex adjustment cost at the average investment rate would amount to $0.45 \%\left(=\frac{1.432}{2} \times(0.08)^{2}\right)$ of capital. To grasp the magnitude of the fixed adjustment, note that the estimated upper bound of 0.119 implies an average fixed cost of $5.95 \%$ of the desired capital stock. However, since firms select into investment, the average fixed cost paid by firms with positive investment is only $2.4 \%$ of the desired capital stock. Table 9 collects all of the parameters that define our model.

Overall, the model does a remarkable job of matching stationary investment statistics and the effects of an actual tax reform as well as untargeted moments that highlight the importance of investment spikes. Given these results, we expect the estimated model to provide a solid foundation to compare the effects of alternative tax policies.

\section{Simulating Alternative Tax Reforms}

As we show in Section 1, the effectiveness of different types of tax incentives at stimulating investment depends on how tax policies impact the extensive margin of investment. We now use the estimated dynamic model to quantify which policies are more effective at stimulating investment and firm value relative to their total fiscal cost. We first build intuition by studying the effects of different changes to the VAT rate and the CIT rate and by considering the introduction of an investment tax credit (ITC). We then quantify the effects of potential reforms that are closely modeled

\footnotetext{
${ }^{56}$ Figure F.3 shows that the criterion function is concave and rises sharply around the estimated parameters.
} 
on the recent US tax reform. Throughout, we consider the effects of unexpected and permanent tax policy changes.

\subsection{Extensive-Margin Responses and Fiscal Effectiveness}

One of the benefits of our model is that it allows us to provide a menu of policy options for government officials who want to stimulate investment. Figure 7 allows a government official to compare reforms that result in a similar loss of tax revenue. Panel A of Figure 7 compares the effects on investment of a CIT cut versus those of a VAT cut. The solid blue line reports the effects of reducing the CIT rate from $15.4 \%$ to $1 \%$. Each marker in the line represents the simulated effects of reducing the CIT rate to a given rate, where we calculate the effects over a 10-year window. For example, the $\mathrm{x}$-axis shows that reducing the CIT rate to $10 \%$ results in a tax revenue loss of $20 \%$ (which includes VAT and CIT revenue). The y-axis shows that this reform results in an investment increase of close to $15 \%$. The dashed red line allows us to compare this CIT cut with a VAT cut that has the same effect on tax revenue. Specifically, cutting the VAT rate to $3 \%$ would result in a similar revenue loss as the CIT cut discussed above, but would increase investment by $35 \%$.

By comparing investment and tax revenues, Figure 7 helps us determine which policies are more effective at stimulating investment. ${ }^{57}$ The blue line in Panel A shows that the effect on investment is always smaller than the effect on tax revenue and implies an investment-to-tax-revenue elasticity of close to $0.67 .{ }^{58}$ Because the dashed red line is always above the 45-degree line, the investment-totax-revenue elasticity is always greater than one. These simulations show that a VAT cut is more effective at stimulating investment for a given revenue cost than a CIT cut.

The superior fiscal effectiveness of the VAT reform is driven by extensive-margin responses, as they impact both the cost of these reforms and their effects on investment. First, extensivemargin responses drive the costs of different policies. CIT cuts are more costly since they benefit all firms - even those in the inaction region - while only firms that invest benefit from a VAT cut. Second, following the intuition from Figure 4 in Section 1, cuts to the VAT rate narrow the inaction region, leading more firms to undertake new investment projects. To illustrate the importance of this mechanism, we use our simulated data to study the composition of investment responses. In the case of the VAT reform (setting $\nu=0$ ), of the overall $43 \%$ increase in investment, $64 \%$ was driven by extensive-margin responses. In contrast, while cutting the CIT rate to $7.4 \%$ - at the cost of a similar impact on revenue - increases investment by $20 \%$, only $34 \%$ of this increase was due to extensive-margin responses.

Panel B of Figure 7 compares the effects of a VAT cut to those of introducing an investment

\footnotetext{
${ }^{57}$ In contrast, approaches that rely on TUCC elasticities to forecast the effects of different stimulus policies may not correctly capture extensive-margin responses. This result is partly driven by the fact that policies with similar effects on the TUCC can lead to different extensive-margin effects. As we show in Appendix F, VAT and CIT cuts with the same TUCC change can have different investment elasticities and differ in their fiscal effectiveness.

${ }^{58}$ Given that the different CIT cuts fall in a straight line, this investment-to-tax-revenue elasticity is constant across the different rate cuts.
} 
tax credit (ITC). ${ }^{59}$ In contrast to Panel A, this graph shows that the effects of an investment tax credit mirror those of a VAT cut very closely. The reason for this result is that the ITC also lowers the partial irreversibility of investment. The slight difference in the effectiveness of these policies is due to the fact that the VAT cut reduces the value of depreciation deductions while the ITC does not. Importantly, this graph shows that the lessons of China's 2009 VAT reform are applicable to other countries or states that already have enacted or will enact an ITC.

\subsection{Simulating Tax Reforms}

We now build on the intuition from Figure 7 by studying a broader menu of policy alternatives, including ones recently enacted as part of the US tax reform. We consider the effects of the following policies:

1. the VAT reform with a $17 \%$ tax rate reduction (our baseline);

2. a CIT cut from the current effective tax rate of $15.4 \%$ to $10 \%^{60}$;

3. $100 \%$ bonus depreciation (expensing), which allows firms to deduct capital expenditures immediately;

4. a version of the Tax Cuts and Jobs Act (TCJA) that combines expensing with the CIT cut; and

5. a $17 \%$ investment tax credit.

Table 11 simulates the effects of these policies on investment, firm value, and tax revenues. ${ }^{61}$ Column (1) shows that the baseline VAT cut increased aggregate investment by $43 \%$. We also find a relatively large increase of $10 \%$ in the fraction of firms investing and an increase of $11 \%$ in firm value. Because the VAT on equipment purchases raised a considerable amount of revenue, this simulation entails a revenue loss of $28 \%$. To compare the fiscal effectiveness of different policies, we also report the ratios of the percentage changes in investment and firm value to the percentage change in tax revenue. In the case of the VAT reform, we find that investment increases by $1.6 \%$ for every $1 \%$ loss in tax revenue. Similarly, firm value increases by $0.41 \%$ for a $1 \%$ loss in tax revenue.

We now consider the effects of tax policies that are modeled after the recent US tax reform but that have a similar tax cost to the VAT reform. Column (2) reports the effects of a CIT cut, which has smaller effects on both investment and the fraction of firms that invest in any given year. Column (3) studies the effects of a bonus depreciation policy that allows firms to immediately

\footnotetext{
${ }^{59}$ We model the effect of an ITC on the purchase price of capital as follows: TUCC $=\frac{(1+\nu)\left(1-\tau p_{v}\right)-I T C}{1-\tau}$. Note that an ITC does not affect the book value of capital or its resale price. Similar to a VAT cut, an ITC reduces the gap between the purchase and resale price of capital.

${ }^{60}$ This $35 \%$ reduction in $\tau$ is comparable to the decrease in the CIT following the TCJA in the US.

${ }^{61}$ As in Winberry (2020), firm value is the sum of the value function and the tax value of depreciation allowances. Figure F.5 compares the effects of different VAT, CIT, and ITC incentives on firm value.
} 
deduct the full cost of investment. This policy has similar effects on investment to those of the CIT cut but is less effective at raising firm value. Column (4) combines the effects of a CIT cut and bonus depreciation, mirroring the TCJA in the US. ${ }^{62}$ This policy increases aggregate investment by roughly half of the effect of the VAT reform, even though the tax revenue losses from both policies are similar. This result shows that addressing distortions that generate partial irreversibility may be more important for emerging economies like China than lowering the tax cost of investment.

The last policy we consider is an investment tax credit of $17 \%$. As shown in Figure 7 , this policy is very closely related to a VAT cut since it also reduces the partial irreversibility of investment. For this reason, it is no surprise that column (5) reports ratios of investment and firm value to the tax revenue loss that are comparable to those of the VAT cut. This again shows that the result that tax policy can directly affect the lumpiness of investment is applicable outside the case of China.

\subsection{Model Robustness}

We now show that our baseline simulation results are robust to a number of extensions. ${ }^{63}$ First, we explore the general equilibrium effects of increasing capital prices or interest rates. In our baseline model, we assume that the pre-tax price of capital goods is constant. One concern is that the price of capital increases as the demand goes up (e.g., Goolsbee, 1998). We relax this assumption by calibrating an upward-sloping capital supply curve based on the results of House and Shapiro (2008). Column (2) of Table F.12 shows that this change results in a slightly smaller aggregate effect on investment and an investment-to-tax-revenue elasticity of 0.84. Additionally, we also consider the possibility that borrowing rates increase as a result of the VAT cut. To allow for this possibility, we assume that interest rates have a proportional increase to the TUCC. Table F.13 simulates the effects of the VAT cut assuming interest rate elasticities with respect to the TUCC that range from -0.05 to -0.25 . We find slightly smaller effects when we allow for this mitigating effect. However, even for the largest effect of the TUCC on interest rates, the increase in investment is $80 \%$ of the baseline increase. While a full general equilibrium calculation is beyond the scope of this paper, these extensions show that our main results are not sensitive to allowing for changes in interest rates or in the price of capital goods.

As a second extension, we consider the role of imperfections in the used capital market. A potential concern is that the resale price is smaller than the purchase price, even without taxes. To explore this possibility, we increase the degree of partial irreversibility by reducing the resale price from 1 (as in the baseline model) to 0.80 (as in Cooper and Haltiwanger, 2006; Ramey and Shapiro, 2001). Column (3) of Table F.12 shows that our results are virtually unaffected by this change.

While we have shown that our empirical results in Section 4 are not affected by other stimulus

\footnotetext{
${ }^{62}$ Bonus depreciation has a smaller effect on firm value than a CIT cut since this policy only benefits firms that invest. Our simulated TCJA raises overall investment by less than the sum of the CIT cut and bonus depreciation, since the tax cut lowers the value of depreciation deductions.

${ }^{63}$ Appendix F.1 provides additional discussion of these extensions.
} 
policies, it may be important to account for aggregate productivity shocks related to the financial crisis in our counterfactual analysis. Column (4) of Table F.12 shows that our results are very similar when the reform coincides with a (permanent) one-standard-deviation drop in aggregate productivity. $^{64}$

Finally, we address the fact that our simulations of the effects of CIT cuts on investment abstracted from interactions between the CIT rate and both adjustment costs and borrowing costs. ${ }^{65}$ First, we modify our model to consider the possibility that adjustment costs are tax deductible. In this case, a CIT cut directly impacts the importance of fixed and convex adjustment costs, making the pre-tax value of these costs larger. Following this intuition, Table F.14 shows that we find smaller effects following a CIT cut when we assume that adjustment costs are deductible. Second, we now consider the fact that debt is a preferred form of financing since interest payments are tax deductible (Graham, 2000). Because a CIT cut reduces the value of tax-deductible financing, accounting for this effect on the after-tax cost of financing may reduce the effectiveness of CIT cuts at stimulating investment. Table F.14 confirms that when a CIT cut affects a firm's financing costs (through the weighted average cost of capital, WACC), it is less effective at stimulating investment. Therefore, our main result - that policies that directly impact the extensive margins of investment are more effective at stimulating investment - is only strengthened by assuming that adjustment costs or interest costs are tax deductible.

\section{Conclusion}

The universal fact that firms make lumpy investment decisions has important implications for tax policy. This paper develops this point in several ways.

First, the paper shows that models of investment with partial irreversibility or fixed costs of adjustment are required to generate extensive-margin responses to tax policy changes. In these models, the user cost of capital is not a sufficient statistic for how tax policy affects investment. Accounting for how tax policy interacts with investment frictions is necessary to obtain a complete picture of the effects of tax policy on investment behavior.

Second, we analyze an important tax policy change in China that reduced the after-tax cost of investment by close to $15 \%$. We show that this reform directly affected the likelihood of firm inaction by reducing the degree to which partial irreversibility leads firms to delay adjusting their capital stock. We use administrative tax data and a difference-in-differences research design to document that, as a result of the reform, domestic Chinese firms increased investment by $36 \%$ relative to foreign firms. We also find that the majority of the increase in investment was due to

\footnotetext{
${ }^{64}$ While the effects of the VAT reform are robust to coincidental productivity shocks, we do not study whether the effectiveness of fiscal policy depends on the business cycle (Winberry, 2020) or on whether other forms of partial irreversibility endogenously respond to fiscal policy (Lanteri, 2018).

${ }^{65}$ Note that these assumptions do not affect our estimation or our simulation of changes to the VAT system. However, they impact the simulation of changes to the CIT.
} 
extensive-margin responses, including additional investment spikes, and that the non-refundability of excess VAT credits can also generate partial irreversibility.

Finally, we estimate an empirical dynamic model of investment that embeds adjustment frictions and relevant tax parameters. We use the reduced-form estimates of the reform to show that the model can reproduce the effects of an actual tax reform. The model shows that policies that limit partial irreversibility, such as eliminating a tax on investment or subsidizing it through an investment tax credit, are more effective at stimulating investment than policy tools that simply lower the cost of investment, such as a corporate income tax cut. Because other policies - such as investment tax credits and sales taxes - can directly impact extensive-margin investment decisions, these results have important implications for tax policy beyond China.

\section{References}

Abel, Andrew B., "Empirical investment equations: An integrative framework," CarnegieRochester Conference Series on Public Policy, 1980, 12, 39 - 91.

Andrews, Isaiah, Matthew Gentzkow, and Jesse M Shapiro, "Measuring the sensitivity of parameter estimates to estimation moments," The Quarterly Journal of Economics, 2017, 132 (4), 1553-1592.

Arellano, Cristina, Yan Bai, and Jing Zhang, "Firm dynamics and financial development," Journal of Monetary Economics, 2012, 59 (6), 533 - 549.

Auerbach, Alan J, "The Dynamic Effects of Tax Law Asymmetries," The Rreview of economic studies, 1986, 53 (2), 205-225.

Auerbach, Alan J., "Tax Reform and Adjustment Costs: The Impact on Investment and Market Value," International Economic Review, 1989, 30 (4), 939-962.

Auerbach, Alan J and James R Hines, "Investment Tax Incentives and Frequent Tax Reforms," American Economic Review, 1988, 78 (2), 211-216.

Bachmann, Rüdiger, Ricardo J. Caballero, and Eduardo M. R. A. Engel, "Aggregate Implications of Lumpy Investment: New Evidence and a DSGE Model," American Economic Journal: Macroeconomics, October 2013, 5 (4), 29-67.

Bai, Chong-En, Chang-Tai Hsieh, and Zheng Song, "The Long Shadow of a Fiscal Expansion," Brookings Papers on Economic Activity, 2016, pp. 15-16.

_ ,_, Yingyi Qian et al., "The Return to Capital in China," Technical Report, National Bureau of Economic Research, Inc 2006.

Baley, Isaac and Andrés Blanco, "Aggregate Dynamics in Lumpy Economies," Technical Report, Working Paper 2019.

Barro, Robert J. and Jason Furman, "Macroeconomic Effects of the 2017 Tax Reform," Brookings Papers on Economic Activity, 2018, 49 (1 (Spring), 257-345.

Blundell, Richard and Stephen Bond, "GMM estimation with persistent panel data: an application to production functions," Econometric reviews, 2000, 19 (3), 321-340. 
Caballero, Ricardo J and Eduardo MRA Engel, "Explaining investment dynamics in US manufacturing: a generalized (S, s) approach," Econometrica, 1999, 67 (4), 783-826.

Cai, Jing and Ann Harrison, "Industrial Policy in China: Some Unintended Consequences?," Industrial and Labor Relations Review, November 2019.

Chen, Yuyu, Zongyan He, and Lei Zhang, "The Effect of Investment Tax Incentives: Evidence from China's Value-Added Tax Reform," Working Paper, Peking University., 2016.

Chen, Zhao, Zhikuo Liu, Juan Carlos Suárez Serrato, and Daniel Yi Xu, "Notching R\&D Investment with Corporate Income Tax Cuts in China," Technical Report, mimeo, Duke University 2019.

Chirinko, Robert S. and Daniel J. Wilson, "State investment tax incentives: A zero-sum game?," Journal of Public Economics, 2008, 92 (12), 2362 - 2384. New Directions in Fiscal Federalism.

Clementi, Gian Luca and Berardino Palazzo, "Entry, exit, firm dynamics, and aggregate fluctuations," American Economic Journal: Macroeconomics, 2016, 8 (3), 1-41.

Cline, Robert, John Mikesell, Tom Neubig, and Andrew Phillips, "Sales Taxation of Business Inputs Existing Tax Distortions and the Consequences of Extending the Sales Tax to Business Services," Technical Report, Council on State Taxation 2005.

Cong, Lin William, Haoyu Gao, Jacopo Ponticelli, and Xiaoguang Yang, "Credit allocation under economic stimulus: Evidence from China," The Review of Financial Studies, 2019, 32 (9), 3412-3460.

Cooper, Russell W and John C Haltiwanger, "On the nature of capital adjustment costs," The Review of Economic Studies, 2006, 73 (3), 611-633.

Cummins, Jason G, Kevin A Hassett, and R Glenn Hubbard, "A reconsideration of investment behavior using tax reforms as natural experiments," Brookings papers on economic activity, 1994, 1994 (2), 1-74.

David, Joel M. and Venky Venkateswaran, "The Sources of Capital Misallocation," American Economic Review, July 2019, 109 (7), 2531-67.

Desai, Mihir A., C.Fritz Foley, and James R. Hines, "Foreign direct investment in a world of multiple taxes," Journal of Public Economics, 2004, 88 (12), 2727 - 2744.

DiNardo, John, Nicole M. Fortin, and Thomas Lemieux, "Labor Market Institutions and the Distribution of Wages, 1973-1992: A Semiparametric Approach," Econometrica, 1996, 64 (5), 1001-1044.

Ebrill, Liam, Michael Keen, Jean-Paul Bodin, and Victoria Summers, The Modern VAT, International Monetary Fund, 2001.

EY, "Managing indirect tax refunds," Technical Report, Ernst \& Young 2017.

Goolsbee, Austan, "Investment Tax Incentives, Prices, and the Supply of Capital Goods," Quarterly Journal of Economics, 1998, (113), 121-148.

Gourio, Francois and Anil K Kashyap, "Investment spikes: New facts and a general equilibrium exploration," Journal of Monetary Economics, September 2007, 54 (Supplemen), 1-22. 
Graham, John R., "How Big Are the Tax Benefits of Debt?," The Journal of Finance, 2000, 55 (5), 1901-1941.

Hall, Robert E and Dale W Jorgenson, "Tax Policy and Investment Behavior," American Economic Review, 1967, 57 (3), 391-414. Reprinted in Bobbs-Merrill Reprint Series in Economics , Econ-130. Investment 2, ch. 1, pp 1-26.

Hassett, Kevin A and R Glenn Hubbard, "Tax policy and business investment," in "Handbook of public economics," Vol. 3, Elsevier, 2002, pp. 1293-1343.

Hayashi, Fumio, "Tobin's marginal q and average q: A neoclassical interpretation," Econometrica: Journal of the Econometric Society, 1982, pp. 213-224.

Hennesy, Christopher A. and Toni M. Whited, "How Costly Is External Financing? Evidence from a Structural Estimation," The Journal of Finance, 2007, 62 (4), 1705-1745.

House, Christopher L and Matthew D Shapiro, "Temporary Investment Tax Incentives: Theory with Evidence from Bonus Depreciation," The American Economic Review, 2008, 98 (3), $737-768$.

Hsieh, Chang-Tai and Peter J Klenow, "Misallocation and manufacturing TFP in China and India," The Quarterly journal of economics, 2009, 124 (4), 1403-1448.

Hsu, Po-Hsuan, Xuan Tian, and Yan Xu, "Financial development and innovation: Crosscountry evidence," Journal of Financial Economics, 2014, 112 (1), 116-135.

Jones, Charles I, "Intermediate goods and weak links in the theory of economic development," American Economic Journal: Macroeconomics, 2011, 3 (2), 1-28.

Khan, Aubhik and Julia K. Thomas, "Idiosyncratic Shocks and the Role of Nonconvexities in Plant and Aggregate Investment Dynamics," Econometrica, 2008, 76 (2), 395-436.

Kim, Hyunseob and Howard Kung, "The asset redeployability channel: How uncertainty affects corporate investment," The Review of Financial Studies, 2017, 30 (1), 245-280.

Lanteri, Andrea, "The Market for Used Capital: Endogenous Irreversibility and Reallocation over the Business Cycle," American Economic Review, September 2018, 108 (9), 2383-2419.

Levinsohn, James and Amil Petrin, "Estimating Production Functions Using Inputs to Control for Unobservables," The Review of Economic Studies, 04 2003, 70 (2), 317-341.

Liu, Yongzheng and Jie Mao, "How do Tax Incentives Affect Investment and Productivity? Firm-Level Evidence from China," Technical Report, International Center for Public Policy, Andrew Young School of Policy Studies, Georgia State University 2018.

Maffini, Giorgia, Jing Xing, and Michael P Devereux, "The impact of investment incentives: evidence from UK corporation tax returns," American Economic Journal: Economic Policy, 2016.

Ministry of Finance, "Announcement on deepening VAT reform," 2019.

Moon, Terry S., "Capital Gains Taxes and Real Corporate Investment," Job Market Paper, Princeton University, 2019.

NBS China, "China Statistical Yearbook," National Bureau of Statistics of China, 2018.

Ohrn, Eric, "The Effect of Corporate Taxation on Investment and Financial Policy: Evidence from the DPAD," American Economic Journal: Economic Policy, May 2018, 10 (2), 272-301. 
_ , "The Effect of Tax Incentives on U.S. Manufacturing: Evidence from State Accelerated Depreciation Policies," Working Paper, February 2018.

Ottonello, Pablo and Thomas Winberry, "Financial Heterogeneity and the Investment Channel of Monetary Policy," 2019.

Ramey, ValerieA. and MatthewD. Shapiro, "Displaced Capital: A Study of Aerospace Plant Closings," Journal of Political Economy, 2001, 109 (5), 958-992.

Rao, Nirupama, "Do tax credits stimulate R\&D spending? The effect of the R\&D tax credit in its first decade," Journal of Public Economics, 2016, 140, 1-12.

Salinger, Michael A and Lawrence H Summers, "Tax Reform and Corporate Investment: A Microeconometric Simulation Study," Working Paper 757, National Bureau of Economic Research September 1981.

Summers, Lawrence H, "Taxation and corporate investment: A q-theory approach," Brookings Papers on Economic Activity, 1981, 1981 (1), 67-140.

Winberry, Thomas, "Lumpy Investment, Business Cycles, and Stimulus Policy," forthcoming, American Economic Review, 2020.

Yagan, Danny, "Capital Tax Reform and the Real Economy: The Effects of the 2003 Dividend Tax Cut," The American Economic Review, 2015, 105 (12), 3531-3563.

Zwick, Eric and James Mahon, "Tax Policy and Heterogeneous Investment Behavior," The American Economic Review, 2017, 107 (1), 217-248. 
Figure 1: Cross-Country Comparison of Investment

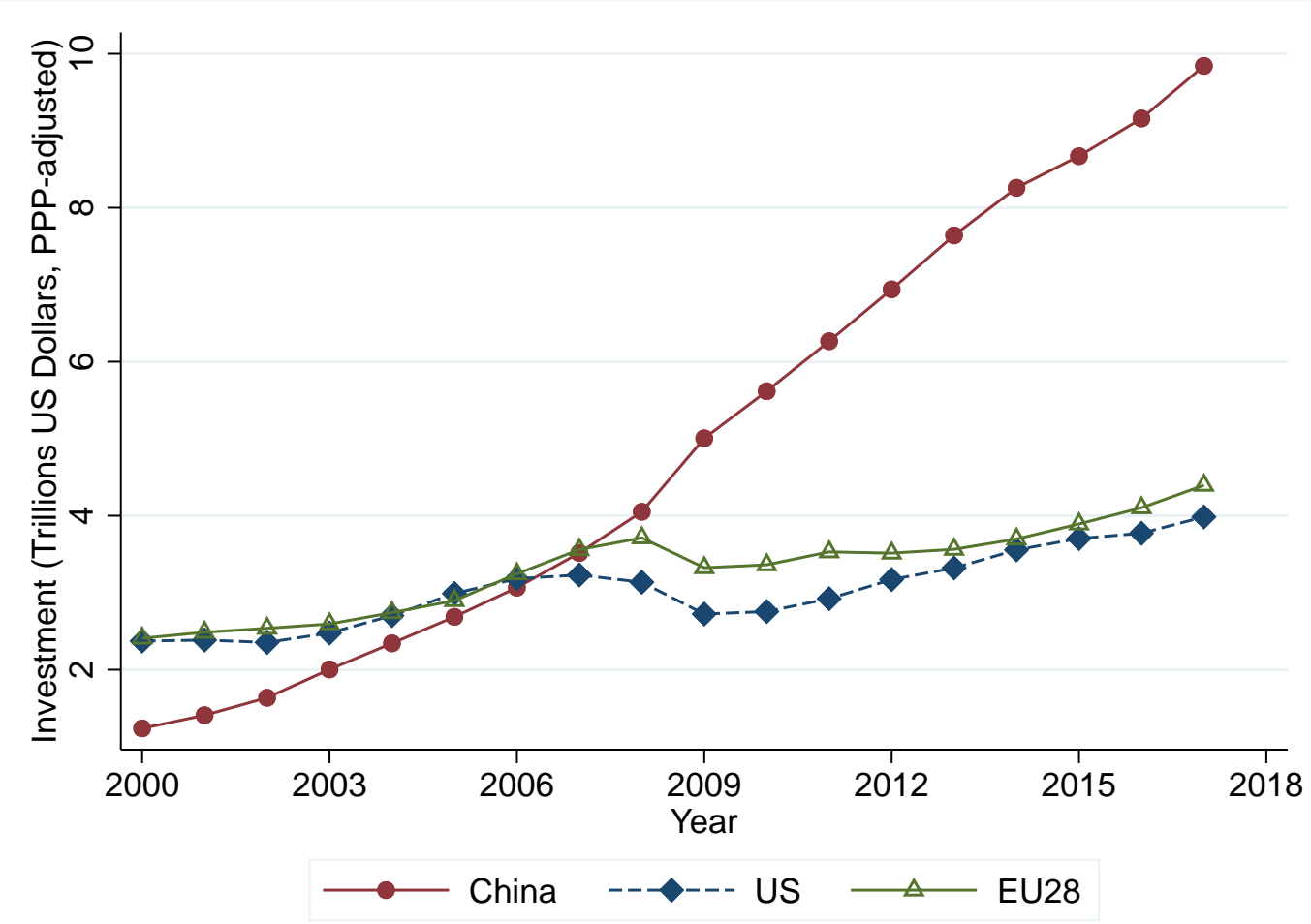

Notes: This figure displays investment in the United States, the European Union, and China from 2000 to 2017 as reported by the OECD. The figure shows that investment in China has long surpassed investment levels in the US and the European Union and that is has increased drastically since 2000. 
Figure 2: Effects of Partial Irreversibility

A. Marginal Product of Capital

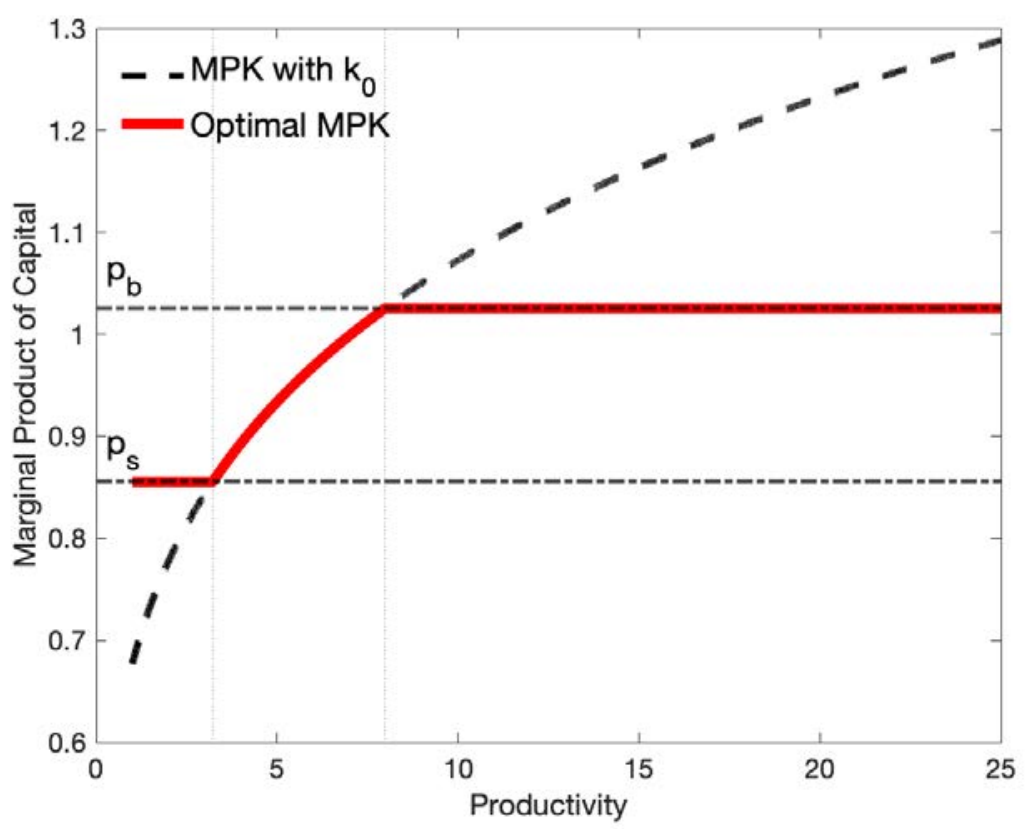

B. Optimal Capital

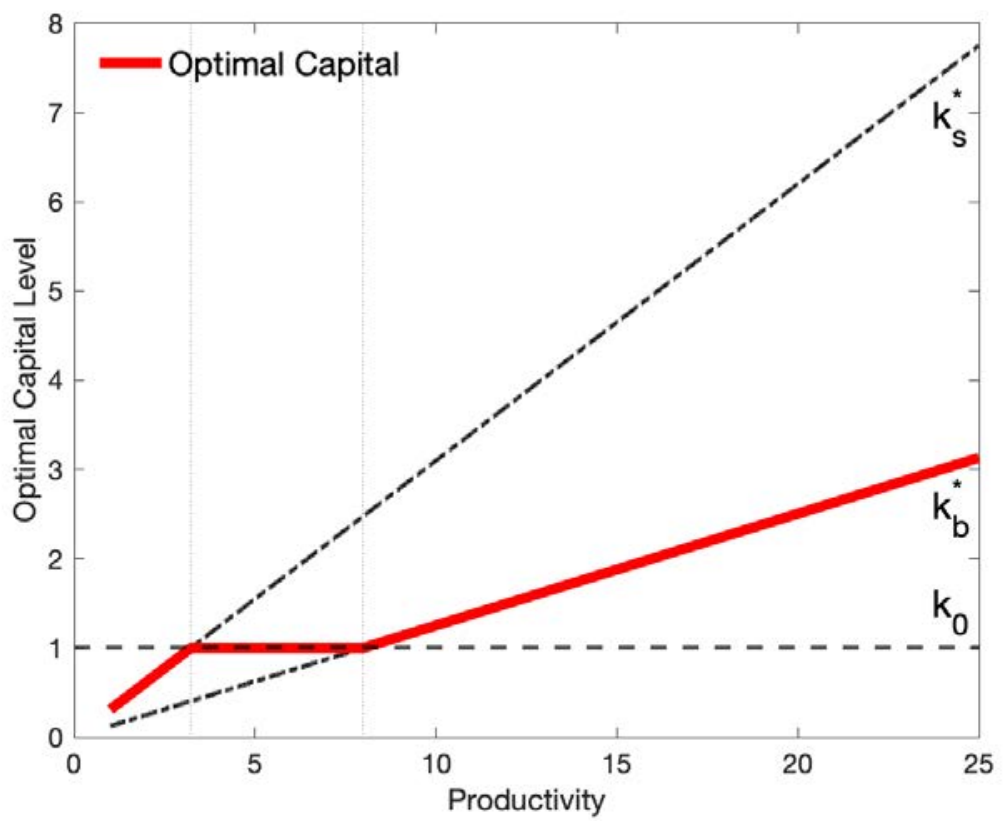

Notes: These figures plot the marginal product of capital and the optimal capital against productivity in a simple static model with only partial irreversibility; i.e., the resale price $\left(p^{s}\right)$ is smaller than the purchase price $\left(p^{b}\right)$. Panel A plots the marginal product of capital (MPK) against productivity. The dashed line corresponds to the MPK at initial capital stock $k_{0}$. The upper horizontal line indicates the purchase price $p^{b}$. The lower horizontal line indicates the resale price $p^{s}$. The red line indicates the MPK at associated optimal capital levels. In Panel B, the red line plots the optimal capital level against productivity. 


\section{Figure 3: Effects of Fixed Costs}

\section{A. Optimal Profit}

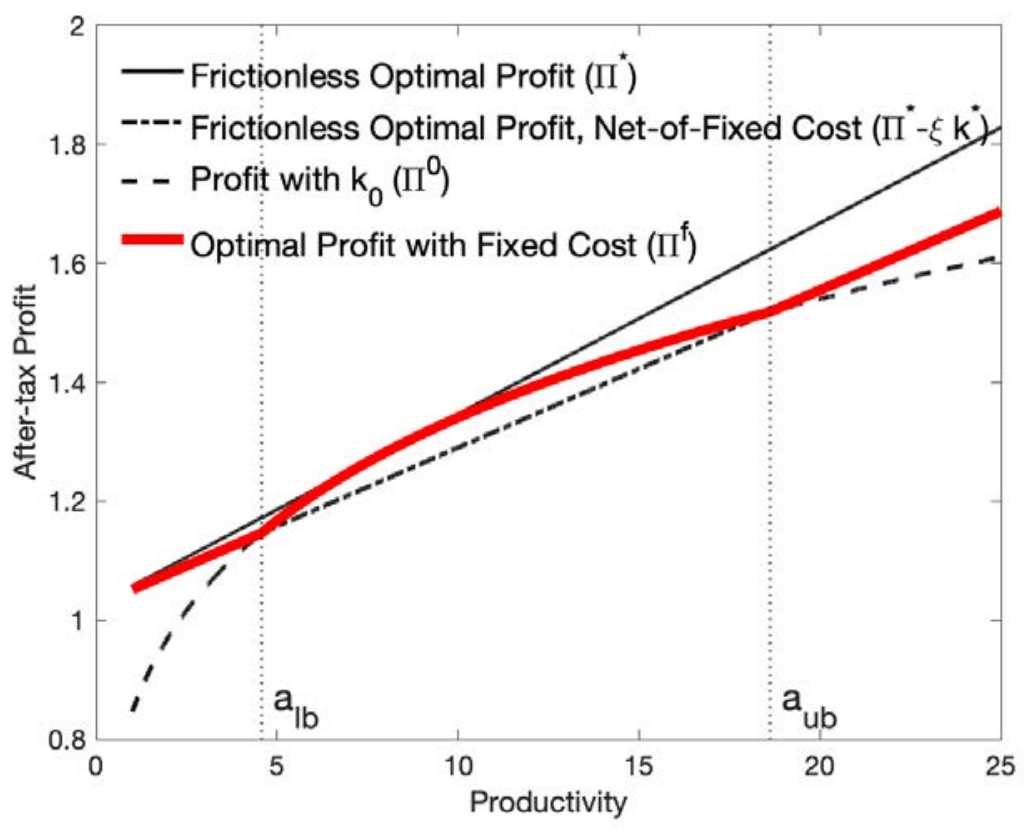

\section{B. Optimal Capital}

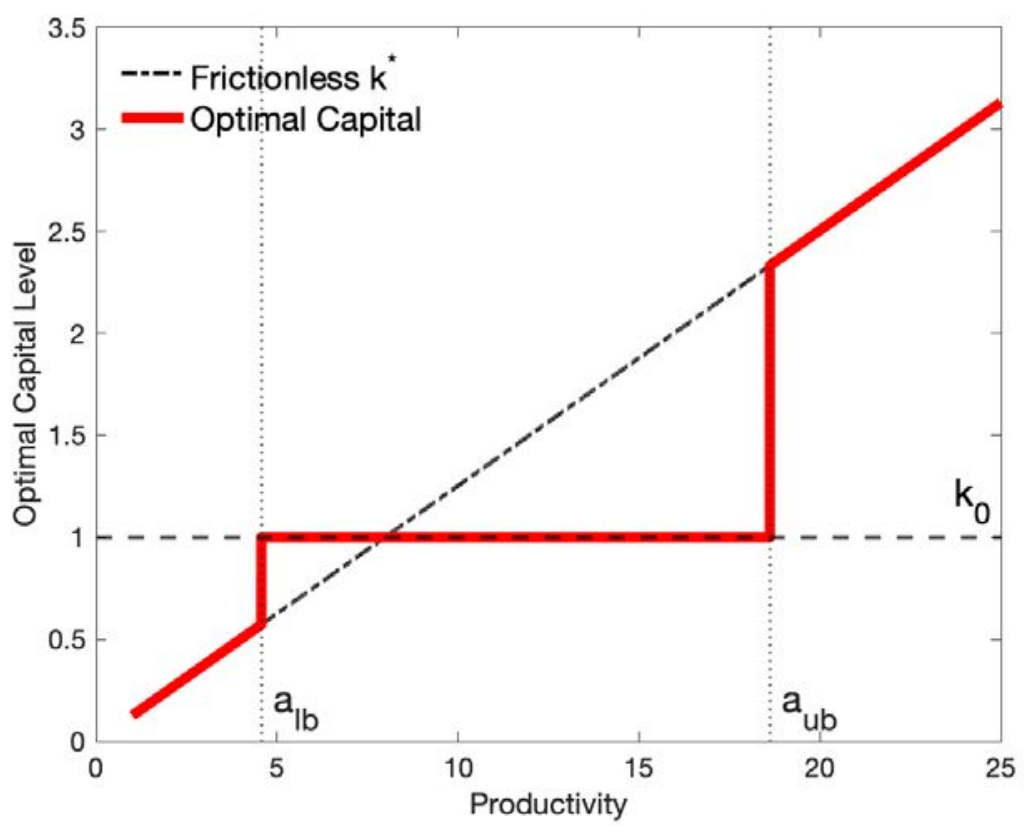

Notes: These figures plot the optimal profit and capital against productivity in a simple static model with fixed costs only. In Panel A, the solid line indicates the optimal profit without any frictions $\left(\Pi^{*}\right)$. The dot-dashed line indicates the optimal profit net of fixed cost $\left(\tilde{\Pi}^{*}=\Pi^{*}-\xi k^{*}\right)$. The dashed line indicates the profit evaluated at the initial capital level $\left(\Pi^{0}\right)$. The red line indicates the upper envelope of $\tilde{\Pi}^{*}$ and $\Pi^{0}$, which is the optimal profit in the presence of fixed costs. In Panel B, the dot-dashed line indicates the frictionless optimal capital level $\left(k^{*}\right)$ against productivity. The dashed line indicates the initial capital $k_{0}$. The red line indicates the optimal capital level taking into account the fixed costs. 
Figure 4: Effects of Tax Policy and Investment Frictions on Policy Functions

\section{A. Pre-reform}

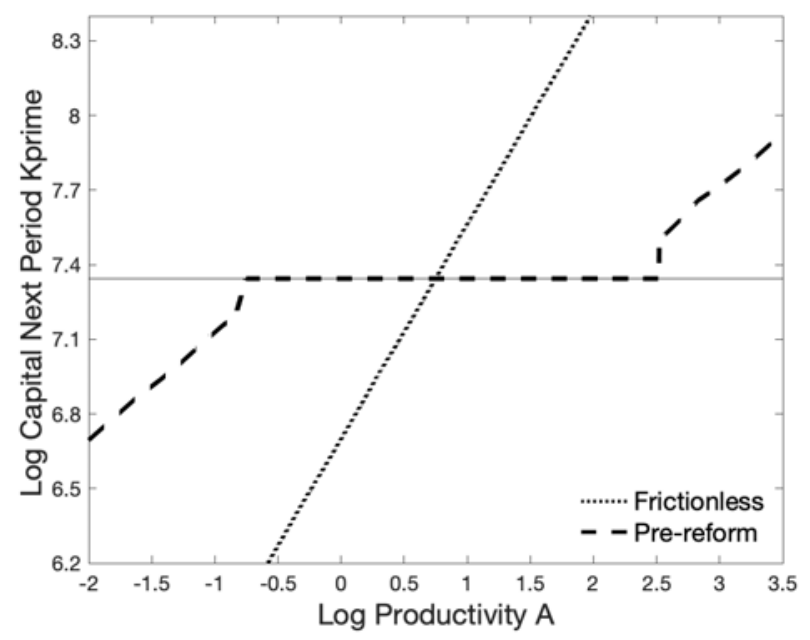

C. CIT Reform (15.4\% to 0)

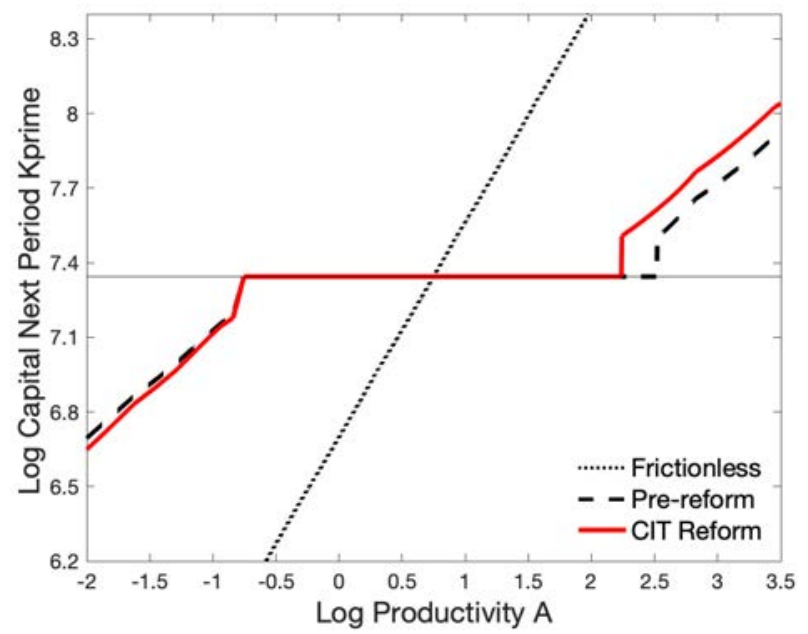

B. VAT Reform ( $17 \%$ to $12.9 \%)$

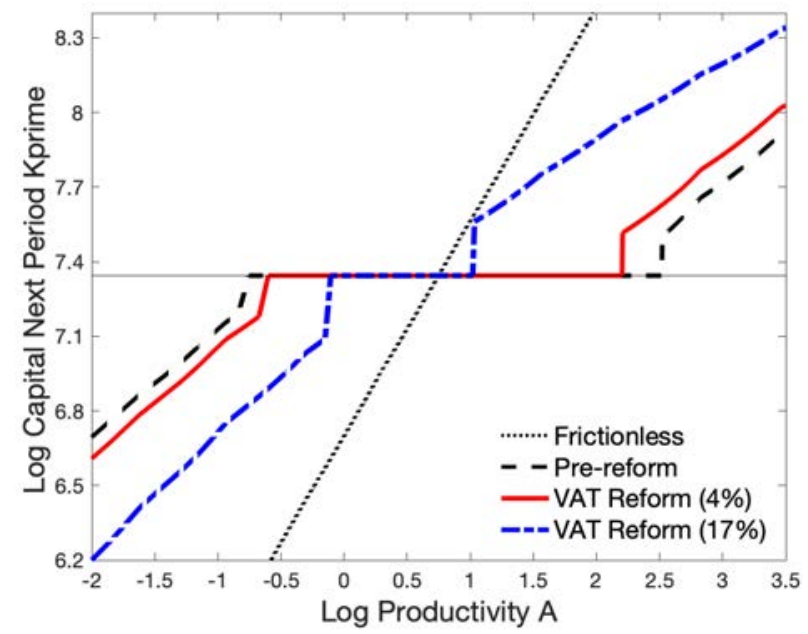

D. Bonus Depreciation (10 years to 1 year)

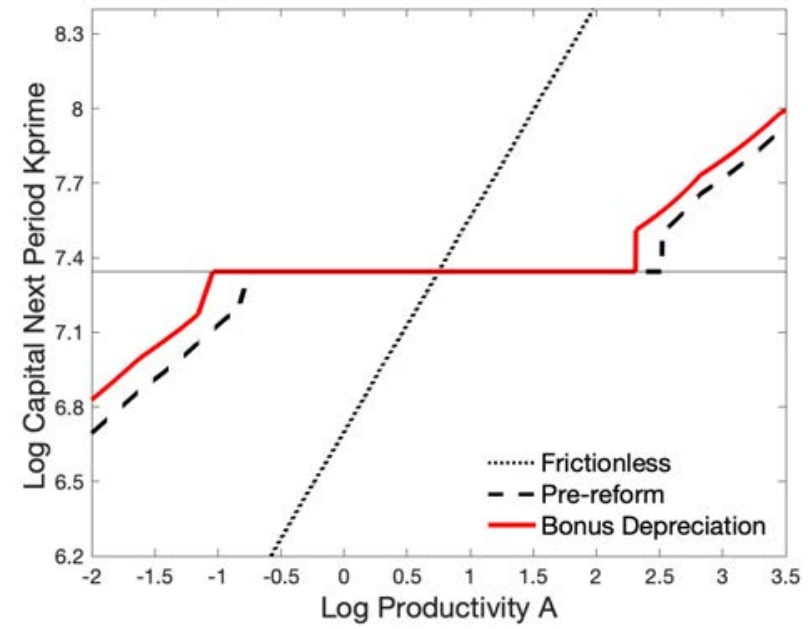

Notes: These figures display the policy functions against productivity in a dynamic investment model before the reform and after VAT reform, CIT reform and bonus depreciation, respectively. The three reforms generate the same reduction in the tax component of the user cost of capital. In Panel A, the dotted straight line indicates the optimal policy (the logarithm of the capital stock in the next period as a function of productivity) in the frictionless case. The dashed line indicates the optimal policy before the reform in the presence of all investment frictions - convex costs, fixed costs and partial irreversibility. Panel B adds the policy function (the red line) after reducing the VAT rate from $17 \%$ to $12.9 \%$; Panel C plots the policy function after reducing the CIT rate from $15.4 \%$ to 0; Panel D plots the policy function after a bonus depreciation policy that fully accelerates the timing of depreciation deductions. 


\section{Figure 5: Distribution and Autocorrelation of the Investment Rate}

\section{A. Distribution of the Investment Rate}

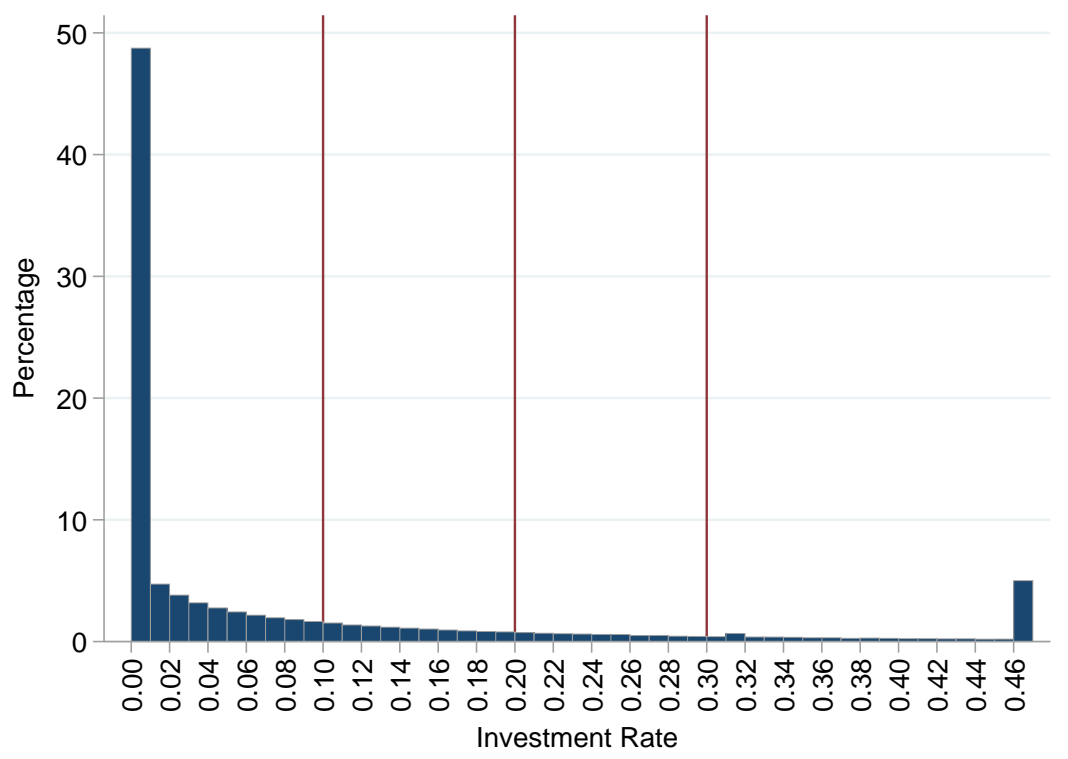

\section{B. Autocorrelation of the Investment Rate}

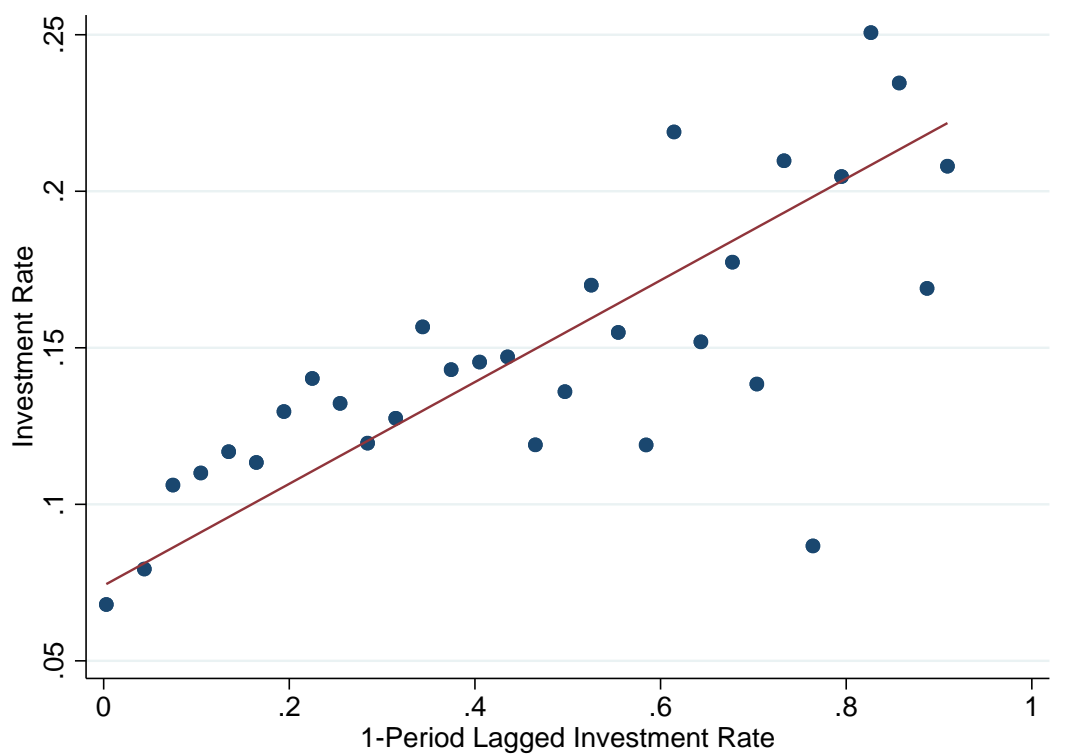

Notes: These figures display notable features of the investment in our tax data. Panel A plots the distribution of the investment rate of domestic firms before the reform. We winsorize the investment rate at the top 5\%. Panel B plots the investment rate against the one-period-lagged investment rate. We group the lagged investment rate into equally sized bins from 0 to 1 and then calculate the average investment rate for each bin. The red line is the OLS linear fit line. 


\section{Figure 6: Reduced-Form Effects of China's 2009 VAT Reform}

\section{A. Extensive Margin}

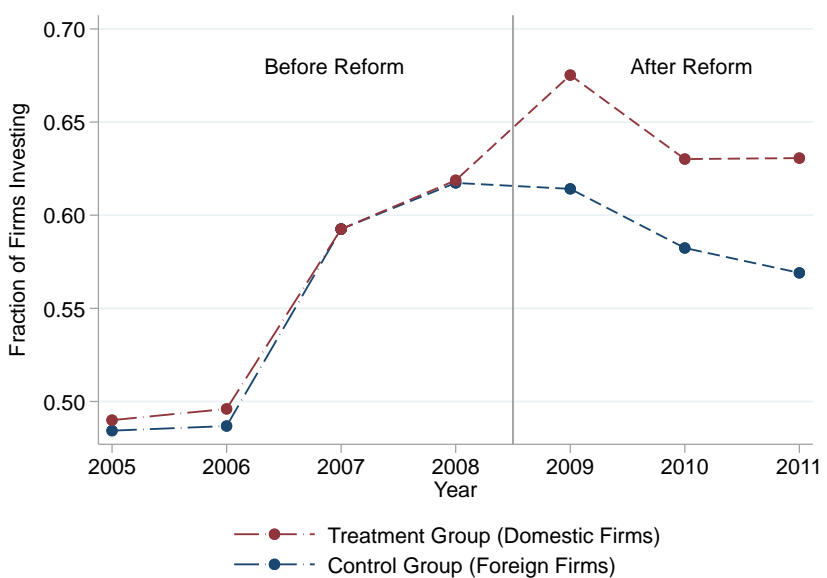

\section{Extensive Margin}

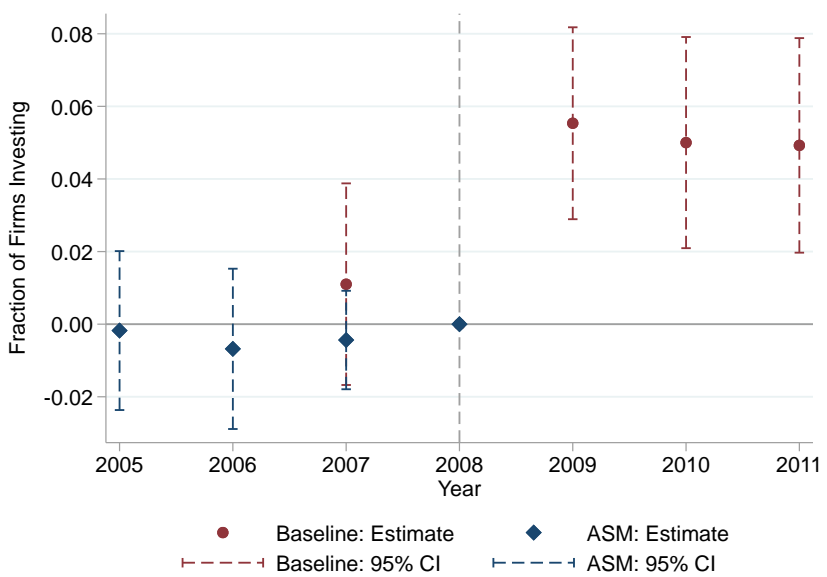

B. Investment Rate

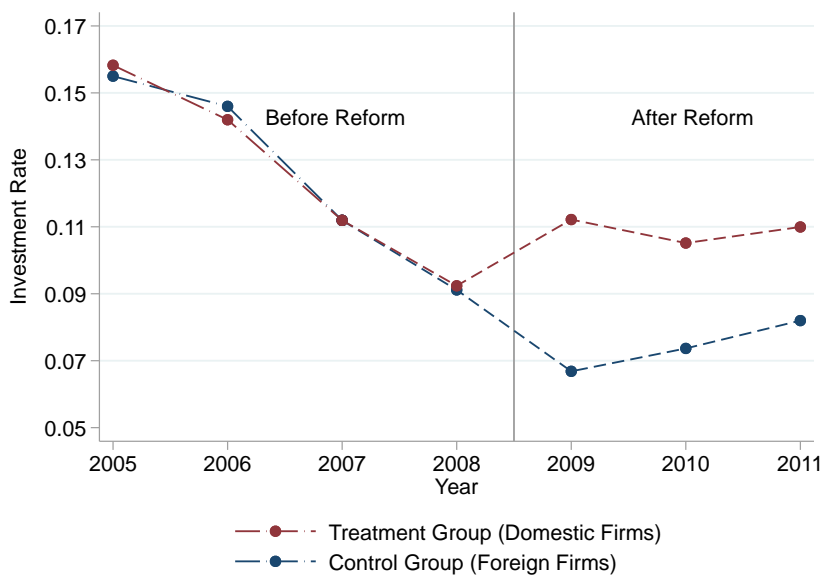

D. Investment Rate

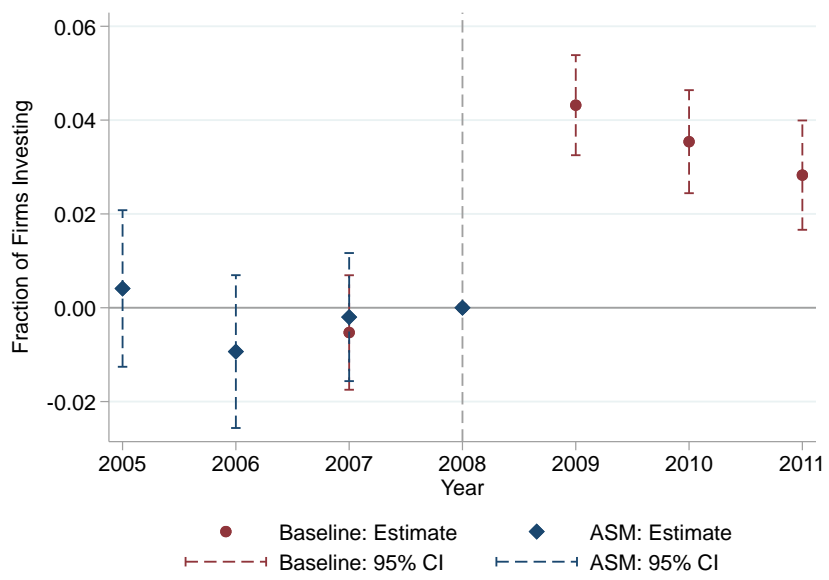

Notes: These figures show the effects of the VAT reform on the investment of domestic and foreign firms. To construct these figures, we first use tax data to calculate the average investment rate in equipment for each year from 2007 to 2011 for domestic firms (the treatment group) and foreign firms (the control group). For easier comparison, we set 2008 as the base year and align the investment rate of equipment for domestic and foreign firms to the pooled average rate in 2008. In addition, we complement the tax data with Chinese Annual Survey of Manufacturing (ASM) data. That is, we merge the 2005-2006 ASM data with the 2007-2008 tax data and calculate the average rate of total investment for each year from 2005 to 2008 for domestic and foreign firms. Similarly, we align the rates of total investment of the two groups to the pooled average investment rate of equipment in 2008. To do so, we subtract the average rate of total investment in 2008 from each average rate and add the pooled average investment rate of equipment that we obtained from the tax data. 


\section{Figure 7: Simulating Alternative Tax Reforms: Elasticity of Investment to Tax Revenue}

A. VAT Cuts vs. CIT Cuts

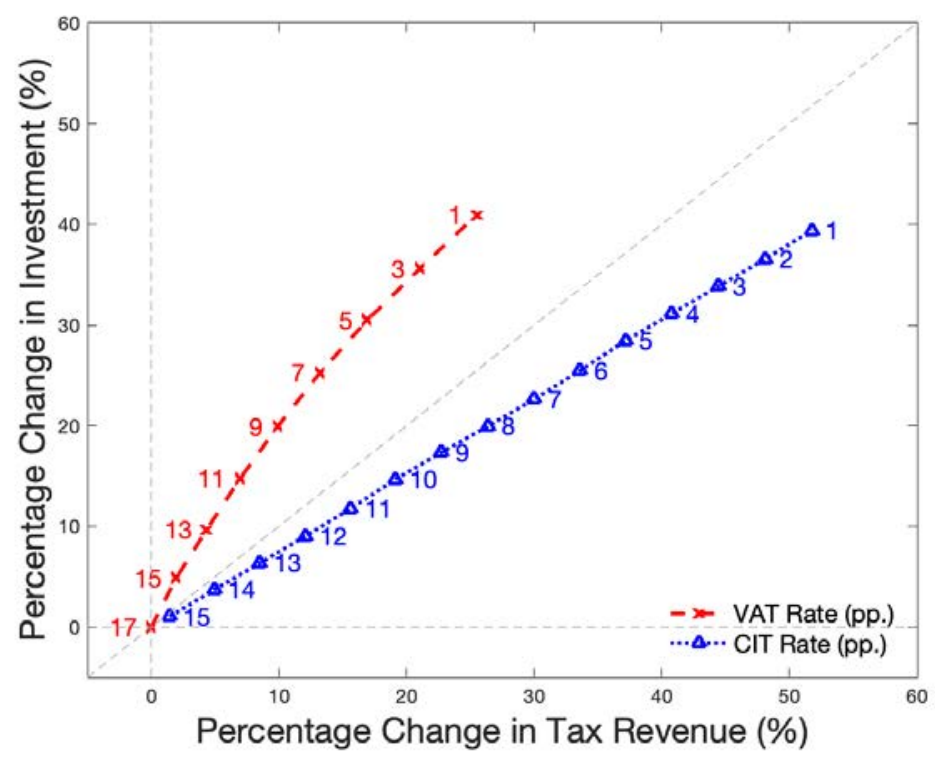

B. VAT Cuts vs. ITC

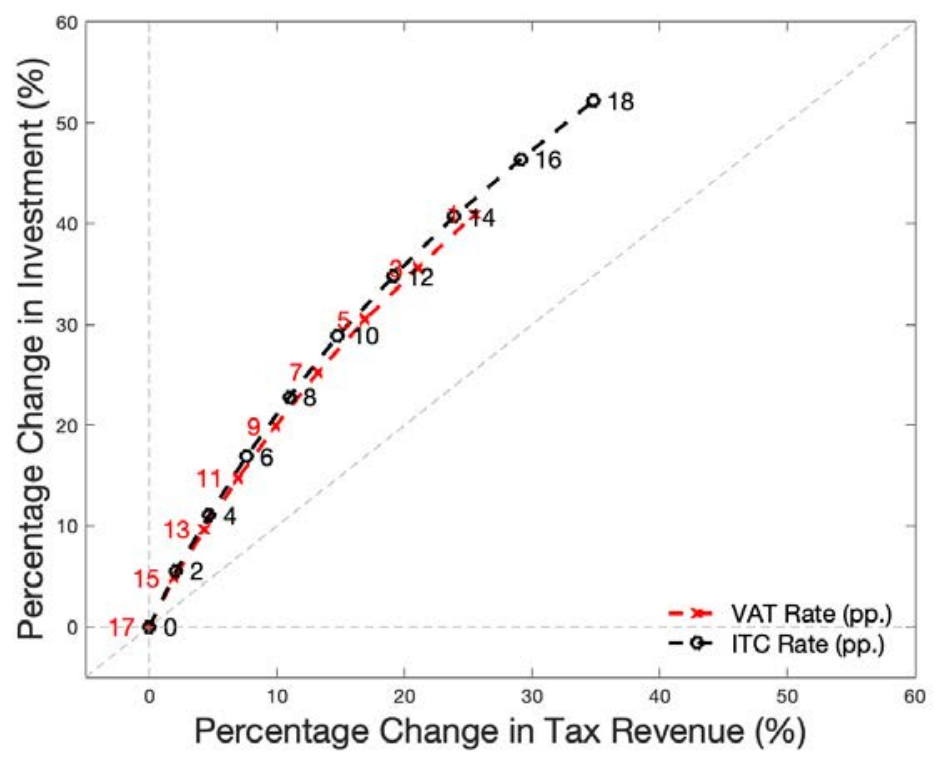

Notes: These figures plot the simulated percentage change in aggregate investment to the percentage loss in tax revenue at different rates of VAT cut, CIT cut and investment tax credit (ITC) policies. For each tax rate, we solve the model, simulate investment and tax revenue, and calculate the corresponding changes in each outcome. Panel A plots the percentage change in aggregate investment against the percentage change in tax revenue. The red solid curve corresponds to VAT cuts from $17 \%$ to different rates. The blue dotted line corresponds to CIT cuts from $15.4 \%$ to different rates. Similarly, Panel B compares the percentage change in tax revenue from VAT cuts with that from an ITC. 
Table 1: VAT Reform and Investment Costs: Example of a 1,000 RMB Equipment Purchase

\begin{tabular}{lrrr}
\hline \hline & Pre-reform & Post-reform & Change \\
\hline VAT-Included Cost & 1170 & 1170 & \\
Deductible from VAT & $\mathbf{0}$ & $\mathbf{1 7 0}$ & $\mathbf{+ 1 7 0}$ \\
Book Value & 1170 & 1000 & -170 \\
PV of Total Depreciation & 948.6 & 810.8 & -137.8 \\
Deductible from CIT & 237.2 & 202.7 & -34.5 \\
\hline After-Tax Cost of Investment & $\mathbf{9 3 2 . 8}$ & $\mathbf{7 9 7 . 3}$ & $\mathbf{- 1 3 5 . 5}$ \\
\hline
\end{tabular}

Notes: This calculation assumes a discount rate of $5 \%$ and a marginal corporate income tax rate of $25 \%$. According to Chinese accounting standards, the book value of the asset would be depreciated over 10 years using a straight-line depreciation method. This calculation assumes a zero salvage value. 


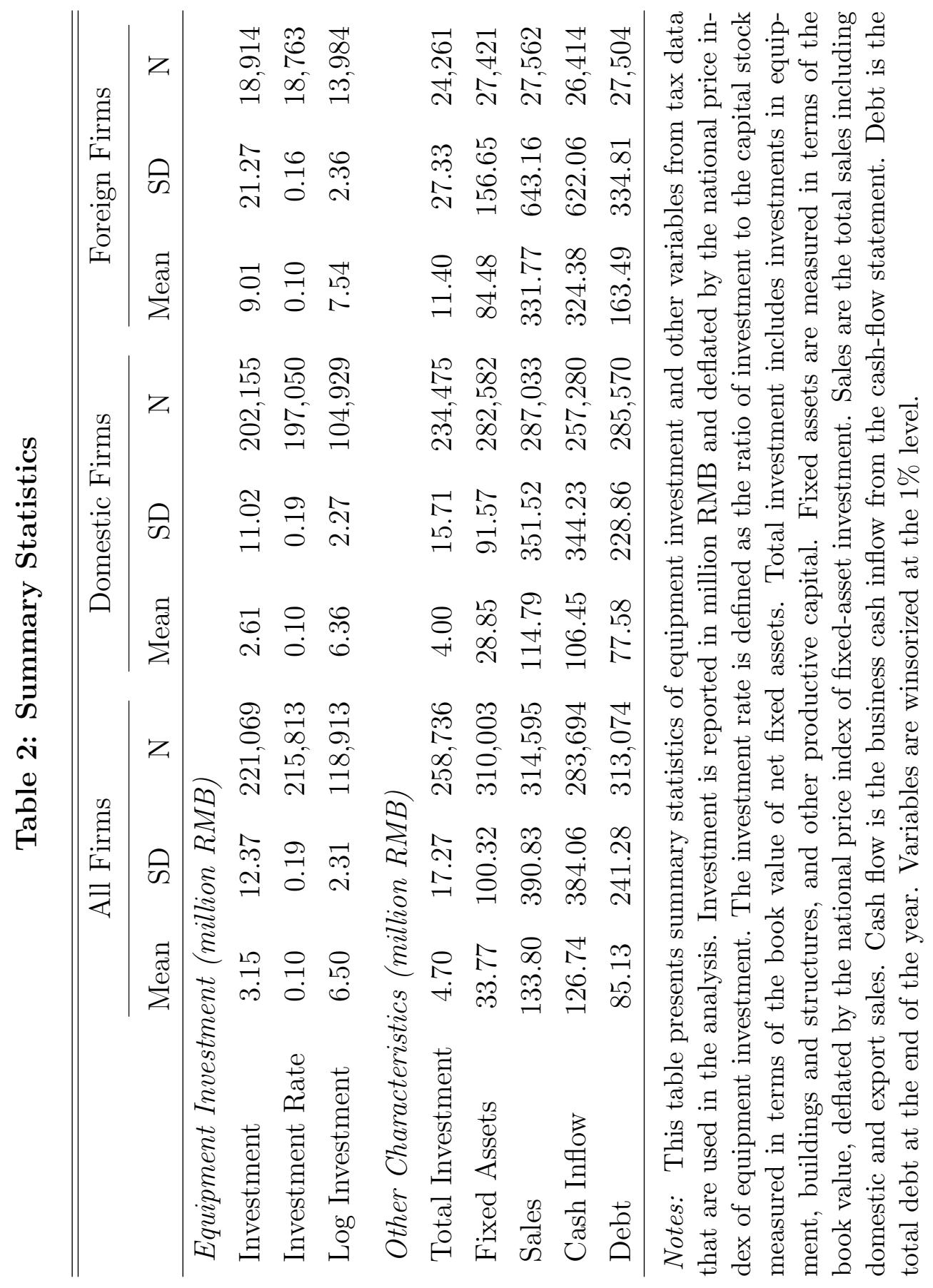


Table 3: Estimates of Difference-in-Difference Regressions

\begin{tabular}{|c|c|c|c|c|c|c|}
\hline & \multicolumn{3}{|c|}{ Extensive Margin: \% Firms } & \multicolumn{3}{|c|}{ Intensive Margin: Investment Rate } \\
\hline & (1) & $(2)$ & $(3)$ & $(4)$ & $(5)$ & (6) \\
\hline $\begin{array}{l}\text { A. Main Results } \\
\text { Domestic } \times \text { Post }\end{array}$ & $\begin{array}{c}0.058^{* * *} \\
(0.010)\end{array}$ & $\begin{array}{c}0.044^{* * *} \\
(0.010)\end{array}$ & $\begin{array}{c}0.046^{* * *} \\
(0.010)\end{array}$ & $\begin{array}{c}0.036^{* * *} \\
(0.004)\end{array}$ & $\begin{array}{c}0.037^{* * *} \\
(0.004)\end{array}$ & $\begin{array}{c}0.038^{* * *} \\
(0.004)\end{array}$ \\
\hline $\begin{array}{l}N \\
\text { Industry } \times \text { Year FE } \\
\text { Province } \times \text { Year FE }\end{array}$ & $\begin{array}{c}86870 \\
\mathrm{Y}\end{array}$ & $\begin{array}{c}86870 \\
\mathrm{Y}\end{array}$ & $\begin{array}{l}86870 \\
\text { Y } \\
\text { Y }\end{array}$ & $\begin{array}{c}81270 \\
\mathrm{Y}\end{array}$ & $\begin{array}{c}81270 \\
\mathrm{Y}\end{array}$ & $\begin{array}{l}81270 \\
\text { Y } \\
\text { Y }\end{array}$ \\
\hline \multicolumn{7}{|c|}{ B. Robustness Checks: Sample Selection } \\
\hline Domestic $\times$ Post & $\begin{array}{c}0.060^{* * *} \\
(0.021)\end{array}$ & $\begin{array}{c}0.053^{* * *} \\
(0.008)\end{array}$ & $\begin{array}{c}0.045^{* * *} \\
(0.006)\end{array}$ & $\begin{array}{c}0.033^{* * *} \\
(0.008)\end{array}$ & $\begin{array}{c}0.044^{* * *} \\
(0.003)\end{array}$ & $\begin{array}{c}0.039^{* * *} \\
(0.003)\end{array}$ \\
\hline $\begin{array}{l}N \\
\text { Industry } \times \text { Year FE } \\
\text { Province } \times \text { Year FE }\end{array}$ & $\begin{array}{l}82785 \\
\text { Y } \\
\text { Y }\end{array}$ & $\begin{array}{l}221069 \\
\text { Y } \\
\text { Y }\end{array}$ & $\begin{array}{l}107255 \\
\text { Y } \\
\text { Y }\end{array}$ & $\begin{array}{l}79195 \\
\text { Y } \\
\text { Y }\end{array}$ & $\begin{array}{l}215813 \\
\text { Y } \\
\text { Y }\end{array}$ & $\begin{array}{l}100980 \\
\text { Y } \\
\text { Y }\end{array}$ \\
\hline C. Robustness Checks & $\begin{array}{l}\text { Different } \\
\text { Non- } \\
\text { Exporters }\end{array}$ & $\begin{array}{l}\text { amples } \\
\text { Non- } \\
\text { SOE }\end{array}$ & $\begin{array}{l}\text { Non- } \\
\text { Public }\end{array}$ & $\begin{array}{l}\text { Non- } \\
\text { Exporters }\end{array}$ & $\begin{array}{l}\text { Non- } \\
\text { SOE }\end{array}$ & $\begin{array}{l}\text { Non- } \\
\text { Public }\end{array}$ \\
\hline Domestic $\times$ Post & $\begin{array}{c}0.067^{* * *} \\
(0.020)\end{array}$ & $\begin{array}{c}0.046^{* * *} \\
(0.010)\end{array}$ & $\begin{array}{c}0.046^{* * *} \\
(0.010)\end{array}$ & $\begin{array}{c}0.037^{* * *} \\
(0.009)\end{array}$ & $\begin{array}{c}0.037^{* * *} \\
(0.004)\end{array}$ & $\begin{array}{c}0.038^{* * *} \\
(0.004)\end{array}$ \\
\hline $\begin{array}{l}\mathrm{N} \\
\text { Industry } \times \text { Year FE } \\
\text { Province } \times \text { Year FE }\end{array}$ & $\begin{array}{l}61195 \\
Y \\
Y\end{array}$ & $\begin{array}{l}83559 \\
\mathrm{Y} \\
\mathrm{Y}\end{array}$ & $\begin{array}{l}85298 \\
Y \\
Y\end{array}$ & $\begin{array}{l}56445 \\
\mathrm{Y} \\
\mathrm{Y}\end{array}$ & $\begin{array}{l}78152 \\
\mathrm{Y} \\
\mathrm{Y}\end{array}$ & $\begin{array}{l}79798 \\
\text { Y } \\
Y\end{array}$ \\
\hline \multicolumn{7}{|c|}{ D. Additional Firm-Level Controls } \\
\hline Domestic $\times$ Post & $\begin{array}{c}0.055^{* * *} \\
(0.010)\end{array}$ & $\begin{array}{c}0.060^{* * *} \\
(0.010)\end{array}$ & $\begin{array}{c}0.061^{* * *} \\
(0.011)\end{array}$ & $\begin{array}{c}0.036^{* * *} \\
(0.004)\end{array}$ & $\begin{array}{c}0.037^{* * *} \\
(0.004)\end{array}$ & $\begin{array}{c}0.036^{* * *} \\
(0.005)\end{array}$ \\
\hline $\begin{array}{l}N \\
\text { Industry } \times \text { Year FE } \\
\text { Province } \times \text { Year FE }\end{array}$ & $\begin{array}{l}83418 \\
\text { Y } \\
\text { Y }\end{array}$ & $\begin{array}{l}86284 \\
\text { Y } \\
\text { Y }\end{array}$ & $\begin{array}{l}86870 \\
\mathrm{Y} \\
\mathrm{Y}\end{array}$ & $\begin{array}{l}79547 \\
\text { Y } \\
\text { Y }\end{array}$ & $\begin{array}{l}80823 \\
\text { Y } \\
\text { Y }\end{array}$ & $\begin{array}{l}81270 \\
\text { Y } \\
\text { Y }\end{array}$ \\
\hline \multicolumn{6}{|c|}{ E. Alternative Investment Measures } & \\
\hline Domestic $\times$ Post & $\begin{array}{c}0.449^{* * *} \\
(0.052)\end{array}$ & $\begin{array}{c}0.404^{* * *} \\
(0.054)\end{array}$ & $\begin{array}{c}0.414^{* * *} \\
(0.054)\end{array}$ & $\begin{array}{c}0.716^{* * *} \\
(0.083)\end{array}$ & $\begin{array}{c}0.633^{* * *} \\
(0.086)\end{array}$ & $\begin{array}{c}0.653^{* * *} \\
(0.087)\end{array}$ \\
\hline $\begin{array}{l}N \\
\text { Industry } \times \text { Year FE } \\
\text { Province } \times \text { Year FE }\end{array}$ & $\begin{array}{c}20720 \\
\mathrm{Y}\end{array}$ & $\begin{array}{c}20720 \\
\mathrm{Y}\end{array}$ & $\begin{array}{l}20720 \\
\mathrm{Y} \\
\mathrm{Y}\end{array}$ & $\begin{array}{c}86870 \\
\mathrm{Y}\end{array}$ & $\begin{array}{c}86870 \\
\mathrm{Y}\end{array}$ & $\begin{array}{l}86870 \\
\mathrm{Y} \\
\mathrm{Y}\end{array}$ \\
\hline
\end{tabular}

Notes: This table uses tax data to estimate difference-in-difference regressions of the form:

$$
Y_{i t}=\gamma G_{i} \times \text { Post }_{t}+\mu_{i}+\delta_{j t}+X_{i t}^{\prime} \beta+\varepsilon_{i j t},
$$

where $Y_{i t}$ is equipment investment, $G_{i}$ is the treatment indicator set to 1 for domestic firms and 0 for foreign firms, and Post $t$ is the post-reform indicator set to 1 for years since 2009. $\mu_{i}$ is the firm fixed effect. Panel A reports the baseline results. The dependent variable for columns (1)-(3) is a dummy variable set to 1 if a firm makes an investment; the dependent variable for columns (4)-(6) is firm's investment rate. Columns (1) and (4) control for industry-year fixed effects. Columns (2) and (5) control for province-year fixed effects. Columns (3) and (6) include both fixed effects. Panel B reports robustness checks: column (1) weights observations by the inverse probability weighting (IPW); column (2) uses an unbalanced panel; column (3) uses all foreign firms as the control group. Panel $\mathrm{C}$ reports another set of robustness checks: column (1) exclude exporters; column (2) exclude state-owned firms (SOEs); column (3) excludes public firms. Panel D augments the regression with additional controls. Column (1) controls for firms' net cash flow scaled by the capital stock. Column (2) adds quadratics in sales, profit margin, and age. Column (3) adds the statutory CIT rate. Panel E runs the baseline specification with the log and inverse hyperbolic sine of investment as dependent variables. All regressions include firm fixed effects. Standard errors are clustered at the lism level. 
Table 4: Estimates of Placebo Tests

\begin{tabular}{|c|c|c|c|c|c|c|}
\hline & \multicolumn{3}{|c|}{ Extensive Margin: \% Firms Investing } & \multicolumn{3}{|c|}{ Intensive Margin: Investment Rate } \\
\hline & (1) & $(2)$ & $(3)$ & $(4)$ & $(5)$ & $(6)$ \\
\hline & Baseline & Pilot & Structures & Baseline & Pilot & Structures \\
\hline \multirow{2}{*}{ Domestic $\times$ Post } & $0.046^{* * *}$ & -0.010 & $0.023^{* *}$ & $0.038^{* * *}$ & 0.017 & -0.002 \\
\hline & $(0.010)$ & $(0.032)$ & $(0.011)$ & $(0.004)$ & $(0.013)$ & $(0.003)$ \\
\hline$N$ & 86955 & 13932 & 81270 & 86955 & 13932 & 81270 \\
\hline Industry $\times$ Year FE & $\mathrm{Y}$ & $\mathrm{Y}$ & $\mathrm{Y}$ & $\mathrm{Y}$ & $\mathrm{Y}$ & $\mathrm{Y}$ \\
\hline Province $\times$ Year FE & $\mathrm{Y}$ & $\mathrm{Y}$ & $\mathrm{Y}$ & $\mathrm{Y}$ & $\mathrm{Y}$ & $\mathrm{Y}$ \\
\hline
\end{tabular}

Notes: This table uses tax data to estimate difference-in-difference regressions of the form:

$$
Y_{i t}=\gamma G_{i} \times \text { Post }_{t}+\mu_{i}+\delta_{j t}+\eta_{s t}+\varepsilon_{i t},
$$

where $Y_{i t}$ is a measure of investment, $G_{i}$ is the treatment indicator set to 1 for domestic firms and 0 for foreign firms, and Post $_{t}$ is the post-reform indicator set to 1 for years since 2009. $\mu_{i}$ is the firm fixed effect. $\delta_{j t}$ and $\eta_{s t}$ are industry-year and province-year fixed effects, respectively. Panel A uses domestic firms and foreign firms in the pilot program as the treatment and control groups, respectively. The dependent variable for columns (1)-(3) is a dummy variable set to 1 if a firm makes an investment in equipment; the dependent variable for columns (4)-(6) is firm's equipment investment rate. Panel B uses investment in buildings/structures as dependent variables. The treatment and control groups are the same as those in the baseline analysis, where the non-pilot domestic firms are the treatment group and foreign firms with preferential treatment are the control group. All regressions include firm fixed effects as well as industry-year and province-year fixed effects. Standard errors are clustered at the firm level. 
Table 5: Estimates of Triple-Differences Regressions

\begin{tabular}{|c|c|c|c|c|c|c|}
\hline & \multicolumn{3}{|c|}{ Extensive Margin: \% Firms Investing } & \multicolumn{3}{|c|}{ Intensive Margin: Investment Rate } \\
\hline & $(1)$ & $(2)$ & $(3)$ & $(4)$ & $(5)$ & $(6)$ \\
\hline & Baseline & Pilot & Structures & Baseline & Pilot & Structures \\
\hline \multirow[t]{2}{*}{ Domestic $\times$ Post } & $0.046^{* * *}$ & -0.036 & $0.028^{* *}$ & $0.038^{* * *}$ & 0.011 & 0.002 \\
\hline & $(0.010)$ & $(0.030)$ & $(0.011)$ & $(0.004)$ & $(0.012)$ & $(0.003)$ \\
\hline \multirow[t]{2}{*}{ Domestic $\times$ Post $\times$ Non-Pilot } & & $0.080^{* *}$ & & & $0.030^{* *}$ & \\
\hline & & $(0.032)$ & & & $(0.013)$ & \\
\hline \multirow[t]{2}{*}{ Domestic $\times$ Post $\times$ Equipment } & & & $0.036^{* *}$ & & & $0.033^{* * *}$ \\
\hline & & & $(0.015)$ & & & $(0.005)$ \\
\hline$N$ & 86955 & 100040 & 162540 & 81355 & 92875 & 162540 \\
\hline Industry $\times$ Year FE & $\mathrm{Y}$ & $\mathrm{Y}$ & $\mathrm{Y}$ & $\mathrm{Y}$ & $\mathrm{Y}$ & $\mathrm{Y}$ \\
\hline Province $\times$ Year FE & $\mathrm{Y}$ & $\mathrm{Y}$ & $\mathrm{Y}$ & $\mathrm{Y}$ & $\mathrm{Y}$ & $\mathrm{Y}$ \\
\hline
\end{tabular}

Notes: This table uses tax data to estimate triple-differences regressions. For comparison, columns (1) and (4) report the baseline estimates from difference-in-difference regressions. Columns (2) and (5) use firms in the pilot program as an additional control group and estimate the triple-differences regression of the form:

$$
Y_{i t}=\gamma_{1} G_{i} \times \text { Post }_{t}+\gamma_{2} P_{i} \times \text { Post }_{t}+\gamma_{3} G_{i} \times P_{i} \times \text { Post }_{t}+\mu_{i}+\delta_{j t}+\eta_{s t}+\varepsilon_{i t},
$$

where $Y_{i t}$ is equipment investment, $P_{i}$ is an indicator set to 1 for pilot firms and 0 for non-pilot firms, $G_{i}$ is the treatment indicator set to 1 for domestic firms and 0 for foreign firms, and Post $_{t}$ is the post-reform indicator set to 1 for years since 2009. $\mu_{i}$ is the firm fixed effect. $\delta_{j t}$ and $\eta_{s t}$ are industry-year and province-year fixed effects, respectively. Columns (3) and (6) use investment in structures as an additional control group and estimate the triple-differences regression of the form:

$$
Y_{k i t}=\gamma_{1} G_{i} \times \text { Post }_{t}+\gamma_{2} A_{k} \times \text { Post }_{t}+\gamma_{3} G_{i} \times A_{k} \times \text { Post }_{t}+\gamma_{4} G_{i} \times A_{k}+\mu_{i}+\delta_{j t}+\eta_{s t}+\varepsilon_{k i t},
$$

where $k$ denotes the investment type, i.e., equipment and structures. $A_{k}$ is an indicator set to 1 for investment in equipment and 0 for investment in structures. The other variables are defined the same as above. The dependent variable for columns (1)-(3) is a dummy variable set to 1 if a firm makes an investment; the dependent variable for columns (4)-(6) is the firm's investment rate. All regressions include firm fixed effects as well as industry-year and province-year fixed effects. Standard errors are clustered at the firm level. 


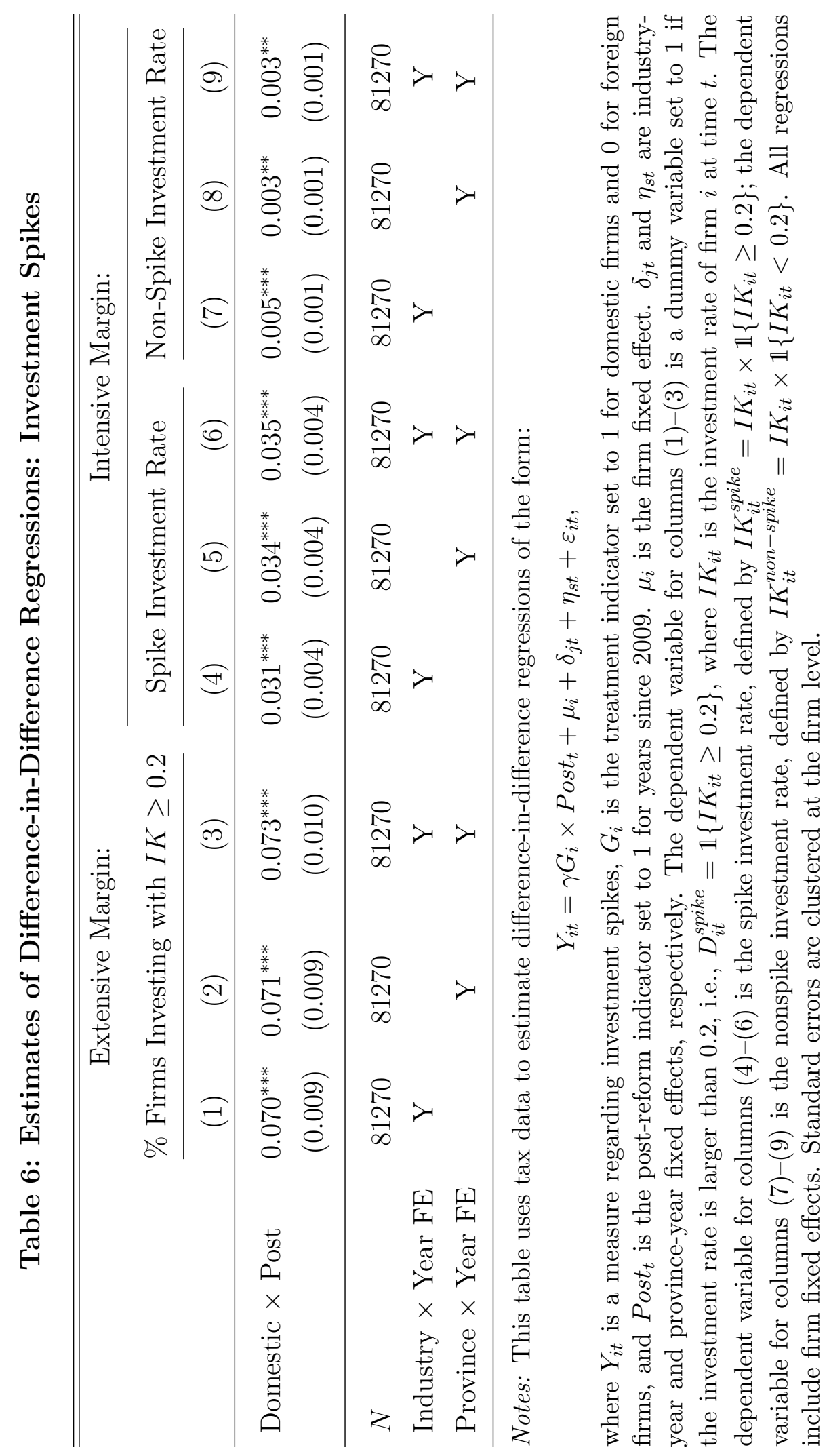




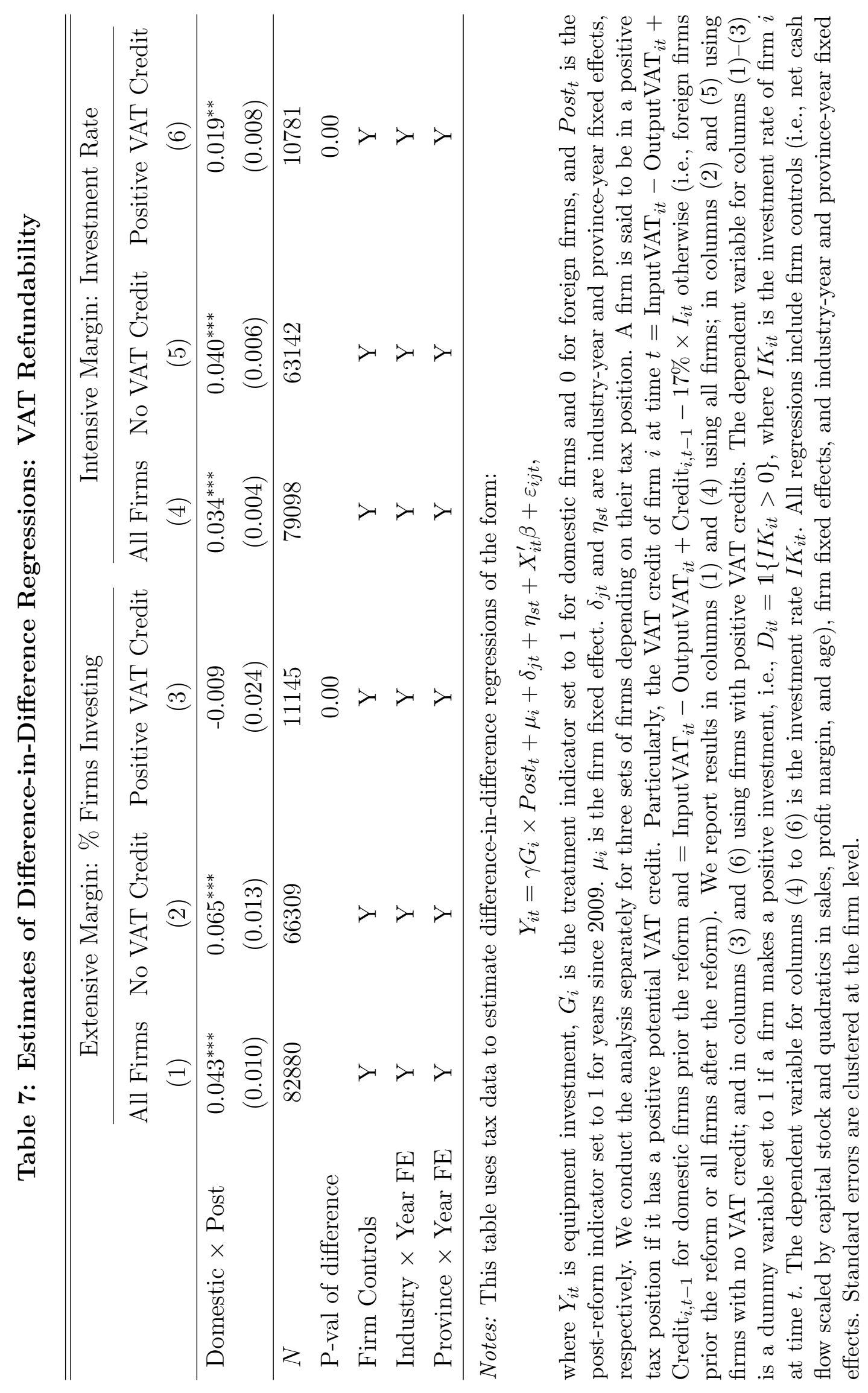




\section{Table 8: Estimates of Difference-in-Difference Regressions: Redeployability}

\begin{tabular}{|c|c|c|c|c|c|c|}
\hline & \multicolumn{2}{|c|}{ Extensive Margin } & \multicolumn{2}{|c|}{ Investment Spikes } & \multicolumn{2}{|c|}{ Intensive Margin } \\
\hline & (1) & (2) & (3) & (4) & (5) & (6) \\
\hline Domestic $\times$ Post & $\begin{array}{c}0.044^{* * *} \\
(0.010)\end{array}$ & $\begin{array}{c}0.044^{* * *} \\
(0.010)\end{array}$ & $\begin{array}{c}0.071^{* * *} \\
(0.009)\end{array}$ & $\begin{array}{c}0.071^{* * *} \\
(0.009)\end{array}$ & $\begin{array}{c}0.037^{* * *} \\
(0.004)\end{array}$ & $\begin{array}{c}0.037^{* * *} \\
(0.004)\end{array}$ \\
\hline Domestic $\times$ Post $\times$ Redeployability & & $\begin{array}{c}0.005 \\
(0.003)\end{array}$ & & $\begin{array}{c}0.005^{*} \\
(0.003)\end{array}$ & & $\begin{array}{l}0.003^{* *} \\
(0.001) \\
\end{array}$ \\
\hline$N$ & 86870 & 86870 & 81270 & 81270 & 81270 & 81270 \\
\hline Province $\times$ Year FE & $\mathrm{Y}$ & $\mathrm{Y}$ & Y & $\mathrm{Y}$ & Y & Y \\
\hline
\end{tabular}

Notes: This table shows the heterogeneous responses according to industry irreversibility. We use tax data to estimate regressions of the form:

$$
Y_{i t}=\gamma_{1} G_{i} \times \text { Post }_{t}+\gamma_{2} G_{i} \times \text { Post }_{t} \times \text { Redeployability }_{j}+\mu_{i}+\eta_{s t}+\varepsilon_{i j t},
$$

where $Y_{i t}$ is equipment investment, $G_{i}$ is the treatment indicator set to 1 for domestic firms and 0 for foreign firms, and Post $t_{t}$ is the post-reform indicator set to 1 for years since 2009. Redeployability is $_{\text {ine }}$ redeployability index of industry $j$ from Kim and Kung (2017), which measures industry-level irreversibility. $\mu_{i}$ is the firm fixed effect, and $\eta_{s t}$ is the province-year fixed effect. For comparison, columns (1), (3) and (5) report the baseline estimates from difference-in-difference regressions. The dependent variable for columns (1) and (2) is a dummy variable set to 1 if a firm makes a positive investment. The dependent variable for columns (3) and (4) is a dummy variable set to 1 if the investment rate is larger than 0.2 . The dependent variable for columns (5) and (6) is the firm's investment rate. All regressions include firm fixed effects. Standard errors are clustered at the firm level. 
Table 9: Summary of Assigned and Estimated Parameters

\begin{tabular}{lcc}
\hline \hline Description & & Value (S.E) \\
\hline Panel A. Fixed Parameters & $\beta$ & \\
\hline Discount factor & $\nu$ & 0.950 \\
VAT rate & $\tau$ & 0.170 \\
CIT rate & $p_{v}$ & 0.154 \\
PV depreciation schedule & & \\
& $G M M$ & \\
Panel B. Parameters Estimated via System & GM & \\
\hline Profit curvature & $\theta$ & $0.734(0.030)$ \\
Persistence firm transitory shocks & $\rho_{\varepsilon}$ & $0.860(0.012)$ \\
SD firm transitory shocks & $\sigma_{\varepsilon}$ & $0.529(0.005)$ \\
SD firm permanent shocks & $\sigma_{\omega}$ & $0.854(0.007)$ \\
Persistence aggregate shocks & $\rho_{b}$ & $0.009(0.152)$ \\
SD aggregate shocks & $\sigma_{b}$ & $0.010(0.001)$ \\
& & \\
Panel C. Parameters Estimated by MSM & & \\
\hline Convex cost & $\gamma$ & $1.432(0.061)$ \\
Upper bound of fixed cost & $\bar{\xi}$ & $0.119(0.004)$ \\
Economic depreciation rate & $\delta$ & $0.071(0.001)$ \\
\hline
\end{tabular}

Notes: This table summarizes the parameters from Section 5. Panel A displays the parameters we set (i.e., those not estimated) to simulate the model. Specifically, we set tax parameters to their empirical counterparts. Panel B summarizes the estimated parameters from the firststage production function estimation and productivity decomposition. In particular, we estimate the profit curvature $(\theta)$ and the persistence of firm transitory shocks $\left(\rho_{\varepsilon}\right)$ using system GMM. Standard errors are reported in parentheses. The rest of the parameters in Panel B are the results of the productivity decomposition (see Section 5.1). The standard errors of those parameters (i.e., $\sigma_{\varepsilon}, \sigma_{\omega}, \rho_{b}$, and $\sigma_{b}$ ) are calculated from 100 bootstrap samples. Panel $\mathrm{C}$ displays the estimated adjustment frictions and depreciation rate using the method of simulated moments (MSM) (see Section 5.2). Standard errors of those parameters (i.e., $\gamma$, $\bar{\xi}$, and $\delta$ ) are calculated from 100 bootstrap samples. 


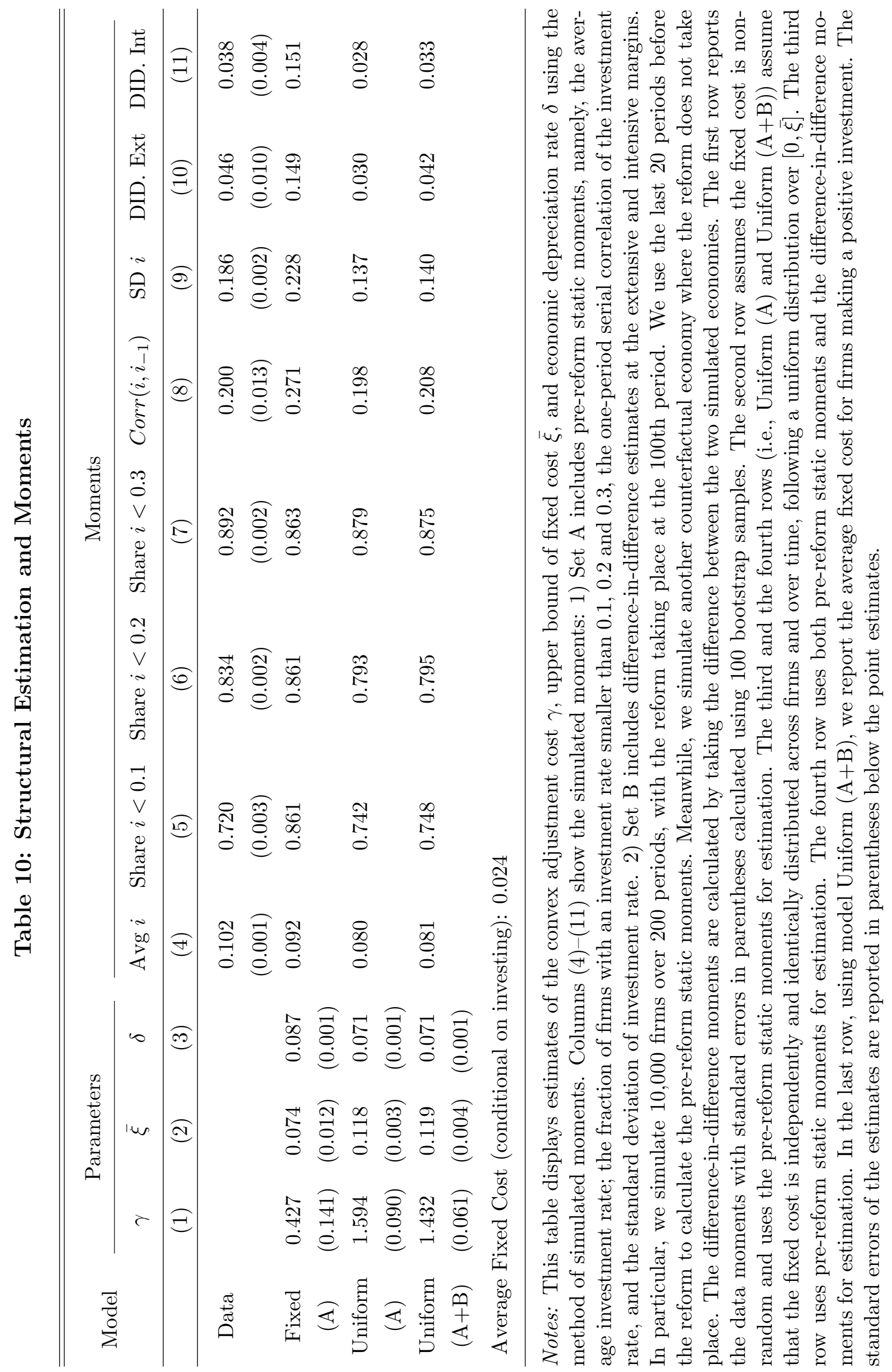


Table 11: Simulating Tax Reforms

\begin{tabular}{lccccc}
\hline \hline & $\begin{array}{c}\text { Baseline } \\
17 \%\end{array}$ & $\begin{array}{c}\text { CIT Cut } \\
15.4 \% \text { to } 10 \%\end{array}$ & $\begin{array}{c}\text { Bonus } \\
\text { Depreciation }\end{array}$ & $\begin{array}{c}\text { TCJA: } \\
\text { BD+CIT }\end{array}$ & $\begin{array}{c}\text { ITC } \\
17 \%\end{array}$ \\
\hline Percentage Change in & $(1)$ & $(2)$ & $(3)$ & $(4)$ & $(5)$ \\
\hline Aggregate Investment & 0.434 & 0.147 & 0.098 & 0.215 & 0.495 \\
Fraction of Firms Investing & 0.098 & 0.062 & 0.032 & 0.084 & 0.101 \\
& & & & & \\
Tax Revenue & -0.279 & -0.191 & -0.131 & -0.286 & -0.319 \\
Firm Value & 0.114 & 0.103 & 0.017 & 0.116 & 0.132 \\
& & & & & \\
Ratio of Investment to Tax Revenue & 1.557 & 0.767 & 0.744 & 0.753 & 1.551 \\
Ratio of Firm Value to Tax Revenue & 0.410 & 0.540 & 0.133 & 0.406 & 0.415 \\
\hline
\end{tabular}

Notes: This table displays the simulated responses to five scenarios: column (1) considers a reduction of the VAT rate from $17 \%$ to zero, i.e., our baseline reform; column (2) considers a reduction of the effective CIT rate from $15.4 \%$ to $10 \%$; column (3) considers a policy that allows firms to fully depreciate capital expenses immediately, i.e., bonus depreciation; column (4) considers a combination of a CIT cut and bonus depreciation, i.e., a version of the Tax Cuts and Jobs Act (TCJA); and column (5) considers a policy granting a 17\% investment tax credit (ITC). We report percentage (\%) changes in the outcomes of interest. For instance, our baseline $17 \%$ VAT cut increases aggregate investment by $43 \%$ over a 10 -year window. 


\section{Online Appendix: Not for Publication}

This appendix includes supplemental information and additional analyses. Appendix A provides detailed derivations of the model. Appendix B describes additional policy details. Appendix C describes the data sources. Additional results of reduced-form analysis, structural estimation and simulations are reported in Appendix D, E and F, respectively.

\section{A Model Appendix}

\section{A.1 Static Model}

This section documents derivations of the static models following the setup of the firm problem in Section 1.

\section{A.1.1 Partial Irreversibility}

Assume the purchase price of capital is $p^{b}$ and the resale price is $p^{s}<p^{b}$. The firm's problem is now:

$$
\max \{\underbrace{\max _{K>K_{0}}(1-\tau) A^{1-\theta} K^{\theta}-p^{b}\left(K-K_{0}\right)}_{\text {Invest }}, \underbrace{\max _{K<K_{0}}(1-\tau) A^{1-\theta} K^{\theta}-p^{s}\left(K-K_{0}\right)}_{\text {Disinvest }}, \underbrace{(1-\tau) A^{1-\theta} K_{0}^{\theta}}_{\text {Inaction }},\}
$$

The optimal capital level $K$ is characterized as follows.

- There exists an upper threshold $\bar{A}$ such that firms invest if their productivity is sufficiently high $A>\bar{A}$. In particular, the optimal capital $K^{b}=A\left[\frac{(1-\tau) \theta}{p^{b}}\right]^{1 /(1-\theta)}$ and

$$
\bar{A}=\left[\frac{p^{b}}{(1-\tau) \theta}\right]^{\frac{1}{1-\theta}} K_{0}
$$

- There exists a lower threshold $\underline{A}$ such that firms disinvest if their productivity is sufficiently low $A<\underline{A}$. In particular, the optimal capital $K^{s}=A\left[\frac{(1-\tau) \theta}{p^{s}}\right]^{1 /(1-\theta)}$ and

$$
\underline{A}=\left[\frac{p^{s}}{(1-\tau) \theta}\right]^{\frac{1}{1-\theta}} K_{0} .
$$

- Firms with productivity $A \in[\underline{A}, \bar{A}]$ remain with $K_{0}$. 


\section{A.1.2 Fixed Cost}

Now assume the firm needs to pay a fixed cost $\xi K^{*}$ to adjust capital. The firm's problem is now:

$$
\max \{\underbrace{\max _{K \neq K_{0}}(1-\tau) A^{1-\theta} K^{\theta}-p\left(K-K_{0}\right)-\xi K^{*}}_{\text {Adjust }}, \underbrace{(1-\tau) A^{1-\theta} K_{0}^{\theta}}_{\text {Inaction }},\}
$$

where $K^{*}$ is given by Equation 1. The optimal profit conditional on adjusting is:

$$
(1-\tau)\left[(1-\theta)-\theta \frac{\xi}{p}\right]\left[\frac{(1-\tau) \theta}{p}\right]^{\theta /(1-\theta)} A+p K_{0}
$$

The fixed costs generates a region of inaction where firms would rather produce with the initial capital stock $K_{0}$ rather than adjust their capital. This region is defined by two values of productivity $\underline{A}$ and $\bar{A}$ at which the firm is indifferent between adjusting and inaction. These values are defined by comparing firm profits from adjusting and inaction:

$$
\underbrace{(1-\tau)\left[(1-\theta)-\theta \frac{\xi}{p}\right]\left[\frac{(1-\tau) \theta}{p}\right]^{\theta /(1-\theta)} A+p K_{0}}_{\text {Profit conditional on adjusting to optimal capital } K^{*}}=\underbrace{(1-\tau) K_{0}^{\theta} A^{1-\theta}}_{\text {Profit using initial capital } K_{0}}, A \in\{\underline{A}, \bar{A}\} .
$$

To see how tax reforms interact with the fixed cost, scale both sides by a factor of $\frac{1}{1-\tau}$ and denote $\mathrm{UCC}=\frac{p}{1-\tau}:$

$$
\underbrace{\left[\frac{(1-\theta)}{\theta} \mathrm{UCC}-\frac{\xi}{1-\tau}\right]\left[\frac{\theta}{\mathrm{UCC}}\right]^{1 /(1-\theta)}}_{\text {Slope }} A+\underbrace{\mathrm{UCCK}_{0}}_{\text {Intercept }}=K_{0}^{\theta} A^{1-\theta}
$$

\section{A.1.3 Convex Adjustment Cost}

In the presence of convex adjustment cost, the firm's problem is:

$$
\max _{K}(1-\tau) A^{1-\theta} K^{\theta}-p\left(K-K_{0}\right)-D(K)
$$

where $p=p_{k}\left(1-\tau p_{v}\right)$ and where we assume that $D^{\prime}(K) \geq 0$ and $D^{\prime \prime}(K) \geq 0$. The firm's FOC is:

$$
\theta(1-\tau) A^{1-\theta} K^{\theta-1}=p+D^{\prime}(K)
$$


Taking logarithms and differentiating FOC (A.5) w.r.t. $p_{k}$, we have:

$$
\begin{aligned}
(\theta-1) \frac{1}{K} \frac{\partial K}{\partial p_{k}} & =\frac{1}{p+D^{\prime}(K)}\left(\frac{\partial p}{\partial p_{k}}+D^{\prime \prime}(K) \frac{\partial K}{\partial p_{k}}\right) \\
(\theta-1) \varepsilon_{K, p_{k}} & =\underbrace{\frac{p}{p+D^{\prime}(K)}}_{s^{p}} \varepsilon_{p, p_{k}}+\frac{D^{\prime}(K)}{p+D^{\prime}(K)} \varepsilon_{K, p_{k}} \underbrace{\left(\frac{D^{\prime \prime}(K) K}{D^{\prime}(K)}\right)}_{\alpha(K)} \\
(\theta-1) \varepsilon_{K, p_{k}} & =s^{p} \varepsilon_{p, p_{k}}+\left(1-s^{p}\right) \varepsilon_{K, p_{k}} \alpha(K) \\
\varepsilon_{K, p_{k}} & =\frac{-s^{p}}{1-\theta+\left(1-s^{p}\right) \alpha(K)},
\end{aligned}
$$

where the second line multiplies by $p_{k}$ and arranges terms into elasticities, the third line introduces $s^{p}=\frac{p}{p+D^{\prime}(K)}$ and $\alpha(K)=\frac{D^{\prime \prime}(K) K}{D^{\prime}(K)} \geq 0$, and the last line solves for $\varepsilon_{K, p_{k}}$ and uses the fact that $\varepsilon_{p, p_{k}}=1$. If there are no convex adjustment $\operatorname{costs}\left(s^{p}=1\right), \varepsilon_{K, p_{k}}$ equals the elasticity in the frictionless case.

Convex costs dampen how firms respond to changes in $p_{k}$ in two ways. First, convex costs decrease the relative importance of $p$ in the total marginal cost of investment $\left(s^{p} \leq 1\right.$ in the numerator). Second, firms take into account the fact that larger deviations from the initial capital impact the marginal cost of investment by moving the firm into more convex regions of the function $D(K)(\alpha(K) \geq 0$ in the denominator $)$.

Similarly, taking logarithms and differentiating FOC (A.5) w.r.t $(1-\tau)$, we have:

$$
\varepsilon_{K, 1-\tau}=\frac{-s^{p} \varepsilon_{U C C, 1-\tau}+\left(1-s^{p}\right)}{1-\theta+\left(1-s^{p}\right) \alpha(K)},
$$

where $\varepsilon_{K, 1-\tau}$ is the elasticity of $\mathrm{UCC}$ with respect to $1-\tau$.

To interpret Equations A.6 and A.7, note that $s^{p}$ is the share of the price of capital in the total marginal cost of investment $\left(p+D^{\prime}(K)\right) .{ }^{66}$ By increasing the marginal cost of investment, convex costs dampen the numerator of these elasticities. In addition, note that $\alpha(K)$ is a measure of the curvature of the adjustment cost function $D^{\prime}(K) .{ }^{67}$ Larger deviations of $K$ from $K_{0}$ also increase the marginal cost of investment. This indirect effect of the convex costs also dampens the elasticities by increasing the value of the denominator.

Comparing Equations A.6 and A.7, we note that changes in $1-\tau$ and $p_{k}$ now have different effects on investment. To see the nature of this difference, note that changes in $1-\tau$ change the after-tax cost of $D(K)$. These adjustment costs are thought to include halts in production. Because these costs are not tax-deductible, we model $D(K)$ as being an after-tax expense.

A particular example of $D(K)$ is the case of quadratic costs. These costs feature prominently in

\footnotetext{
${ }^{66}$ Note $s^{p} \in[0,1]$ as long as $D^{\prime}(K) \geq 0$.

${ }^{67}$ In the context of expected utility theory, $\alpha(K)$ is the Arrow-Prat measure of risk aversion, or the coefficient of relative risk aversion. Note $\alpha(K) \geq 0$ as long as $D(K)$ is convex.
} 
the literature and we use them in our dynamic model. Assuming $D(K)=\frac{\gamma}{2}\left(\frac{K}{K_{0}}-1\right)^{2} K_{0}$ implies $\alpha(K)=\frac{1}{1-K_{0} / K}$ and $s^{p}=\frac{p}{p+\gamma\left(\frac{K}{K_{0}}-1\right)}$. These facts imply the following elasticities:

$$
\varepsilon_{K, p_{k}}=\frac{-1}{(1-\theta)+\frac{\gamma}{p}\left((2-\theta) \frac{K}{K_{0}}-(1-\theta)\right)} \quad \text { and } \quad \varepsilon_{K,(1-\tau)}=\frac{-\varepsilon_{U C C, 1-\tau}+\frac{\gamma}{p}\left(K / K_{0}-1\right)}{(1-\theta)+\frac{\gamma}{p}\left((2-\theta) \frac{K}{K_{0}}-(1-\theta)\right)} .
$$

\section{A.2 Profit Function}

In this section, we micro-found the profit function of the form $\Pi=\left(A^{\Pi}\right)^{1-\theta} K^{\theta}$ by a simple firm optimization problem. Assume the final good market is perfectly competitive. Firms use capital, labor and intermediate goods for production. The production function features decreasing-returnto-scale (DRTS) with the following form:

$$
Y=A^{1-\eta}\left[\left(K^{\alpha} L^{1-\alpha}\right)^{1-\sigma} M^{\sigma}\right]^{\eta}
$$

where $\eta$ is the span-of-control parameter, $\sigma$ is the share of intermediate goods, and $\alpha$ is the capital share in value added. Capital $K$ is pre-determined while labor $L$ and intermediate goods $M$ are chosen contemporaneously after productivity $A$ is realized.

Given the price of final goods $p_{c}$ which is normalized to one, wage $w$, the price of intermediate goods $p^{M}$ and corporate income tax rate $\tau$, the firm's problem is:

$$
\max _{L, M}(1-\tau)\left\{A^{1-\eta}\left[\left(K^{\alpha} L^{1-\alpha}\right)^{1-\sigma} M^{\sigma}\right]^{\eta}-w L-p^{M} M\right\}
$$

Solving the FOCs, we obtain the optimal labor and intermediate inputs:

$$
\begin{aligned}
L^{*} & =\left\{\eta\left[\frac{(1-\alpha)(1-\sigma)}{w}\right]^{1-\sigma \eta}\left[\frac{\sigma}{p^{M}}\right]^{\sigma \eta} A^{1-\eta}\right\}^{\frac{1}{1-\eta[(1-\alpha)(1-\sigma)+\sigma]}} K^{\frac{\alpha(1-\sigma) \eta}{1-\eta[(1-\alpha)(1-\sigma)+\sigma]}}, \\
M^{*} & =\frac{\sigma}{(1-\alpha)(1-\sigma)} \frac{\sigma}{p^{M}} L^{*} .
\end{aligned}
$$


Thus, the optimal revenue and profit are:

$$
\begin{aligned}
R^{*} & =\{\underbrace{\left[\frac{(1-\alpha)(1-\sigma)}{w}\right]^{\frac{1-\sigma \eta}{1-\eta}}\left[\frac{\sigma}{p^{M}}\right]^{\frac{\sigma \eta}{1-\eta}} A}_{A^{R}}\}^{1-\underbrace{\frac{\alpha(1-\sigma) \eta}{1-\eta[(1-\alpha)(1-\sigma)+\sigma]}}_{\theta} K^{\frac{\alpha(1-\sigma) \eta}{1-\eta[(1-\alpha)(1-\sigma)+\sigma]}}=\left(A^{R}\right)^{1-\theta} K^{\theta}}, \\
\Pi^{*} & =\{1-\eta[(1-\alpha)(1-\sigma)+\sigma]\} R^{*} \\
& =\{\underbrace{(1-\tau)^{\frac{1}{1-\theta}}\{1-\eta[(1-\alpha)(1-\sigma)+\sigma]\}^{\frac{1}{1-\theta}} A^{R}}_{A^{\Pi}}\}^{1-\theta} K^{\theta}=\left(A^{\Pi}\right)^{1-\theta} K^{\theta}
\end{aligned}
$$

where the parameter $\theta$, and profit shocks $A^{\Pi}$ are defined by:

$$
\begin{aligned}
\theta & =\frac{\alpha(1-\sigma) \eta}{1-\eta[(1-\alpha)(1-\sigma)+\sigma]}, \\
A^{\Pi} & =(1-\tau)^{\frac{1}{1-\theta}}\{1-\eta[(1-\alpha)(1-\sigma)+\sigma]\}^{\frac{1}{1-\theta}}\left[\frac{(1-\alpha)(1-\sigma)}{w}\right]^{\frac{1-\sigma \eta}{1-\eta}}\left[\frac{\sigma}{p^{M}}\right]^{\frac{\sigma \eta}{1-\eta}} A .
\end{aligned}
$$

\section{A.3 Value Function and Normalization}

This section details the derivation of the value function.

\section{A.3.1 Original Value Function}

The per-period profit is $\Pi\left(K, A^{\Pi}\right)$, where $K$ is pre-determined capital and $A^{\Pi}$ is a profit shock realized at the beginning of the period. Firms pay the input VAT at rate $\nu$ on purchases of new investment, which is not allowed to be deducted from the output VAT. Firms also pay the CIT at rate $\tau$ on profits. Capital depreciates at rate $\delta$. Besides the economic depreciation rate, we also consider a straight-line accounting depreciation rate $(\hat{\delta})$ that determines the deductibility of capital usage from the CIT.

Firms face adjustment frictions including a convex cost $\left(\frac{\gamma}{2}\left(\frac{I}{K}\right)^{2} K\right)$, a random fixed cost $\left(\xi K^{*}\right)$, and partial irreversibility from the non-deductible VAT on new equipment purchases.

Let $D$ be the depreciation allowances accumulating over time. Since the accounting depreciation rate $\hat{\delta}$ differs from the economic depreciation rate $\delta$, firms track the depreciation allowance $D$ besides capital stock $K$. The firm's state variables are $\left(K, D, A^{\Pi}, \xi\right)$. We assume that the fixed cost is i.i.d drawn from the distribution $G(\xi)$ and we define the ex ante value function:

$$
V^{0}\left(K, D, A^{\Pi}\right)=\int_{0}^{\bar{\xi}} V\left(K, D, A^{\Pi}, \xi\right) d G(\xi) .
$$


The firm's problem in recursive formulation is:

$$
V\left(K, D, A^{\Pi}, \xi\right)=\max \left\{V^{b}\left(K, D, A^{\Pi}, \xi\right), V^{s}\left(K, D, A^{\Pi}, \xi\right), V^{i}\left(K, D, A^{\Pi}, \xi\right)\right\},
$$

where

$$
\begin{aligned}
V^{b}\left(K, D, A^{\Pi}, \xi\right) & =(1-\tau) \Pi\left(K, A^{\Pi}\right)+\tau \hat{\delta} D \\
& +\max _{I>0}\left\{-[1+\nu-\tau \hat{\delta}(1+\nu)] I-\frac{\gamma}{2}\left(\frac{I}{K}\right)^{2} K-\xi K^{*}+\beta \mathbb{E}\left[V^{0}\left(K^{\prime}, D^{\prime}, A^{\Pi^{\prime}}\right) \mid A^{\Pi}\right]\right\} \\
V^{s}\left(K, D, A^{\Pi}, \xi\right) & =(1-\tau) \Pi\left(K, A^{\Pi}\right)+\tau \hat{\delta} D \\
& +\max _{I<0}\left\{-[1+-\tau \hat{\delta}(1+\nu)] I-\frac{\gamma}{2}\left(\frac{I}{K} K\right)^{2}-\xi K^{*}+\beta \mathbb{E}\left[V^{0}\left(K^{\prime}, D^{\prime}, A^{\Pi^{\prime}}\right) \mid A^{\Pi}\right]\right\} \\
V^{i}\left(K, D, A^{\Pi}, \xi\right) & =(1-\tau) \Pi\left(K, A^{\Pi}\right)+\tau \hat{\delta} D+\beta \mathbb{E}\left[V^{0}\left(K(1-\delta), D(1-\hat{\delta}), A^{\Pi^{\prime}}\right) \mid A^{\Pi}\right]
\end{aligned}
$$

The capital stock $K$ and depreciation allowance $D$ evolve according to the following laws of motion:

$$
\begin{aligned}
K^{\prime} & =(1-\delta) K+I \\
D^{\prime} & =(1-\hat{\delta})[D+(1+\nu) I] .
\end{aligned}
$$

\section{A.3.2 Simplification}

Winberry (2020) shows that the impact of the depreciation schedule $\hat{\delta}$ on the deductibility of a unit of new capital can be summarized by the sufficient statistic $p_{v}$, which is defined recursively as

$$
p_{v}=\hat{\delta}+(1-\hat{\delta}) \beta \mathbb{E}\left[p_{v}^{\prime}\right]
$$

Furthermore, the function $V\left(K, D, A^{\Pi}, \xi\right)$ has the same solution as the following value function

$$
\tilde{V}\left(K, A^{\Pi}, \xi\right)=\max \left\{\tilde{V}^{b}\left(K, A^{\Pi}, \xi\right), \tilde{V}^{s}\left(K, A^{\Pi}, \xi\right), \tilde{V}^{i}\left(K, A^{\Pi}, \xi\right)\right\}
$$


where

$$
\begin{aligned}
\tilde{V}^{0}\left(K, A^{\Pi}\right) & =\int_{0}^{\bar{\xi}} \tilde{V}\left(K, A^{\Pi}, \xi\right) d G(\xi) \\
\tilde{V}^{b}\left(K, A^{\Pi}, \xi\right) & =\max _{I>0}(1-\tau) \Pi\left(K, A^{\Pi}\right)-\left[\left[1+\nu-\tau p_{v}(1+\nu)\right] I+\frac{\gamma}{2}\left(\frac{I}{K}\right)^{2} K+\xi K^{*}\right] \\
& +\beta \mathbb{E}\left[\tilde{V}^{0}\left(K^{\prime}, A^{\Pi^{\prime}}\right) \mid A^{\Pi}\right] \\
\tilde{V}^{s}\left(K, A^{\Pi}, \xi\right) & =\max _{I<0}(1-\tau) \Pi\left(K, A^{\Pi}\right)-\left[\left[1 \quad-\tau p_{v}(1+\nu)\right] I+\frac{\gamma}{2}\left(\frac{I}{K}\right)^{2} K+\xi K^{*}\right] \\
& +\beta \mathbb{E}\left[\tilde{V}^{0}\left(K^{\prime}, A^{\Pi^{\prime}}\right) \mid A^{\Pi}\right] \\
\tilde{V}^{i}\left(K, A^{\Pi}, \xi\right) & =(1-\tau) \Pi\left(K, A^{\Pi}\right)+\beta \mathbb{E}\left[\tilde{V}^{0}\left(K(1-\delta), A^{\Pi^{\prime}}\right) \mid A^{\Pi}\right]
\end{aligned}
$$

We sketch the brief proof here. Rewrite the value function as

$$
\begin{array}{r}
V(K, D, A, \xi)=(1-\tau) \Pi(K, A)+\tau \hat{\delta} D+\max _{I}-\left\{[1+\nu-\tau \hat{\delta}(1+\nu)] \mathbb{1}_{I>0}+[1-\tau \hat{\delta}(1+\nu)] \mathbb{1}_{I \leq 0}\right\} I \\
-\frac{\gamma}{2}\left(\frac{I}{K}\right)^{2} K-\xi K^{*} \mathbb{1}_{I \neq 0}+\beta \mathbb{E}\left[V\left(K^{\prime}, D^{\prime}, A^{\prime}, \xi^{\prime}\right) \mid A\right]
\end{array}
$$

Consider the set of functions of the form $f(K, A, D, \xi)=g(K, A, \xi)+\tau p_{v} D$, where $p_{v}=\hat{\delta}+(1-$ $\hat{\delta}) \mathbb{E}\left[p_{v}^{\prime}\right]$, and the operator $T$ defined by the right hand side of Bellman Equation (A.11).

Claim: The operator $T$ maps a function of the form $f(K, A, D, \xi)=g(K, A, \xi)+\tau p_{v} D$ to itself. Proof: Applying the operator $T$ to $f(K, A, D, \xi)$, we get that

$$
\begin{array}{r}
T f(K, A, D, \xi)=(1-\tau) \Pi(K, A)+\tau \hat{\delta} D+\max _{I}-\left\{[1+\nu-\tau \hat{\delta}(1+\nu)] \mathbb{1}_{I>0}+[1-\tau \hat{\delta}(1+\nu)] \mathbb{1}_{I \leq 0}\right\} I \\
-\frac{\gamma}{2}\left(\frac{I}{K}\right)^{2} K-\xi K^{*} \mathbb{1}_{I \neq 0}+\beta \mathbb{E}\left[g\left(K^{\prime}, A^{\prime}, \xi^{\prime}\right)+\tau p_{v}^{\prime} D^{\prime} \mid A\right]
\end{array}
$$


By the law of motion for the depreciation allowance $D^{\prime}=(1-\hat{\delta})[D+(1+\nu) I]$, we have that

$$
\begin{aligned}
T f(K, A, D, \xi) & =(1-\tau) \Pi(K, A)+\tau \hat{\delta} D+\max _{I}-\left\{[1+\nu-\tau \hat{\delta}(1+\nu)] \mathbb{1}_{I>0}+[1-\tau \hat{\delta}(1+\nu)] \mathbb{1}_{I \leq 0}\right\} I^{2} \\
& -\frac{\gamma}{2}\left(\frac{I}{K}\right)^{2} K-\xi K^{*} \mathbb{1}_{I \neq 0}+\beta \mathbb{E}\left[g\left(K^{\prime}, A^{\prime}, \xi^{\prime}\right) \mid A\right]+\tau(1-\hat{\delta}) \beta \mathbb{E}\left[p_{v}^{\prime}\right] D+\tau(1-\hat{\delta}) \beta \mathbb{E}\left[p_{v}^{\prime}\right](1+\nu) I \\
& =(1-\tau) \Pi(K, A)+\tau\left[\hat{\delta}+(1-\hat{\delta}) \beta \mathbb{E}\left[p_{v}^{\prime}\right]\right] D+ \\
& \max _{I}-\left\{\left[1+\nu-\tau(1+\nu)\left(\hat{\delta}+(1-\hat{\delta}) \beta \mathbb{E}\left[p_{v}^{\prime}\right]\right)\right] \mathbb{1}_{I>0}+\left[1-\tau(1+\nu)\left(\hat{\delta}+(1-\hat{\delta}) \beta \mathbb{E}\left[p_{v}^{\prime}\right]\right)\right] \mathbb{1}_{I \leq 0}\right\} I \\
& -\frac{\gamma}{2}\left(\frac{I}{K}\right)^{2} K-\xi K^{*} \mathbb{1}_{I \neq 0}+\beta \mathbb{E}\left[g\left(K^{\prime}, A^{\prime}, \xi^{\prime}\right) \mid A\right] \\
& =\Pi(K, A)+\tau p_{v} D+\max _{I}-\left\{\left[1+\nu-\tau(1+\nu) p_{v}\right] \mathbb{1}_{I>0}+\left[1-\tau(1+\nu) p_{v}\right] \mathbb{1}_{I \leq 0}\right\} I \\
& -\frac{\gamma}{2}\left(\frac{I}{K}\right)^{2} K-\xi K^{*} \mathbb{1}_{I \neq 0}+\beta \mathbb{E}\left[g\left(K^{\prime}, A^{\prime}, \xi^{\prime}\right) \mid A\right],
\end{aligned}
$$

where the last equation follows the definition of $p_{v}=\hat{\delta}+(1-\hat{\delta}) \mathbb{E}\left[p_{v}^{\prime}\right]$. Note that the right-hand side of Equation (A.12) is also a function of the form $h(K, A, \xi)+\tau p_{v} D$. That is, the operator $T$ maps function $f(K, A, D, \xi)=g(K, A, \xi)+\tau p_{v} D$ to itself. Since the set of functions $f(K, A, D, \xi)$ is a closed set, there exists a unique fixed point and the fixed point lies in the set. By the definition of value function, which is the fixed point, it follows that $V(K, A, D, \xi)$ is of the form:

$$
V(K, A, D, \xi)=\tilde{V}(K, A, \xi)+\tau p_{v} D
$$

Substituting Equation (A.13) back into the original value function (Equation (A.11)) and cancelingout common terms on both sides, we have

$$
\begin{array}{r}
\tilde{V}(K, A, \xi)=(1-\tau) \Pi(K, A)+\max _{I}-\left\{\left[1+\nu-\tau p_{v}(1+\nu)\right] \mathbb{1}_{I>0}+\left[1-\tau p_{v}(1+\nu)\right] \mathbb{1}_{I \leq 0}\right\} I \\
-\frac{\gamma}{2}\left(\frac{I}{K}\right)^{2} K-\xi K^{*} \mathbb{1}_{I \neq 0}+\beta \mathbb{E}\left[\tilde{V}\left(K^{\prime}, A^{\prime}, \xi^{\prime}\right) \mid A\right] .
\end{array}
$$

\section{A.3.3 Further Normalization}

Recall that we decompose profit shocks into three components $A_{i t}^{\Pi}=\exp \left(\omega_{i}+b_{t}+\varepsilon_{i t}\right)$, where $\omega_{i}$ is firm-specific permanent heterogeneity, $b_{t}$ is the aggregate shock, and $\varepsilon_{i t}$ is the idiosyncratic transitory shock. The state variables are then $(K, \omega, b, \varepsilon, \xi)$. Note that both the profit function and the investment cost function are homogeneous of degree one in the pair $\left(K, A^{\Pi}\right)$, and thus in $(K, \exp (\omega))$. This implies that the value function $V(K, \omega, b, \varepsilon, \xi)$ is also homogeneous of degree one in the pair $(K, \exp (\omega))$.

We can further normalize the value function to $v(k, b, \varepsilon, \xi)$ by defining $k=K / \exp (\omega)$, where 
the normalized value function is given by:

$$
v(k, b, \varepsilon, \xi)=\max \left(v^{b}(k, b, \varepsilon, \xi), v^{s}(k, b, \varepsilon, \xi), v^{i}(k, b, \varepsilon, \xi)\right)
$$

where

$$
\begin{aligned}
v^{0}(k, b, \varepsilon) & =\int_{0}^{\bar{\xi}} v(k, b, \varepsilon, \xi) d G(\xi) \\
v^{b}(k, b, \varepsilon, \xi) & =\max _{i>0}(1-\tau) \pi(k, b, \varepsilon)-\left[\left[1+\nu-\tau p_{v}(1+\nu)\right] i+\frac{\gamma}{2}\left(\frac{i}{k}\right)^{2} k+\xi k^{*}\right]+\beta \mathbb{E}\left[v^{0}\left(k^{\prime}, b^{\prime}, \varepsilon^{\prime}\right) \mid b, \varepsilon\right] \\
v^{s}(k, b, \varepsilon, \xi) & =\max _{i<0}(1-\tau) \pi(k, b, \varepsilon)-\left[\left[1-\tau p_{v}(1+\nu)\right] i+\frac{\gamma}{2}\left(\frac{i}{k}\right)^{2} k+\xi k^{*}\right]+\beta \mathbb{E}\left[v^{0}\left(k^{\prime}, b^{\prime}, \varepsilon^{\prime}\right) \mid b, \varepsilon\right], \\
v^{i}(k, b, \varepsilon, \xi) & =(1-\tau) \pi(k, b, \varepsilon)+\beta \mathbb{E}\left[v^{0}\left(k^{\prime}(1-\delta), b^{\prime}, \varepsilon^{\prime}\right) \mid b, \varepsilon\right]
\end{aligned}
$$

The law of motion for capital $k$ is

$$
k^{\prime}=(1-\delta) k+i
$$

where investment is normalized by $i=k^{\prime}-(1-\delta) k=I / \exp (\omega)$.

\section{B Policy Background}

This appendix section documents details of the VAT reform (Section B.1) and the CIT reform (Section B.2). Table F.1 summarizes the impact of VAT and CIT reforms on the tax components of the user cost of capital (TUCC).

\section{B.1 VAT Reform}

The VAT reform had four stages. Effective on July 1, 2004, stage I started from eight industries in four provinces and cities in Northeast China (Heilongjiang, Jilin, Liaoning, and Dalian city). The eight industries include equipment manufacturing, petrochemical, metallurgical, automotive manufacturing, shipbuilding, agricultural product processing, military manufacturing, and newand high-tech industries.

On July 1, 2007, the reform was extended to twenty-six cities in another six provinces (Henan, Hubei, Shanxi, Anhui, and Jiangxi) with eight qualified industries including equipment manufacturing, petrochemical, metallurgical, automotive manufacturing, agricultural product processing, electricity, mining and new- and high-tech industries.

One year later, on July 1, 2008, stage III extended the reform to five cities and leagues in eastern Inner Mongolia with the same eight industries as those in Northeast China. At the same time, due 
to the Wenchuan earthquake, the government allowed firms in the "key earthquake devastated areas of Wenchuan" to deduct input VAT on equipment. Except for several regulated industries, all other industries were covered. ${ }^{68}$

On January 1, 2009, the reform was unexpectedly extended to all industries across the country. Together with the national expansion of VAT reform, the deduction method of input VAT on equipment changed as well. At the early stages of the reform, the government first collected input VAT and then returned it to firms. To alleviate tax losses, at the beginning of each year the government usually set a limit on the tax return - the increase in VAT payable from the previous year. At the end of the year, if revenue permitted, the full amount of the input VAT on fixed assets would be returned. Since 2009, however, the government switched to the tax credit accounting method so that firms deduct input VAT on equipment from total output VAT directly.

\section{B.2 CIT Reform}

In 2008, the Chinese government implemented a Corporate Income Tax (CIT) reform that harmonized the CIT rate for domestic and foreign firms. This reform reduced the CIT rate for domestic firms from $33 \%$ to $25 \%$ and it raised CIT rate for foreign firms from lower rates to $25 \%$ (e.g., see Chen et al. (2019)).

In spite of the changes to the CIT, the effect on the user cost of capital (TUCC) was limited since the CIT only distorts the capital price through depreciation deductions. Table F.1 summarizes the VAT rate, CIT rate, and TUCCs for domestic and foreign firms from 2007 to 2011. We report two TUCC's - a theoretical one and the sample average. The theoretical TUCC is calculated using the statutory VAT rate as well as the CIT rate $\left(=\left(1+\nu_{\text {statutory }}\right)\left(1-\tau_{\text {statutory }} p_{v}\right) /\left(1-\tau_{\text {statutory }}\right)\right)$; the sample average TUCC is calculated using statutory VAT rate and the empirical CIT rate $\left(=\left(1+\nu_{\text {statutory }}\right)\left(1-\tau_{\text {empirical }} p_{v}\right) /\left(1-\tau_{\text {empirical }}\right)\right) .{ }^{69}$ While the theoretical TUCC drops by 3.8 percentage points in 2008, we do not see a decrease in the sample average. Notably, the TUCC then drops by 18.1 percentage points following the VAT reform in 2009. The theoretical and sample average TUCC for foreign firms barely changed. This confirms that the VAT reform is the major driving force behind the user cost of capital during this period.

\section{Investment Data}

In this section, we provide more details of the data we use and how we construct the key variables in our empirical analysis.

\footnotetext{
${ }^{68}$ The regulated industries include coke processing, electrolytic aluminum production, small-scale steel production, and small thermal power generation.

${ }^{69}$ The empirical CIT rate is calculated as $\tau=$ actual CIT payable/net profit. We do not observe the separate VAT paid for equipment so we use statutory VAT rate for both measures.
} 


\section{Data Detail}

The major dataset we use is the National Tax Survey Database (hereafter "tax data") collected jointly by Ministry of Finance (MoF) and State Administration of Tax (SAT). The two ministries produce two lists of survey firms every year. The first list consists of key firms that are more likely to be large firms and are required to account for at least $10 \%$ of the total number of general VAT tax payers. The key firms include those that accounted for over $70 \%$ of local VAT revenue in the past year, firms with preferential tax treatment, exporters, and publicly listed firms. The other list of firms are randomly selected from the administrative tax database, many of which are smaller firms. During our analysis period from 2007 to 2011, firms from the key list and random list account for $80 \%$ and $20 \%$ of total number of observations, respectively. Taken together, firms in the tax data contribute to over $75 \%$ of national VAT revenue. Since our main specification relies on a balanced set of firms, our results are mostly informed by firms in the first list.

The survey is distributed between March and April, covers activities for the previous year, and is usually gathered by the end of June. For instance, the 2009 survey was conducted in 2010 and reflected investment in 2009.

\section{Measuring Investment in Equipment}

One of the appealing features of tax data is that, instead of constructing investment from capital stocks, we observe investment directly in the data. Specifically, we observe total investment in fixed assets for production purpose (hereafter "total investment") and investment in structures. Following standard classification in the investment literature, we define equipment investment as the difference between total investment and investment in structures. We cross-validate this measure using data in 2007 that separately records investment in equipment. The directly reported measure matches our main measure of equipment investment very well for 2007.

For our empirical analyses, we construct three outcomes for equipment investment. First, we define a dummy variable set to 1 if a firm has positive investment in equipment. Note that, as in other studies that rely on tax data, we do not observe equipment sales. Second, we construct the investment rate as the ratio of investment in equipment to the net value of total fixed assets. Both investment and fixed assets measures are deflated using corresponding price indexes from the China Statistical Yearbook. We winsorize investment rate for the top $1 \%$ of the sample. Finally, we define an investment spike with a dummy variable set to 1 if a firm's investment rate is larger than $20 \%$ of capital.

\section{Additional Reduced-Form Results}

In this section, we present additional reduced-form results. 


\section{D.1 Inverse Probability Weighting (IPW)}

This appendix section documents details of the inverse probability weighting (IPW) method that we use in robustness checks. One concern of our empirical strategy is that domestic and foreign firms might not have similar observable characteristics. To address this concern, we reweight our data to match the distribution of firm characteristics between domestic and foreign firms.

We first generate propensity scores for being treated by estimating a probit model. The model takes the following form:

$$
G_{i}=\mathbb{1}\left\{\alpha+X_{i} \beta+\Delta Y_{i} \gamma+u_{i}>0\right\}
$$

where $G_{i}$ is the treatment variable, $X_{i}$ is a vector of firm-specific variables including whether a firm had VAT preferential treatment (and for export), whether it is an exporter, its sales and number of workers. $\Delta Y_{i}$ includes investment growth measured by whether a firm invests or not, investment rate and IHS investment. ${ }^{70}$ The error term $u_{i}$ is independently and identically drawn from normal distribution. We use information in the pre-reform years to conduct the analysis. That is, we use data in 2007 for all firm-specific terms and use data in 2007 and 2008 for investment growth terms. Table F.2 reports the estimates of the probit model.

We use the specification in column (6) to generate propensity scores for reweighting. Figure F.1 plots the distribution of propensity scores for domestic and foreign firms, respectively. This figure shows that the distributions of propensity scores overlap. Panel (B) of Figure F.2 shows that after reweighting, domestic and foreign firms are balanced in observable characteristics including investment, sales, fixed assets, and the number of workers.

\section{D.2 Event Study Estimates}

Table F.3 reports coefficients used in Figure 6 from 2007 to 2011. Particularly, we run the following regression:

$$
Y_{i j t}=G_{i} \gamma_{t}+\mu_{i}+\varepsilon_{i j t}
$$

where $G_{i}$ is an indicator that equals one for domestic firms, and $\mu_{i}$ is firm fixed effects. The dependent variable $Y_{i j t}$ is the investment measure for firm $i$ in industry $j$ at time $t$ : Columns (1) to (3) report the results at the extensive margin - i.e., the fraction of firms investing; Columns (4) to (6) report the results at the intensive margin-i.e., investment rate. In columns (1) and (3) we control for industry-year fixed effects to account for industry-specific trends; in columns (2) and (5) we control for province-year fixed effects; in columns (3) and (6) we add both industry- and province-year fixed effects.

\footnotetext{
${ }^{70}$ Growth in log investment is not included because of collinearity with the indicator of firm's investing.
} 
These results confirm that domestic and foreign firms had parallel trends before 2008 since the coefficients on 2007 are economically small and statistically insignificant at both the extensive and intensive margin. At the extensive margin, column (1) shows that the reform increased the fraction of domestic firms that invest in equipment by 6.9 percentage points in 2009, which equals to $14.1 \%$ of the pre-reform average fraction of domestic firms investing. Despite of slight decrease, the effects are stable in the following years. The estimates are robust when we add province-year fixed effects. Similar results hold for the investment rate.

Table F.4 conducts the same robustness checks performed in our difference-in-differences analysis and shows that the event study coefficients are robust across specifications. Particularly, in columns (2) and (5) we adjust the regressions with inverse probability weighting (IPW); in columns (3) and (6) we use unbalanced samples at the variable level. Despite slight variation in magnitudes, our baseline estimates are robust.

\section{D.3 User-Cost-of-Capital Investment Elasticities}

As a complement to the difference-in-differences analysis, in this appendix we quantify how changes in the tax component of user-cost-of-capital (TUCC) driven by the reform affected investment outcomes. In particular, we estimate the following regression

$$
Y_{i j t}=\beta \log \left(\mathrm{TUCC}_{i j t}\right)+\mu_{i}+\delta_{j t}+X_{i t}^{\prime} \gamma+\varepsilon_{i j t}
$$

where TUCC is the tax component of user cost of capital from Equation 5. As in Equation 7, we control for firm fixed effects, industry-by-year fixed effects, and we show robustness of our results to controlling for industry-by-year fixed effects and firm-level characteristics.

Two challenges prevent OLS from delivering unbiased estimates of $\beta$ in Equation D.3. First, both investment and the CIT rate, and thus the TUCC, might be correlated with unobserved firm characteristics. For instance, if politically connected firms have lower productivity and enjoy a lower corporate tax rate, an OLS estimation of $\beta$ would bias $\beta$ toward zero. Second, measurement error in investment and the TUCC would also bias the estimate toward zero.

To solve these problems, we use a synthetic TUCC as an instrument for the actual TUCC. In the synthetic TUCC, we allow for $\nu$ to change with the reform but we hold all other aspects of the TUCC constant. Table F.5 shows that this instrument is a powerful predictor of the actual TUCC since, as we discuss in Section 2, the VAT reform had a large effect on the cost of capital. The exclusion restriction that the synthetic tax change identifies changes in the TUCC and is not correlated with differential shocks between foreign and domestic firms is consistent with the difference-in-differences results in the previous section.

Table F.9 reports estimates of semi-elasticities of investment with respect to the TUCC. The coefficients on TUCC are all negative, indicating investment increases as the TUCC declines. While OLS estimates are biased toward zero, we find that IV estimates are much larger in magnitude. 
Columns (2)-(8) in the first panel show that cutting the TUCC by $10 \%$ leads to an increase in the fraction of firms investing by 2.4-3.1 percentage points. Similarly, cutting the TUCC by $10 \%$ would increase the investment rate by about $2 \%$. Relative to the average investment rate of $10 \%$, the second row of results implies an investment elasticity of -2 with respect to the user cost of capital. Indeed, the third column shows TUCC elasticities between -2.4 and -2.1 for the sample of firms with positive investment. Finally, the last row of Table F.9 shows larger estimates for the IHS, which arise from the larger weight the IHS places on extensive-margin responses.

Table F.9 shows that regardless of how we measure outcomes, the estimates of $\beta$ are very stable across specifications that control for different levels of fixed effects or for firm-level controls. In particular, the last column controls for corporate income tax rates, which ensures that our identifying variation only comes from changes driven by the VAT reform.

\section{D.4 Heterogeneous Effects by External Finance Dependence}

An important finding in recent estimates of the effects of tax policy on investment is that the effects of tax policy can interact with financing constraints. For instance, in their study of the effects of bonus depreciation, Zwick and Mahon (2017) find that firms with tighter financial constraints see larger effects on investment. However, this effect may be more important in the case of bonus depreciation, since that policy increases immediate cash flow to these firms. In contrast, while the VAT reform reduces the price of investment and the degree of partial irreversibility, it does not otherwise interact with firms' financial constraints.

To investigate interactions between the VAT reform and financing constraints, we expand our difference-in-differences analysis by including an interaction with an industry-level measure of external finance dependence from Hsu, Tian and Xu (2014). As we show in Table F.8, we do not find that firms in industries with higher external finance dependence have larger responses to the VAT reform. If anything, we find smaller effects along the intensive margin.

\section{E Additional Structural Estimation Results}

This appendix provides additional details on the structural estimation.

\section{E.1 Productivity Estimation via System GMM}

We now document details related to estimating the curvature parameter of profit function $(\theta)$ and the persistence of idiosyncratic shocks $\left(\rho_{\varepsilon}\right)$ using the system GMM estimator of Blundell and Bond $(2000)$. 
Following Appendix A.2, we start by taking logarithms of Equation A.8:

$$
r_{i t}=(1-\theta) a_{i t}^{R}+\theta k_{i t} .
$$

Since we observe sales $r_{i t}$ and capital $k_{i t}$, we can thus back out $\log$ revenue shocks $a_{i t}^{R}$ by $a_{i t}^{R}=$ $\frac{1}{1-\theta}\left(r_{i t}-\theta k_{i t}\right)$, which differ from $a_{i t}^{\Pi}$ by a constant. Without loss of generality, we write $a_{i t}^{R}=$ $b_{t}+\omega_{i}+\varepsilon_{i t}$, where $b_{t}, \omega_{i}, \varepsilon_{i t}$ are aggregate shock, firm permanent component and firm transitory shock, respectively. Let $m_{i t}$ denote classical measure error or any other unexpected optimization errors. Then, combined with Equation (E.1), we have

$$
r_{i t}=\theta k_{i t}+(1-\theta) b_{t}+(1-\theta) \omega_{i}+(1-\theta) \varepsilon_{i t}+m_{i t} .
$$

Recall that the firm transitory shock $\varepsilon_{i t}$ follows an $\operatorname{AR}(1)$ process i.e., $\varepsilon_{i t}=\rho_{\varepsilon} \varepsilon_{i, t-1}+e_{i t}$, where $e_{i t}$ is an innovation term independently and identically distributed across firms and over time. We exploit the $\operatorname{AR}(1)$ property of $\varepsilon_{i t}$ to difference out the persistent component in $\varepsilon_{i t}$. We can then get the following revenue equation:

$$
r_{i t}=\rho_{\varepsilon} r_{i, t-1}+\theta k_{i t}-\rho_{\varepsilon} \theta k_{i, t-1}+b_{t}^{*}+\omega_{i}^{*}+m_{i, t}-\rho_{\varepsilon} m_{i, t-1}+(1-\theta) e_{i t},
$$

where $b_{t}^{*}=(1-\theta) b_{t}-\rho_{\varepsilon}(1-\theta) b_{t-1}$ is year fixed effect and $\omega_{i}^{*}=(1-\theta)\left(1-\rho_{\varepsilon}\right) \omega_{i}$ is the firm fixed effect. We complement Equation (E.2) with its first-differenced (FD) equation:

$$
\Delta r_{i t}=\rho_{\varepsilon} \Delta r_{i, t-1}+\theta \Delta k_{i t}-\rho_{\varepsilon} \theta \Delta k_{i, t-1}+\Delta b_{t}^{*}+\Delta m_{i, t}-\rho_{\varepsilon} \Delta m_{i, t-1}+(1-\theta) \Delta e_{i t} .
$$

We construct a GMM estimator using two sets of moments based on both the level Equation (E.2) and FD Equation (E.3). The first set of moments is

$$
\mathbb{E}\left[z_{i, t-s}^{D}\left(\Delta m_{i, t}-\rho_{\varepsilon} \Delta m_{i, t-1}+(1-\theta) \Delta e_{i t}\right)\right]=0,
$$

where $z_{i, t-s}^{D}=\left[r_{i, t-s}, k_{i, t-s}\right], s \geq 3$. Intuitively, we use lagged revenue and capital in levels $(r$ and $k$ ) to instrument for the FD equation. The second set of moments is

$$
\mathbb{E}\left[z_{i, t-s}^{L}\left((1-\theta)\left(1-\rho_{\varepsilon}\right) \omega_{i}+m_{i, t}-\rho_{\varepsilon} m_{i, t-1}+(1-\theta) e_{i t}\right)\right]=0,
$$

where $z_{i, t-s}^{L}=\left[\Delta r_{i, t-s}, \Delta k_{i, t-s}\right], s \geq 2$. Here, we use the first difference of lagged revenue and capital 
( $\Delta r$ and $\Delta k$ ), to instrument for the level equation. ${ }^{71}$ In our data, we have the moment condition

$$
\mathbb{E}\left[Z_{i}^{\prime} U_{i}\right]=0, \quad \forall i
$$

where

$$
\begin{aligned}
& Z_{i}=\left[\begin{array}{cc}
Z_{i}^{D} & \mathbf{0} \\
\mathbf{0} & Z_{i}^{L}
\end{array}\right]=\left[\begin{array}{ccccc}
r_{i, 07} & k_{i, 07} & \mathbf{0} & \mathbf{0} & \mathbf{0} \\
\mathbf{0} & r_{i, 07} k_{i, 07} r_{i, 08} k_{i, 08} & \mathbf{0} & \mathbf{0} \\
\mathbf{0} & \mathbf{0} & \Delta r_{i, 08} \Delta k_{i, 08} & \mathbf{0} \\
\mathbf{0} & \mathbf{0} & \mathbf{0} & \Delta r_{i, 08} \Delta k_{i, 08} \Delta r_{i, 09} \Delta k_{i, 09}
\end{array}\right] \\
& U_{i}=\left[\begin{array}{c}
U_{i}^{D} \\
U_{i}^{L}
\end{array}\right]=\left[\begin{array}{c}
\Delta m_{i, 10}-\rho_{\varepsilon} \Delta m_{i, 09}+(1-\theta) \Delta e_{i, 10} \\
\Delta m_{i, 11}-\rho_{\varepsilon} \Delta m_{i, 10}+(1-\theta) \Delta e_{i, 11} \\
(1-\theta)\left(1-\rho_{\varepsilon}\right) \omega_{i}+m_{i, 10}-\rho_{\varepsilon} m_{i, 09}+(1-\theta) e_{i, 10} \\
(1-\theta)\left(1-\rho_{\varepsilon}\right) \omega_{i}+m_{i, 11}-\rho_{\varepsilon} m_{i, 10}+(1-\theta) e_{i, 11}
\end{array}\right]
\end{aligned}
$$

We then estimate $\theta$ and $\rho_{\varepsilon}$ using the GMM estimator.

\section{E.2 Markup}

An alternative way to obtain the revenue equation in Appendix A.2 is to assume that the firm has a CRTS production function and faces a CES demand function with elasticity $1 / \zeta$. This simple monopolistic competitive model yields a constant markup, which maps to our estimate of $\theta$. In this case, we can write the curvature of profit function $(\theta)$ as a function of other primitive parameters

$$
\theta=\frac{\alpha(1-\sigma)(1-\zeta)}{1-(1-\zeta)[(1-\alpha)(1-\sigma)+\sigma]},
$$

where $\alpha$ is the share of capital out of value added and $\sigma$ is the share of materials. The gross markup equals to $1 /(1-\zeta)$. To be consistent with the empirical markup calculated from data, we consider the markup excluding capital cost, which equals $1 /\{(1-\zeta)[(1-\alpha)(1-\sigma)+\sigma]\}$. Using Equation (E.4) we obtain:

$$
\operatorname{markup}_{\text {theoretical }}=\frac{1}{\theta} \frac{\alpha(1-\sigma)}{(1-\alpha)(1-\sigma)+\sigma}+1
$$

Given an estimate of $\theta$ and values of $\alpha$ and $\sigma$ we can calculate the markup. Setting $\alpha=1 / 2$ (Bai et al., 2006) and $\sigma=0.7$ (Jones, 2011), the theoretical markup is 1.224 .

\footnotetext{
${ }^{71}$ The identification of the first-differenced equation relies on the sequential exogeneity, as well as classical measurement error assumption; the identification of the level equation is that the changes in revenue and capital are uncorrelated to firm-specific permanent component and the measurement error.
} 
In data, we calculate the markup by

$$
\text { markup }_{\text {empirical }}=\frac{\text { total sales }}{\text { major business costs }}
$$

The average empirical markup is around 1.223. It is reassuring that the theoretical markup calculated from our estimate of $\theta$ is comparable to the empirical markup from data.

\section{E.3 Productivity Decomposition}

In this appendix we document details of the productivity decomposition we use to obtain the standard deviation of firm idiosyncratic and permanent shocks $\left(\sigma_{\varepsilon}, \sigma_{\omega}\right)$, and the persistence and standard deviation of aggregate shocks $\left(\rho_{b}, \sigma_{b}\right)$.

We first construct revenue shocks using the estimate $\hat{\theta}$

$$
\hat{a}_{i t}^{R}=r_{i t}-\hat{\theta} k_{i t}
$$

Here we use "purified" revenue - projecting revenue on higher-order polynomials of capital and labor - to get rid of disturbances such as measurement errors. With $\hat{a}_{i t}$ in hand, we exploit the $\operatorname{AR}(1)$ property of $\varepsilon_{i t}$ to write:

$$
\hat{a}_{i t}-\hat{\rho}_{\varepsilon} a_{i t-1}=b_{t}-\hat{\rho}_{\varepsilon} b_{t-1}+\left(1-\hat{\rho_{\varepsilon}}\right) \omega_{i}+e_{i t},
$$

where $e_{i t}$ is an innovation term of $\varepsilon_{i t}$ independently and identically distributed across firms and over time. We run a regression of $\hat{a}_{i t}-\hat{\rho}_{\varepsilon} \hat{a}_{i t-1}$ on time dummies and obtain the residual: $u_{i t}=$ $\left(1-\hat{\rho_{\varepsilon}}\right) \omega_{i}+e_{i t}$.

We then calculate the variance of $\omega_{i}$ and $\varepsilon_{i t}$ from $\operatorname{var}\left(u_{i t}\right)$ and $\operatorname{cov}\left(u_{i t}, u_{i t-1}\right)$ solving the following equations:

$$
\sigma_{\omega}^{2}=\frac{\operatorname{cov}\left(u_{i t}, u_{i t-1}\right)}{\left(1-\hat{\rho}_{\varepsilon}\right)^{2}} \quad \text { and } \quad \sigma_{\varepsilon}^{2}=\frac{\operatorname{var}\left(u_{i t}\right)-\operatorname{cov}\left(u_{i t}, u_{i t-1}\right)}{\left(1-{\hat{\rho_{\varepsilon}}}^{2}\right)}
$$

Lastly, we recover $\left(\rho_{b}, \sigma_{b}\right)$ using the coefficients on time dummies from the regression above. Denote the coefficients by $\beta_{t}$. Then $\rho_{b}$ and $\sigma_{b}$ jointly solve the following equations:

$$
\begin{aligned}
& \operatorname{var}\left(\beta_{t}\right)=\left(-2{\hat{\rho_{\varepsilon}}}_{\rho_{b}}+1+{\hat{\rho_{\varepsilon}}}^{2}\right) \sigma_{b}^{2} \\
& \operatorname{cov}\left(\beta_{t}\right)=\left[-\hat{\rho}_{\varepsilon} \rho_{b}^{2}+\left(1+{\hat{\rho_{\varepsilon}}}^{2}\right) \rho_{b}-\hat{\rho}_{\varepsilon}\right] \sigma_{b}^{2} .
\end{aligned}
$$

We bootstrap this procedure 100 times to obtain standard errors for these parameters. 


\section{E.4 Adjustment Cost Estimation}

In this appendix we report additional results for estimation using method of simulated moments (MSM). The criterion function is:

$$
g(\phi)=[\hat{m}-m(\phi)]^{\prime} W[\hat{m}-m(\phi)]
$$

We use grid-search to find the parameter values that minimize the criterion function $g(\phi)$. Using the grid-search results as initial values, we further refine our estimates by pattern-search. To confirm our estimates minimizes the criterion function, we plot the loss function against each parameter in Figure F.3, holding the other two parameters at their estimated values. For example, Panel (A) plots $\log \operatorname{loss}$ function $\log (g)$ against convex adjustment cost $\gamma$, with $\bar{\xi}$ held at its estimate $\hat{\bar{\xi}}=0.119$ and $\delta$ held at $\hat{\delta}=0.071$. The loss function is convex and rises steeply around our estimated value, confirming that our estimates minimize the criterion function.

\section{E.5 Sensitivity Analysis}

Lastly, we construct the sensitivity measures proposed by Andrews et al. (2017):

$$
\Lambda=-\left(G^{\prime} W G\right)^{-1} G^{\prime} W \times g(m)
$$

where $G$ is the Jacobian matrix, $W$ is the weighting matrix (identity matrix here), and $g(m)$ is a vector of moments with misspecification. Here, we consider the misspecification to be a $10 \%$ deviation from the moment value. Table F.10 reports the complete sensitivity matrix.

For the parameter $\xi$, changes in the share of investment rate below $10 \%$ and $30 \%$ have the largest effect. An increase in the share below 10\% - which implies greater inaction - results in larger fixed costs. For the parameter $\delta$, we find that moments that skew the distribution toward zero also lower the value of this parameter. For the parameter $\gamma$, an increase in serial correlation results in a lower estimate of convex costs. These results are consistent with our discussion of identification in Section 5.2 .

\section{F Additional Simulation Results}

This appendix discusses additional simulation results. First, we show that our baseline simulation results are robust to the following extensions: 1) allowing for an upward-sloping capital supply; 2) allowing for an interest rate response to the TUCC; 3) allowing the net-of-tax resale price to be less than one; 4) aggregate productivity shocks; and 5) allowing for adjustment costs to be tax deductible; and 6) allowing changes in the CIT to impact the weighted average cost of capital (WACC) which is affected by CIT cut. Lastly, we show VAT and CIT cuts with the same TUCC 
reduction may have different effectiveness in stimulating investment.

\section{F.1 Robustness of Policy Simulations}

We first show that our baseline simulation results are robust to the following extensions.

\section{Upward-sloping Capital Supply}

In our baseline model we assume that capital price - net of taxes - is constant. One concern is that the capital price is endogenous and increases as the demand goes up (e.g., Goolsbee, 1998). We relax the assumption of constant capital price by incorporating an upward-sloping capital supply. We assume a functional form of capital supply, which allows us to solve for the price change from the quantity change, i.e., investment response. The capital supply has constant elasticity:

$$
p^{K}=I^{1 / \varepsilon^{s}}
$$

where $\varepsilon^{s}$ is the elasticity of capital supply with respect to pre-tax capital price. Following estimates from House and Shapiro (2008), we set $\varepsilon^{s}$ to be $10 .{ }^{72}$ Using our difference-in-difference estimate for investment rate $-36 \%$ increase - it follows that the capital price increases by $3.6 \%$.

As a robustness check to our main simulation, we feed in a $3.6 \%$ increase in capital price to the model - both the purchase and resale price of capital - in response to the reform. In particular, the VAT reform reduces the purchase price of capital from $\left(1-\tau p_{v}\right)(1+17 \%)$ to $(1+3.6 \%) \times\left(1-\tau p_{v}\right)$, and increases the resale price of capital from $1-\tau p_{v}(1+17 \%)$ to $(1+3.6 \%) \times\left(1-\tau p_{v}\right)$. Column (2) of Table F.12 reports the simulation results. Even after accounting for this price response, the reform results in a substantial increase in investment. While the drop-in capital price is smaller, the decrease in partial irreversibility continues to stimulate investment.

\section{Interest Rate Effects of TUCC}

As an alternative general equilibrium response, we consider the possibility that interest rates increase following tax incentives for investment. To allow for this possibility, we assume that the interest rate has a negative elasticity with respect to the TUCC, $\epsilon_{T U C C}^{r}$. In Table F.13, we conduct several robustness checks allowing $\epsilon_{T U C C}^{r}$ to vary between -0.25 and -0.05 . While stronger interest rate responses lead to smaller effects on aggregate investment, even in the most responsive scenario, we find that the overall increase in investment is close to $80 \%$ of the baseline case that assumes a fixed interest rate. Therefore, the result that policies that target extensive margins of investment are more effective at stimulating investment is robust to allowing for interest rate responses to tax policy.

\footnotetext{
${ }^{72}$ House and Shapiro (2008) estimate the elasticity of supply to be between 6 and 14 using Bonus Depreciation in the US.
} 


\section{Resale Price}

Our baseline model assumes that the net-of-tax resale price is the same as the net-of-tax purchase price of capital. One concern is that the capital market for used capital is imperfect and that the resale price is smaller than the purchase price even without taxes. To explore this possibility, we reduce the resale price from one (as in the baseline model) to 0.80 (e.g., Ramey and Shapiro, 2001; Cooper and Haltiwanger, 2006). As we show in column (3) of table F.12, the results do not change. Both the pre-reform static moments and simulated investment responses - i.e., the average investment rate and the fraction of firms investing - to various tax reforms are almost identical to our baseline results. This is because, even without the imperfect resale price of capital, the VAT and fixed cost generate considerable inaction. Hence, lowering the resale price has little impact on overall investment patterns.

\section{Aggregate Productivity Shocks}

Since the VAT reform took place in 2009 as one of the measures to deal with the financial crisis, the response to the reform may reflect a concomitant drop in aggregate productivity. To explore this possibility, we feed in a one standard-deviation drop in (permanent) aggregate productivity at the same time of the tax reform. Column (4) of Table F.12 reports the results of this simulation. Our results are robust to allowing for a concomitant productivity drop.

\section{Deductible Adjustment Costs}

Our baseline model assumes that adjustment costs, i.e., convex and fixed adjustment costs, are non-deductible from CIT. Put differently, the adjustment costs are paid by after-tax profits. It is possible that those costs are tax-deductible and thus paid by pre-tax profits. For instance, the fixed costs might represent costs of hiring workers to install equipment, where labor costs are taxdeductible. If this were the case, a change in the CIT rate would impact the adjustment costs as well. To explore this possibility, we simulate the effects of a CIT cut assuming that firms pay convex costs $(1-\tau) \gamma^{D}$ and fixed costs $(1-\tau) \xi^{D}$, where $\gamma^{D}=\frac{\hat{\gamma}}{(1-0.154)}$ is the tax-deductible convex cost, and similarly for $\xi^{D}$. In column (3) of Table F.14, we simulate the effects of CIT cuts under this alternative assumption. Since the adjustment costs are paid by pre-tax profits, a reduction in the CIT rate decreases the tax benefit and increases the effective adjustment costs. As a result, the investment response is smaller than in our baseline simulation of a CIT cut.

\section{Weighted Average Cost of Capital}

Our model assumes that changes in CIT do not affect the cost of capital. Note that this assumption has no effect on our estimation. However, the effects of changes in CIT may be different if the CIT affects the costs of capital. 
Here, we extend the constant interest rate $r$ by allowing the CIT to impact the weighted average cost of capital (WACC). WACC considers two ways through which a firm raises capital - equity and debt. Because the cost of interest payments for debt financing, but not for equity financing, are deductible from the tax base of corporate income tax (CIT), changing the CIT rate affects the cost of debt financing, and thus how firms discount future profit. The WACC is defined as follows:

$$
\mathrm{WACC}=\text { Share }_{\mathrm{debt}}(1-\tau) r+\left(1-\text { Share }_{\mathrm{debt}}\right) r_{k},
$$

where Share debt $_{\text {is }}$ the share of capital financed through debt and, accordingly, $\left(1-\right.$ Share $\left._{\text {debt }}\right)$ is the share of capital financed through equity. $r$ is the real interest rate and $r_{k}$ is the capital return. In the simulation, we calibrate the share of debt financing to be 0.65 to match the average debt to capital ratio. To focus on how the policy - CIT rate here-we keep $r$ and $r_{k}$ constant and match baseline discount rate at $95 \%$.

Column (4) in Table F.14 reports the simulation results allowing for interactions between the CIT and the WACC. In particular, the discount rate $\beta=\frac{1}{1+\text { WACC }}$. The CIT rate affects the cost of capital through two channels. First, as in our baseline simulation with constant WACC, it reduces the after-tax price of capital $\frac{(1+\nu)\left(1-\tau p_{v}\right)}{1-\tau}$. Additionally, it increases the expected return on capital, $\frac{1}{\beta}-(1-\delta)$, by reducing the discount rate $\beta$. Due to the second channel-increasing expected return of capital - which offsets the decreasing capital price, the response of investment rate is smaller. The tax revenue loss is larger since the investment increase is smaller with the same reduced tax rate. Similarly, the increase in firm value is smaller as well. As a result, the ratios of investment and firm value to tax revenue are also smaller.

\section{F.2 TUCC Elasticities are Not Sufficient Statistics}

To show that the TUCC is not a sufficient statistic, Table F.15 displays the investment responses at the intensive margin (i.e., average investment rate) and the extensive margin (i.e., the fraction of firms investing) to different reforms with the same TUCC reduction. We use the estimated frictions, i.e., $\gamma=1.43, \bar{\xi}=0.12$, to simulate tax cuts. Table F.15 shows the results with initial VAT rate at $17 \%$ and CIT rate at $15.4 \%$. We compare two reforms with the same reduction in TUCC: 1 ) VAT reform cuts VAT from $17 \%$ to $14.2 \%$ (i.e., $2.8 \%$ rate reduction), and 2) CIT reform cuts CIT rate from $15.4 \%$ to $5.4 \%$ (i.e., $10 \%$ rate reduction). Both reforms reduce TUCC by $2.4 \%$. Column (3) also allows the CIT cut to affect the WACC, as in the last section. Because these different reforms have the same effect on the TUCC, the fact that the effects on investment differ implies that TUCC elasticities are not sufficient statistics for the effects of different policies on investment.

Note that, while a $10 \%$ CIT cut has a stronger effect on investment than a $2.8 \%$ VAT cut, the CIT cut is far less effective than the VAT cut since the former also leads to large decreases in tax revenue. Furthermore, once we consider the effect on the WACC, the CIT cut is even less effective at stimulating investment. 


\section{Figure F.1: Distribution of Propensity Score}

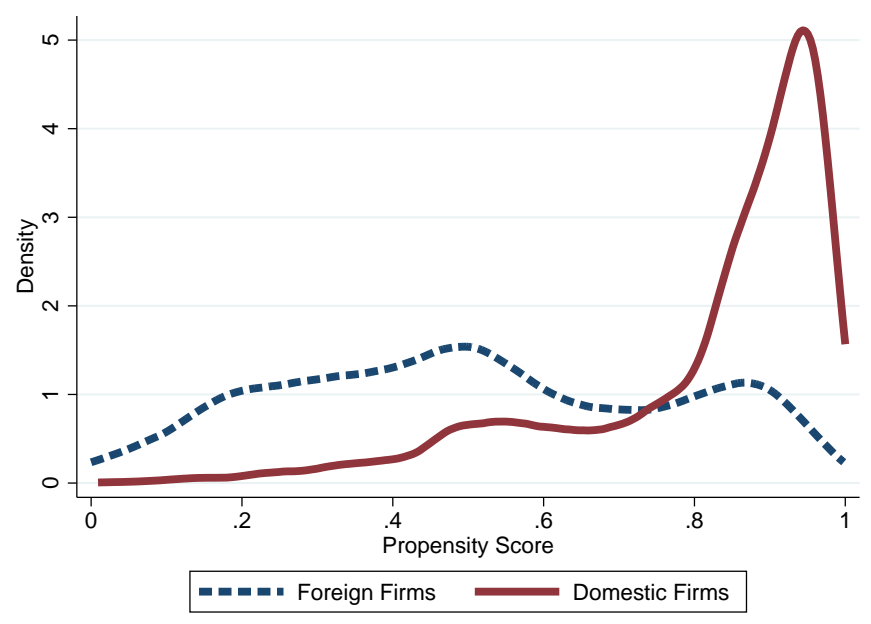

Notes: This figure plots the distributions of estimated propensity scores for domestic firms (solid line) and foreign firms (dash line), respectively. The propensity score is estimated using a probit model (see Equation (D.1)). The estimation results are reported in column (6) in Table F.2. The dependent variable is an indicator $=1$ if a firm is in the treatment group, i.e., domestic firms. The regressors include: whether a firm had VAT preferential treatment, whether a firm had export VAT preferential treatment, whether it is an exporter, sales, logarithm of the number of workers, growth in the fraction of firms investing, growth in the investment rate, growth in the log investment, and growth in the IHS measure of investment. The regression is performed using pre-reform data form 2007 and 2008. All regressions include region and industry fixed effects, and firm fixed effects. 


\section{Figure F.2: Mean Difference between Treatment and Control Groups}
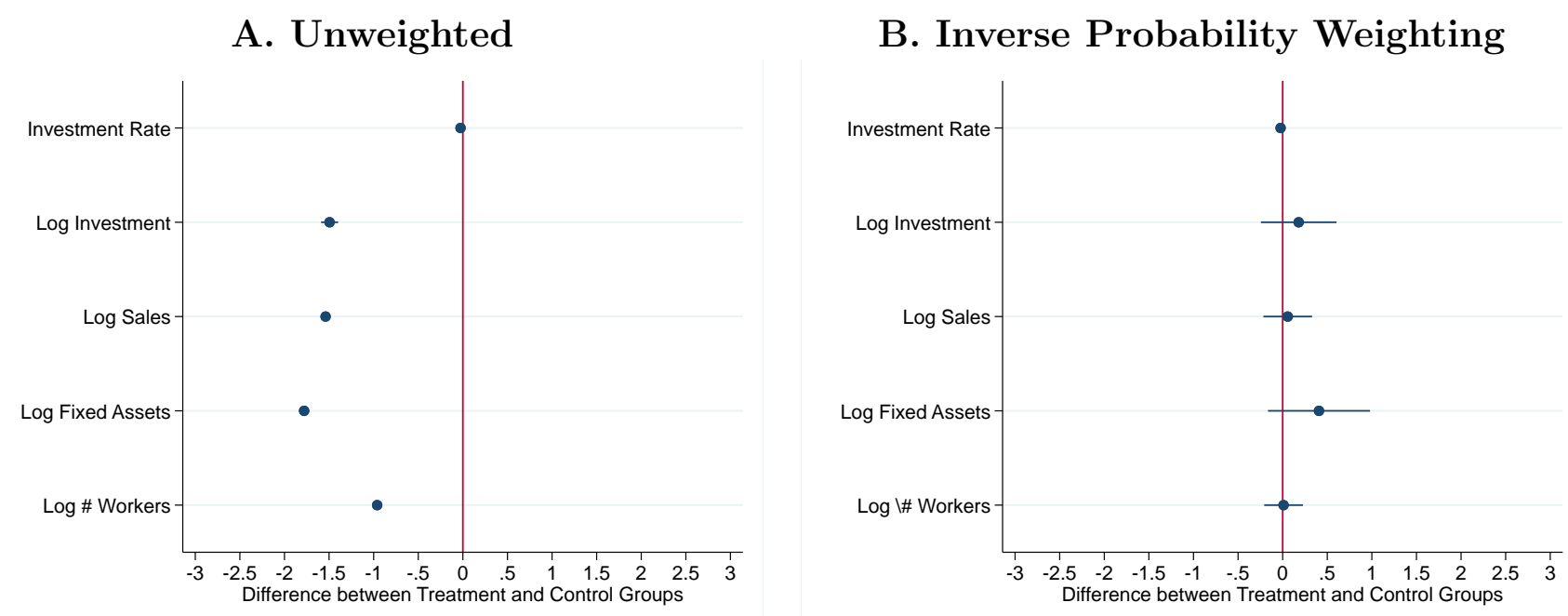

Notes: This graph shows the difference in major variables between the treatment group (i.e., domestic firms) and control group (i.e., foreign firms). The left panel shows the differences before weighting; The right panel shows the differences using inverse probability weighting (IPW). The propensity score is estimated using probit model (see Equation (D.1)). The estimation results are reported in column (6) in Table F.2. 


\section{Figure F.3: Loss Function from Structural Estimation}

A. $\gamma$

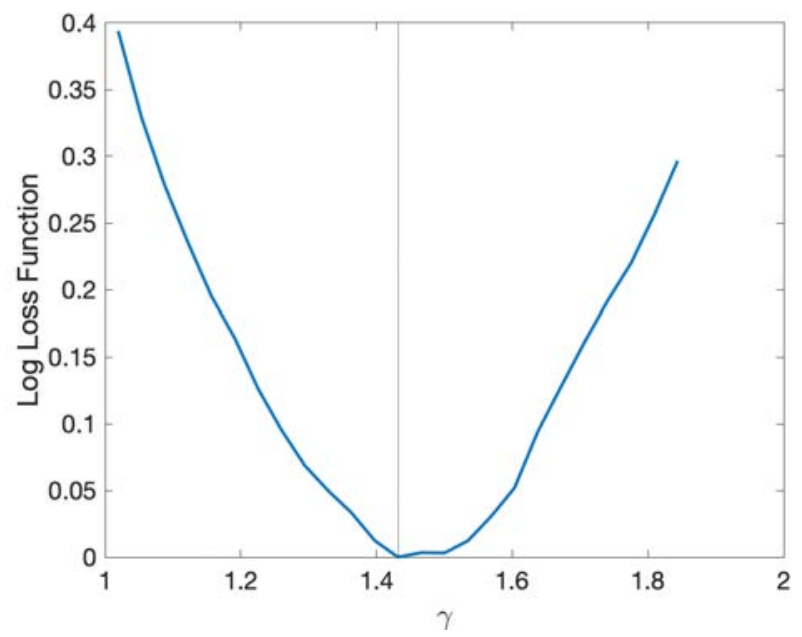

B. $\bar{\xi}$

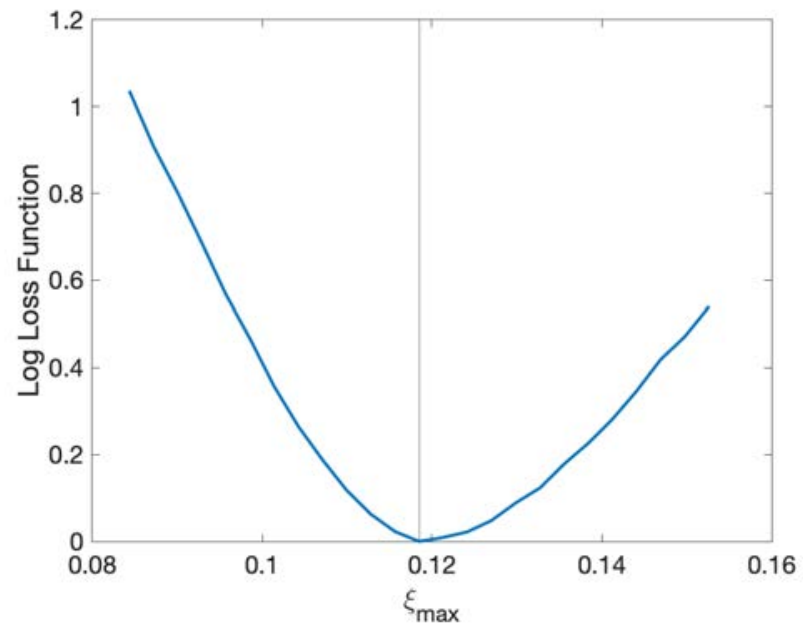

C. $\delta$

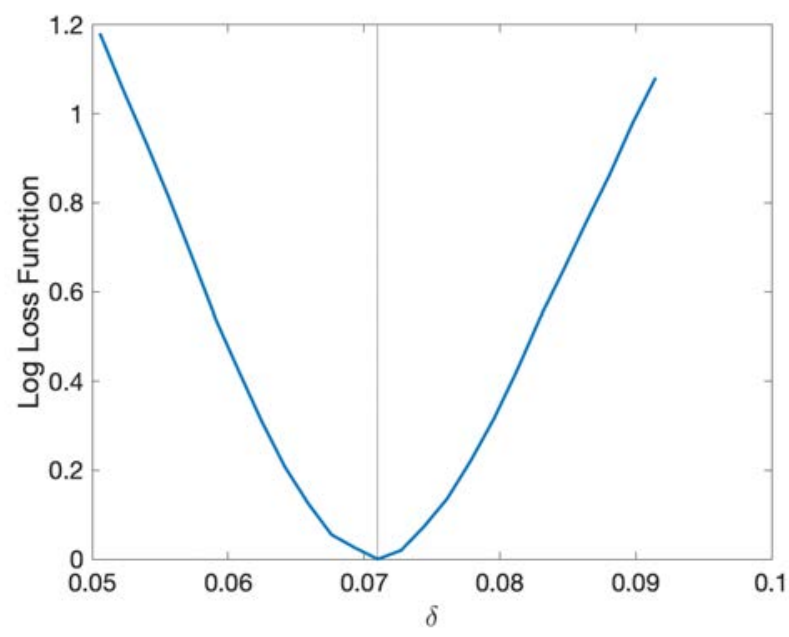

Notes: This graph displays the loss function against each parameter, holding the other two parameters at optimal values. The loss function is calculated by:

$$
g(\phi)=[\hat{m}-m(\phi)]^{\prime} \hat{W}[\hat{m}-m(\phi)],
$$

where the moments $m(\phi)$ include six pre-reform static moments, as well as two investment responses from reduced-form analysis (see Section 5.2). We use the identity matrix as the weighting matrix. Panel A plots $\log \operatorname{loss}$ function against values of $\gamma$, holding $\bar{\xi}$ and $\delta$ at their optimal values. The vertical line indicates the estimated $\gamma=1.432$. Panel B and $\mathrm{C}$ plot the log loss function against $\bar{\xi}$ and $\delta$, respectively. 
Figure F.4: Correlation between Serial Correlation and Convex Adjustment Cost $\gamma$

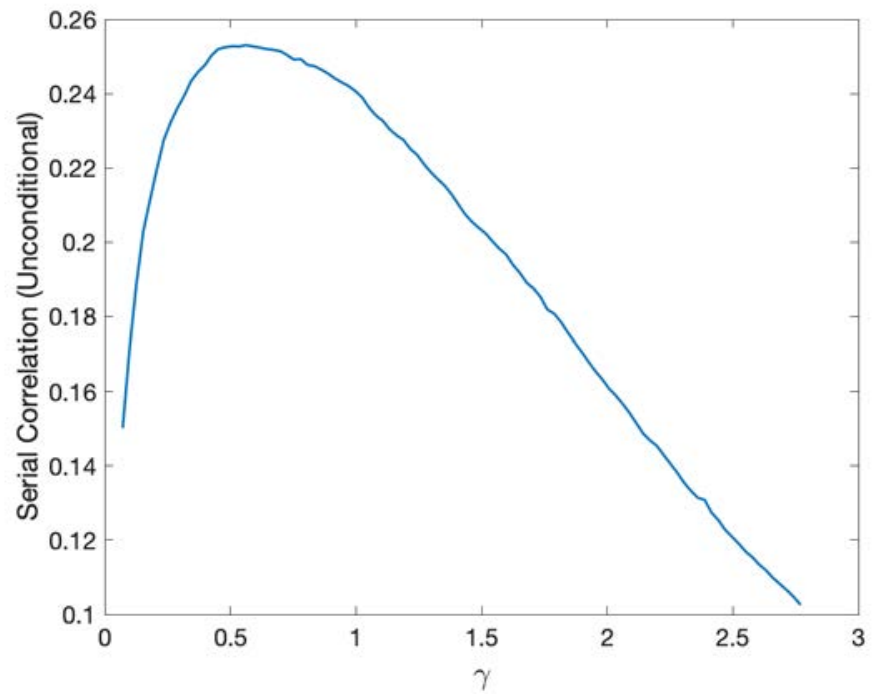

Notes: This graph plots simulated serial correlations against convex cost $\gamma$, holding the other two parameters at their estimated values, i.e., fixed $\operatorname{cost} \bar{\xi}=0.119$ and depreciation rate $\delta=0.710$. 


\section{Figure F.5: Simulating Alternative Tax Reforms: Elasticity of Firm Value to Tax Revenue}

\section{VAT Cuts vs. CIT Cuts}

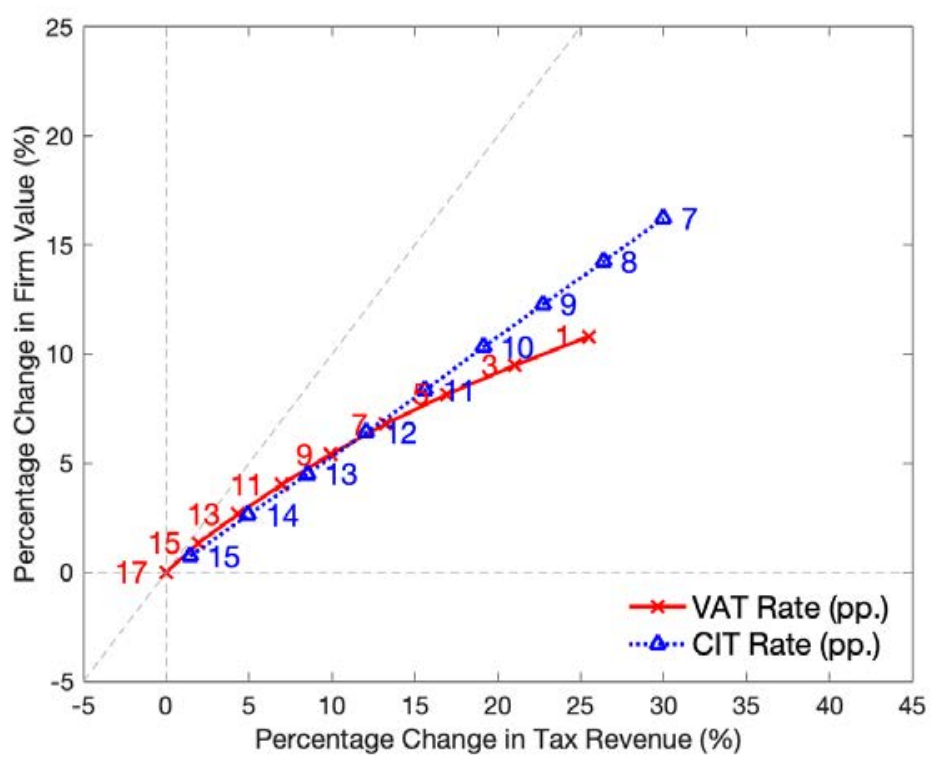

\section{VAT Cuts vs. ITC}

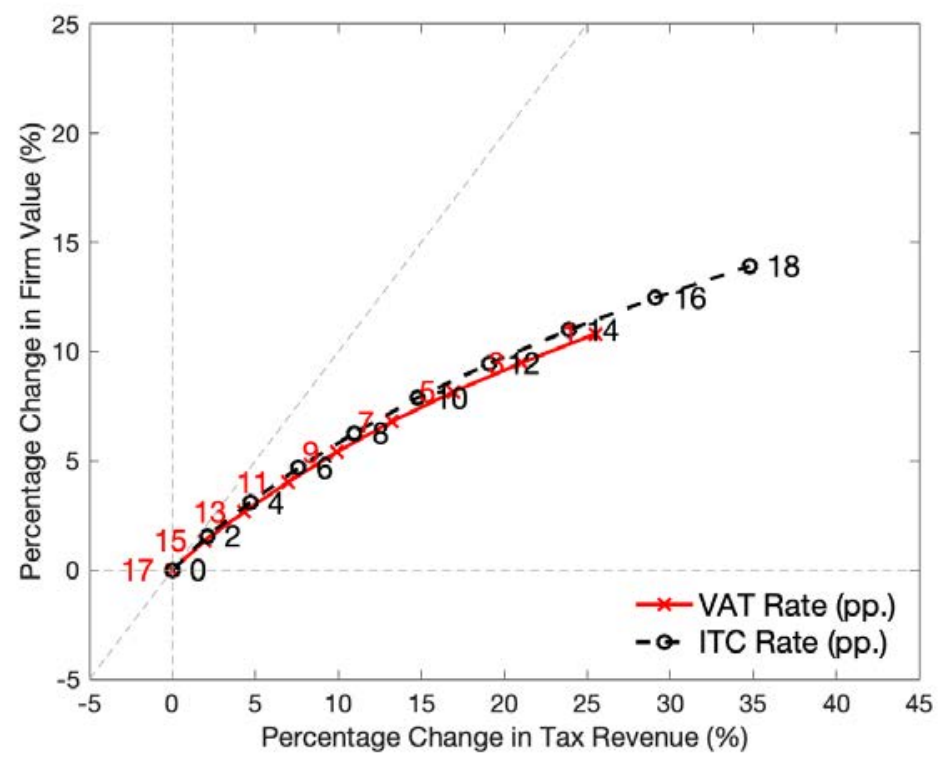

Notes: These figures plot the simulated percentage change in the average firm value to the percentage loss in tax revenue at different rates of VAT cut, CIT cut and investment tax credit (ITC) policies. For each tax rate, we solve the model; simulate investment, tax revenue and firm value; and calculate the corresponding changes in each outcome. Panel A plots the percentage change in the average firm value against the percentage change in tax revenue. The red solid curve corresponds to VAT cuts from $17 \%$ to different rates. The blue dotted line corresponds to CIT cuts from $15.4 \%$ to different rates. Similarly, Panel B compares the percentage change in tax revenue from VAT cuts with that from an ITC. 
Table F.1: Changes in Tax Rate, Theoretical and Effective User Cost of Capital

\begin{tabular}{lccccc}
\hline \hline \multirow{2}{*}{ Year } & CIT $(\%)$ & VAT $(\%)$ & \multicolumn{3}{c}{ User Cost of Capital } \\
\cline { 4 - 6 } & $(1)$ & $(2)$ & $(3)$ & $(4)$ & $(5)$ \\
\hline \multicolumn{2}{l}{ A. Domestic Firms } & & & & \\
\hline 2007 & 33 & 17 & 1.284 & 1.222 & 30,789 \\
2008 & 25 & 17 & 1.247 & 1.233 & 44,893 \\
2009 & 25 & 0 & 1.066 & 1.042 & 53,580 \\
2010 & 25 & 0 & 1.066 & 1.037 & 56,579 \\
2011 & 25 & 0 & 1.066 & 1.040 & 56,955 \\
& & & & & \\
B. Foreign Firms & & & & \\
\hline 2007 & 20 & 0 & 1.049 & 1.023 & 15,984 \\
2008 & 25 & 0 & 1.066 & 1.038 & 16,842 \\
2009 & 25 & 0 & 1.066 & 1.035 & 20,394 \\
2010 & 25 & 0 & 1.066 & 1.038 & 20,596 \\
2011 & 25 & 0 & 1.066 & 1.044 & 20,555 \\
\hline
\end{tabular}

Notes: This table displays summary statistics of user cost of capital (TUCC) of domestic and foreign firms, respectively. TUCC is calculated by TUCC $=(1+\nu)\left(1-\tau p_{v}\right) /(1-\tau)$, where $\nu$ is VAT rate, $\tau$ is CIT rate, $p_{v}=0.803$ is discounted present value of capital depreciation schedule. Column (1) and (2) report the statutory rates of CIT and VAT for domestic and foreign firms, respectively. Theoretical TUCC is calculated using statutory VAT and CIT rates. Sample average refers to the average TUCC in tax data, which is calculated using statutory VAT rate but empirical CIT rate. The sample average statistics are calculated using full balanced panel, i.e., firms existing for five years in the sample. Empirical CIT rate is calculated by $\tau=$ actual CIT payable/net profit, which is closer to the "effective" CIT rate. 
Table F.2: Estimates of Probit Model of Propensity Score

\begin{tabular}{|c|c|c|c|c|c|c|}
\hline & $\overline{(1)}$ & $\overline{(2)}$ & $(3)$ & $\overline{(4)}$ & (5) & (6) \\
\hline Had VAT PT & $\begin{array}{c}0.112^{* * *} \\
(0.020)\end{array}$ & $\begin{array}{l}0.106^{* *} \\
(0.044)\end{array}$ & $\begin{array}{c}0.116^{* * *} \\
(0.038)\end{array}$ & $\begin{array}{l}0.131^{*} \\
(0.067)\end{array}$ & $\begin{array}{c}0.119^{* * *} \\
(0.037)\end{array}$ & $\begin{array}{l}0.107^{* *} \\
(0.046)\end{array}$ \\
\hline Had Export VAT PT & $\begin{array}{c}-0.797^{* * *} \\
(0.042)\end{array}$ & $\begin{array}{c}-0.896^{* * *} \\
(0.094)\end{array}$ & $\begin{array}{c}-0.902^{* * *} \\
(0.085)\end{array}$ & $\begin{array}{c}-0.770^{* * *} \\
(0.130)\end{array}$ & $\begin{array}{c}-0.925^{* * *} \\
(0.083)\end{array}$ & $\begin{array}{c}-0.866^{* * *} \\
(0.097)\end{array}$ \\
\hline Exporter & $\begin{array}{c}-1.004^{* * *} \\
(0.250)\end{array}$ & $\begin{array}{c}-0.287^{* *} \\
(0.112)\end{array}$ & $\begin{array}{c}-0.309^{* * *} \\
(0.100)\end{array}$ & $\begin{array}{c}-0.373^{* *} \\
(0.157)\end{array}$ & $\begin{array}{c}-0.280^{* * *} \\
(0.098)\end{array}$ & $\begin{array}{c}-0.328^{* * *} \\
(0.115)\end{array}$ \\
\hline Sales & $\begin{array}{c}-0.001^{* * *} \\
(0.000)\end{array}$ & $\begin{array}{c}-0.001^{* * *} \\
(0.000)\end{array}$ & $\begin{array}{c}-0.001^{* * *} \\
(0.000)\end{array}$ & $\begin{array}{c}-0.001^{* * *} \\
(0.000)\end{array}$ & $\begin{array}{c}-0.001^{* * *} \\
(0.000)\end{array}$ & $\begin{array}{c}-0.001^{* * *} \\
(0.000)\end{array}$ \\
\hline Log Workers & $\begin{array}{c}-0.375^{* * *} \\
(0.024)\end{array}$ & $\begin{array}{c}-0.545^{* * *} \\
(0.045)\end{array}$ & $\begin{array}{c}-0.653^{* * *} \\
(0.050)\end{array}$ & $\begin{array}{c}-0.356^{* * *} \\
(0.101)\end{array}$ & $\begin{array}{c}-0.547^{* * *} \\
(0.045)\end{array}$ & $\begin{array}{c}-0.651^{* * *} \\
(0.050)\end{array}$ \\
\hline$\%$ Firms Investing Growth & & $\begin{array}{l}-0.267 \\
(0.346)\end{array}$ & & & & $\begin{array}{c}2.953 \\
(1.872)\end{array}$ \\
\hline Investment Rate Growth & & & $\begin{array}{c}-0.272 \\
(0.358)\end{array}$ & & & $\begin{array}{c}-1.049^{* *} \\
(0.496)\end{array}$ \\
\hline Log Investment Growth & & & & $\begin{array}{l}-0.020 \\
(0.099)\end{array}$ & & \\
\hline IHS Investment Growth & & & & & $\begin{array}{c}0.022 \\
(0.019)\end{array}$ & $\begin{array}{l}0.102^{*} \\
(0.058)\end{array}$ \\
\hline \#Obs & 77,939 & 21,433 & 20,172 & 5,836 & 21,422 & 20,170 \\
\hline Industry FE & Y & $\mathrm{Y}$ & Y & Y & Y & $\mathrm{Y}$ \\
\hline Region FE & Y & $\mathrm{Y}$ & Y & Y & Y & Y \\
\hline
\end{tabular}

Notes: This table displays probit regression results for the propensity score estimation in Equation (D.1). The dependent variable is an indicator $=1$ if a firm is in the treatment group. The variables on the right hand side include: whether a firm had VAT preferential treatment, whether a firm had export VAT preferential treatment, whether it is an exporter, sales, logarithm of the number of workers, growth in the fraction of firms investing, growth in the investment rate, growth in the log investment, and growth in the IHS measure of investment. The regression is performed using pre-reform data form 2007 and 2008. All regressions include region and industry fixed effects, and firm fixed effects. Standard errors are clustered at the firm level. 
Table F.3: Estimates of Event Study

\begin{tabular}{|c|c|c|c|c|c|c|}
\hline & \multicolumn{3}{|c|}{ Extensive Margin } & \multicolumn{3}{|c|}{ Investment Rate } \\
\hline & (1) & (2) & (3) & (4) & (5) & (6) \\
\hline 2007 & $\begin{array}{c}0.006 \\
(0.013)\end{array}$ & $\begin{array}{c}0.004 \\
(0.014)\end{array}$ & $\begin{array}{c}0.011 \\
(0.014)\end{array}$ & $\begin{array}{l}-0.000 \\
(0.006)\end{array}$ & $\begin{array}{l}-0.007 \\
(0.006)\end{array}$ & $\begin{array}{l}-0.005 \\
(0.006)\end{array}$ \\
\hline 2008 & $\begin{array}{c}0.000 \\
(.)\end{array}$ & $\begin{array}{c}0.000 \\
(.)\end{array}$ & $\begin{array}{c}0.000 \\
(.)\end{array}$ & $\begin{array}{c}0.000 \\
(.)\end{array}$ & $\begin{array}{c}0.000 \\
(.)\end{array}$ & $\begin{array}{c}0.000 \\
(.)\end{array}$ \\
\hline 2009 & $\begin{array}{c}0.069^{* * *} \\
(0.013)\end{array}$ & $\begin{array}{c}0.045^{* * *} \\
(0.013)\end{array}$ & $\begin{array}{c}0.055^{* * *} \\
(0.013)\end{array}$ & $\begin{array}{c}0.044^{* * *} \\
(0.005)\end{array}$ & $\begin{array}{c}0.043^{* * *} \\
(0.005)\end{array}$ & $\begin{array}{c}0.043^{* * *} \\
(0.005)\end{array}$ \\
\hline 2010 & $\begin{array}{c}0.051^{* * *} \\
(0.014)\end{array}$ & $\begin{array}{c}0.047^{* * *} \\
(0.015)\end{array}$ & $\begin{array}{c}0.050^{* * *} \\
(0.015)\end{array}$ & $\begin{array}{c}0.034^{* * *} \\
(0.005)\end{array}$ & $\begin{array}{c}0.032^{* * *} \\
(0.005)\end{array}$ & $\begin{array}{c}0.035^{* * *} \\
(0.006)\end{array}$ \\
\hline 2011 & $\begin{array}{c}0.064^{* * *} \\
(0.014) \\
\end{array}$ & $\begin{array}{c}0.044^{* * *} \\
(0.015) \\
\end{array}$ & $\begin{array}{c}0.049^{* * *} \\
(0.015)\end{array}$ & $\begin{array}{c}0.029^{* * *} \\
(0.006)\end{array}$ & $\begin{array}{c}0.027^{* * *} \\
(0.006)\end{array}$ & $\begin{array}{c}0.028^{* * *} \\
(0.006)\end{array}$ \\
\hline$N$ & 86870 & 86870 & 86870 & 81270 & 81270 & 81270 \\
\hline$N_{\text {firms }}$ & 17374 & 17374 & 17374 & 16254 & 16254 & 16254 \\
\hline Industry $\times$ Year FE & $\mathrm{Y}$ & & Y & $\mathrm{Y}$ & & $\mathrm{Y}$ \\
\hline Province $\times$ Year FE & & $\mathrm{Y}$ & $\mathrm{Y}$ & & $\mathrm{Y}$ & $\mathrm{Y}$ \\
\hline
\end{tabular}

Notes: This table uses tax data to estimate event study regressions of the form:

$$
Y_{i t}=G_{i} \times \gamma_{t}+\mu_{i}+\delta_{j t}+\eta_{s t}+\varepsilon_{i t}
$$

where $G_{i}$ is the treatment indicator set to 1 for domestic firms and 0 for foreign firms, $\mu_{i}$ is firm fixed effect, $\delta_{j t}$ and $\eta_{s t}$ are industry-year and province-year fixed effects, respectively. Dependent variable $Y_{i t}$ is the investment measure for firm $i$ at time $t$ : Column (1) to (3) report the estimated $\gamma_{t}(t=2007, \cdots, 2011)$ at the extensive margin - i.e., the fraction of firms investing; Column (4) to (6) report the results at the intensive margin - i.e., investment rate. In column (1) and (3) we control for industry-year fixed effects; in column (2) and (5) we control for province-year fixed effects; in column (3) and (6) we add both industryand province-year fixed effects. All regressions include firm fixed effects. Standard errors are clustered at the firm level. 
Table F.4: Event Study: Robustness Checks

\begin{tabular}{|c|c|c|c|c|c|c|}
\hline & \multicolumn{3}{|c|}{ Extensive Margin } & \multicolumn{3}{|c|}{ Investment Rate } \\
\hline & $\begin{array}{l}\text { Baseline } \\
\quad(1)\end{array}$ & $\begin{array}{l}\text { IPW } \\
(2)\end{array}$ & $\begin{array}{c}\text { Unbalanced } \\
(3)\end{array}$ & $\begin{array}{c}\text { Baseline } \\
(4)\end{array}$ & $\begin{array}{l}\text { IPW } \\
(5)\end{array}$ & $\begin{array}{c}\text { Unbalanced } \\
(6)\end{array}$ \\
\hline 2007 & $\begin{array}{c}0.006 \\
(0.013)\end{array}$ & $\begin{array}{c}0.044 \\
(0.028)\end{array}$ & $\begin{array}{l}-0.001 \\
(0.011)\end{array}$ & $\begin{array}{l}-0.000 \\
(0.006)\end{array}$ & $\begin{array}{c}0.012 \\
(0.011)\end{array}$ & $\begin{array}{l}-0.003 \\
(0.005)\end{array}$ \\
\hline 2008 & $\begin{array}{c}0.000 \\
(.)\end{array}$ & $\begin{array}{c}0.000 \\
(.)\end{array}$ & $\begin{array}{c}0.000 \\
(.)\end{array}$ & $\begin{array}{c}0.000 \\
(.)\end{array}$ & $\begin{array}{c}0.000 \\
(.)\end{array}$ & $\begin{array}{c}0.000 \\
(.)\end{array}$ \\
\hline 2009 & $\begin{array}{c}0.069^{* * *} \\
(0.013)\end{array}$ & $\begin{array}{c}0.108^{* * *} \\
(0.026)\end{array}$ & $\begin{array}{c}0.058^{* * *} \\
(0.010)\end{array}$ & $\begin{array}{c}0.044^{* * *} \\
(0.005)\end{array}$ & $\begin{array}{c}0.045^{* * *} \\
(0.009)\end{array}$ & $\begin{array}{c}0.046^{* * *} \\
(0.004)\end{array}$ \\
\hline 2010 & $\begin{array}{c}0.051^{* * *} \\
(0.014)\end{array}$ & $\begin{array}{c}0.092^{* * *} \\
(0.032)\end{array}$ & $\begin{array}{c}0.058^{* * *} \\
(0.010)\end{array}$ & $\begin{array}{c}0.034^{* * *} \\
(0.005)\end{array}$ & $\begin{array}{c}0.032^{* * *} \\
(0.011)\end{array}$ & $\begin{array}{c}0.039^{* * *} \\
(0.004)\end{array}$ \\
\hline 2011 & $\begin{array}{c}0.064^{* * *} \\
(0.014)\end{array}$ & $\begin{array}{l}0.091^{* *} \\
(0.045)\end{array}$ & $\begin{array}{c}0.059^{* * *} \\
(0.010)\end{array}$ & $\begin{array}{c}0.029^{* * *} \\
(0.006)\end{array}$ & $\begin{array}{l}0.030^{* *} \\
(0.013)\end{array}$ & $\begin{array}{l}0.032^{* * *} \\
(0.004)\end{array}$ \\
\hline$N$ & 86870 & 82785 & 221069 & 81270 & 79195 & 215813 \\
\hline$N_{\text {firms }}$ & 17374 & 16557 & 60870 & 16254 & 15839 & 60513 \\
\hline Industry $\times$ Year FE & $\mathrm{Y}$ & $\mathrm{Y}$ & $\mathrm{Y}$ & $\mathrm{Y}$ & $\mathrm{Y}$ & $\mathrm{Y}$ \\
\hline
\end{tabular}

Notes: This table uses tax data to conduct robustness checks for the event study regressions of the form:

$$
Y_{i t}=G_{i} \times \gamma_{t}+\mu_{i}+\delta_{j t}+\eta_{s t}+\varepsilon_{i t}
$$

where $G_{i}$ is the treatment indicator set to 1 for domestic firms and 0 for foreign firms, $\mu_{i}$ is firm fixed effect, $\delta_{j t}$ and $\eta_{s t}$ are industry-year and province-year fixed effects, respectively. Dependent variable $Y_{i t}$ is the investment measure for firm $i$ at time $t$ : Column (1) to (3) report the estimated $\gamma_{t}(t=2007, \cdots, 2011)$ at the extensive margin - i.e., the fraction of firms investing; Column (4) to (6) report the results at the intensive margin - i.e., investment rate. We report the baseline results (column (1) and (4)) In column (2) and (5) we adjust the regressions by inverse probability weighting (IPW, see Section D.1). In column (3) and (6) we use the unbalanced sample for the analysis (i.e., unbalanced at the variable level but balanced at the firm level). All regressions include industry-year fixed effects and firm fixed effects. Standard errors are clustered at the firm level. 
Table F.5: Estimates of Difference-in-Difference Regressions: TUCC

\begin{tabular}{lccccccc}
\hline \hline & \multicolumn{3}{c}{ TUCC } & & \multicolumn{3}{c}{ Log TUCC } \\
\cline { 2 - 3 } \cline { 7 - 8 } & $(1)$ & $(2)$ & $(3)$ & & $(4)$ & $(5)$ & $(6)$ \\
\hline Domestic $\times$ Post & $-0.193^{* * *}$ & $-0.194^{* * *}$ & $-0.194^{* * *}$ & & $-0.171^{* * *}$ & $-0.171^{* * *}$ & $-0.171^{* * *}$ \\
& $(0.001)$ & $(0.001)$ & $(0.001)$ & & $(0.001)$ & $(0.001)$ & $(0.001)$ \\
\hline$N$ & 77677 & 77677 & 77677 & & 77677 & 77677 & 77677 \\
$N_{\text {firm }}$ & 17371 & 17371 & 17371 & & 17371 & 17371 & 17371 \\
Industry $\times$ Year FE & $\mathrm{Y}$ & & $\mathrm{Y}$ & & $\mathrm{Y}$ & & $\mathrm{Y}$ \\
Province $\times$ Year FE & & $\mathrm{Y}$ & $\mathrm{Y}$ & & $\mathrm{Y}$ & $\mathrm{Y}$ \\
\hline
\end{tabular}

Notes: This table estimates difference-in-difference regressions of the form:

$$
Y_{i t}=\gamma G_{i} \times \text { Post }_{t}+\mu_{i}+\delta_{j t}+\eta_{s t}+\varepsilon_{i j t},
$$

where $Y_{i t}$ is the user cost of capital (TUCC), $G_{i}$ is the treatment indicator set to 1 for domestic firms and 0 for foreign firms, and Post $t$ is the post-reform indicator set to 1 for years since 2009. $\mu_{i}$ is firm fixed effect, $\delta_{j t}$ and $\eta_{s t}$ are industry-year and province-year fixed effects, respectively. Particularly, the dependent variable for column (1) to $(3)$ is $T U C C=(1+\nu)\left(1-\tau p_{v}\right) /(1-\tau)$ where $\nu$ is the statutory VAT rate, $\tau$ is the empirical CIT rate, and $p_{v}$ is the discounted present value of capital depreciation schedule. The dependent variable for column (4) to (6) is the logarithm of TUCC. Column (1) and (4) control for industry-year fixed effects. Column (2) and (5) control for province-year fixed effects. Column (3) and (6) include both fixed effects. All regressions include firm fixed effects. Standard errors are clustered at the firm level. 
Table F.6: Robustness Check: Investment Including Leasing

\begin{tabular}{lcccccccc}
\hline \hline & \multicolumn{3}{c}{ Extensive Margin } & & \multicolumn{3}{c}{ Investment Rate } \\
\cline { 2 - 3 } & $(1)$ & $(2)$ & $(3)$ & & $(4)$ & $(5)$ & $(6)$ \\
& $0.059^{* * *}$ & $0.044^{* * *}$ & $0.046^{* * *}$ & & $0.035^{* * *}$ & $0.037^{* * *}$ & $0.038^{* * *}$ \\
& $(0.010)$ & $(0.010)$ & $(0.010)$ & & $(0.004)$ & $(0.004)$ & $(0.004)$ \\
\hline$N$ & 86870 & 86870 & 86870 & & 81270 & 81270 & 81270 \\
$N_{\text {firm }}$ & 17374 & 17374 & 17374 & & 16254 & 16254 & 16254 \\
Industry $\times$ Year FE & $\mathrm{Y}$ & & $\mathrm{Y}$ & & $\mathrm{Y}$ & & $\mathrm{Y}$ \\
Province $\times$ Year FE & & $\mathrm{Y}$ & $\mathrm{Y}$ & & $\mathrm{Y}$ & $\mathrm{Y}$ \\
\hline
\end{tabular}

Notes: This table uses tax data to estimate difference-in-difference regressions of the form:

$$
Y_{i t}=\gamma G_{i} \times \text { Post }_{t}+\mu_{i}+\delta_{j t}++\eta_{s t}+\varepsilon_{i t},
$$

where $Y_{i t}$ is a measure of investment including leasing, $G_{i}$ is an indicator set to 1 for domestic firms and 0 for foreign firms, and Post $t_{t}$ is the post-reform indicator set to 1 for years since 2009. $\mu_{i}$ is firm fixed effect, $\delta_{j t}$ and $\eta_{s t}$ are industry-year and province-year fixed effects, respectively. We construct an alternative investment measure to include leased equipment. The dependent variable for column (1) to (3) is a dummy variable set to 1 if the leasing-included investment rate is positive. The dependent variable for column (4) to (6) is leasing-included investment rate. Column (1) and (4) control for industry-year fixed effects. Column (2) and (5) control for province-year fixed effects. Column (3) and (6) include both fixed effects. All regressions include firm fixed effects. Standard errors are clustered at the firm level. 


\section{Table F.7: Extensive Margin Responses of Investment in Structures}

\begin{tabular}{lcccc}
\hline \hline & \multicolumn{3}{c}{ \% Firms Investing with Investment Rate } \\
\cline { 2 - 5 } & $\geq 1 \%$ & $\geq 2 \%$ & $\geq 3 \%$ & $\geq 20 \%$ \\
& $(1)$ & $(2)$ & $(3)$ & $(4)$ \\
\hline Domestic $\times$ Post & $0.028^{* *}$ & $0.020^{*}$ & 0.017 & 0.001 \\
& $(0.011)$ & $(0.011)$ & $(0.010)$ & $(0.007)$ \\
Domestic $\times$ Equipment $\times$ Post & $0.036^{* *}$ & $0.056^{* * *}$ & $0.077^{* * *}$ & $0.065^{* * *}$ \\
& $(0.015)$ & $(0.015)$ & $(0.015)$ & $(0.011)$ \\
\hline $\mathrm{N}$ & 162540 & 162540 & 162540 & 162540 \\
$N_{\text {firm }}$ & 16254 & 16254 & 16254 & 16254 \\
Industry $\times$ Year FE & $\mathrm{Y}$ & $\mathrm{Y}$ & $\mathrm{Y}$ & $\mathrm{Y}$ \\
Province $\times$ Year FE & $\mathrm{Y}$ & $\mathrm{Y}$ & $\mathrm{Y}$ & $\mathrm{Y}$ \\
\hline \hline
\end{tabular}

Notes: This table uses tax data to estimate triple-differences regressions of the form:

$$
Y_{\text {kit }}=\gamma_{1} G_{i} \times \text { Post }_{t}+\gamma_{2} A_{k} \times \text { Post }_{t}+\gamma_{3} G_{i} \times A_{k} \times \text { Post }_{t}+\gamma_{4} G_{i} \times A_{k}+\mu_{i}+\delta_{j t}+\eta_{s t}+\varepsilon_{i j t},
$$

where $k$ denotes the type of investment, i.e. equipment and structures. $A_{k}$ is an indicator set to 1 for investment in equipment and 0 for investment in structures. $Y_{i t}$ is a dummy variable that is set to 1 if the investment rate is larger than a certain threshold specified in the column header. For instance, the dependent variable for column (2) is a dummy variable set to 1 if the investment rate is larger than $0.5 \%$, i.e. $D_{i k}=\mathbb{1}\left\{I K_{i t} \geq 0.005\right\}$, where $I K_{i t}$ is the investment rate of firm $i$ at time $t . G_{i}$ is an indicator set to 1 for domestic firms and 0 for foreign firms, and Post $t_{t}$ is the post-reform indicator set to 1 for years since 2009. All regressions include firm fixed effects, industry-year and province-year fixed effects. Standard errors are clustered at the firm level. 


\section{Table F.8: Estimates of Difference-in-Difference Regressions: External Finance Dependence}

\begin{tabular}{|c|c|c|c|c|c|c|}
\hline & \multicolumn{2}{|c|}{ Extensive Margin } & \multicolumn{2}{|c|}{ Investment Spikes } & \multicolumn{2}{|c|}{ Intensive Margin } \\
\hline & (1) & (2) & (3) & (4) & (5) & (6) \\
\hline Domestic $\times$ Post & $\begin{array}{c}0.041^{* * *} \\
(0.010)\end{array}$ & $\begin{array}{c}0.042^{* * *} \\
(0.010)\end{array}$ & $\begin{array}{c}0.071^{* * *} \\
(0.009)\end{array}$ & $\begin{array}{c}0.070^{* * *} \\
(0.010)\end{array}$ & $\begin{array}{c}0.037^{* * *} \\
(0.004)\end{array}$ & $\begin{array}{c}0.037^{* * *} \\
(0.004)\end{array}$ \\
\hline Domestic $\times$ Post $\times$ EFD & & $\begin{array}{c}0.005 \\
(0.003)\end{array}$ & & $\begin{array}{l}-0.002 \\
(0.003)\end{array}$ & & $\begin{array}{c}-0.004^{* * *} \\
(0.002)\end{array}$ \\
\hline $\begin{array}{l}N \\
\text { Industry } \times \text { Year FE }\end{array}$ & 81270 & 81270 & 81270 & 81270 & 81270 & 81270 \\
\hline Province $\times$ Year FE & Y & $\mathrm{Y}$ & Y & Y & $\mathrm{Y}$ & $\mathrm{Y}$ \\
\hline
\end{tabular}

Notes: This table shows the heterogeneous responses by industry's external finance dependence, by using tax data to estimate regressions of the form:

$$
Y_{i t}=\gamma_{1} G_{i} \times \text { Post }_{t}+\gamma_{2} G_{i} \times \text { Post }_{t} \times E F D_{j}+\mu_{i}+\eta_{s t} \varepsilon_{i t},
$$

where $Y_{i t}$ is equipment investment, $G_{i}$ is an indicator set to 1 for domestic firms and 0 to foreign firms, respectively, and Post $t_{t}$ is the post-reform indicator set to 1 for years since 2009. EF $D_{j}$ is the external finance dependence index of industry $j$ from Hsu et al. (2014) that measures the industry-level dependence on external finance. $\mu_{i}$ is firm fixed effect, and $\eta_{s t}$ is provinceyear fixed effect. For comparison, Column (1), (3) and (5) report the baseline estimates from difference-in-difference regressions. The dependent variable for column (1) and (2) is a dummy variable set to 1 if a firm makes positive investment. The dependent variable for column (3) and (4) is a dummy variable set to 1 if the investment rate is larger than 0.2 . The dependent variable for column (5) and (6) is firm's investment rate. All regressions include firm fixed effects. Standard errors are clustered at the firm level. 


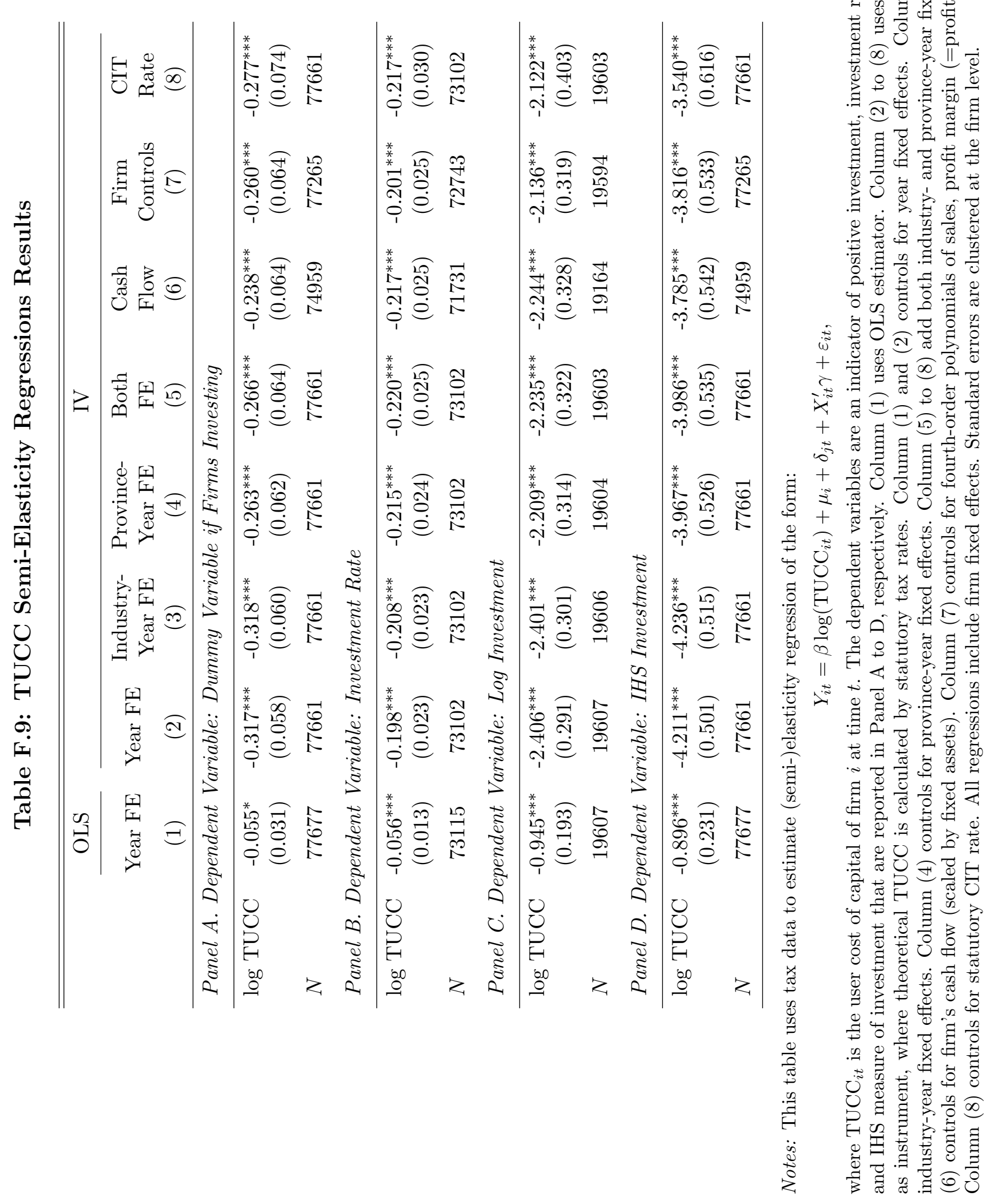


Table F.10: Sensitivity Analysis of Structural Moments

\begin{tabular}{lccc}
\hline \hline \multirow{2}{*}{ Moments } & \multicolumn{3}{c}{$10 \%$ Change } \\
\cline { 2 - 4 } & $\gamma$ & $\bar{\xi}$ & $\delta$ \\
\hline Pre-Reform Static Moments & & \\
Avg. Investment Rate & -0.0058 & 0.0007 & 0.0006 \\
Share $<0.1$ & -0.5705 & 0.0218 & -0.0065 \\
Share $<0.2$ & -0.1568 & -0.0011 & -0.0098 \\
Share $<0.3$ & 0.5000 & -0.0322 & -0.0108 \\
Serial Correlation & -0.0562 & -0.0052 & 0.0002 \\
SD. Investment Rate & -0.0739 & 0.0047 & 0.0013 \\
Reduced-Form Investment Responses & \\
Extensive DID & -0.0163 & -0.0002 & -0.0001 \\
Intensive DID & -0.0118 & 0.0002 & 0.0000 \\
\hline
\end{tabular}

Notes: This table displays sensitivity matrix:

$$
\Lambda=-\left(G^{\prime} W G\right)^{-1} G^{\prime} W \times g(m),
$$

where $G$ is the Jacobian matrix, $W$ is the weighting matrix (identity matrix here), and $g(m)$ is a vector of moments with misspecification. Here, we consider the misspecification to be a $10 \%$ deviation from the moment value. 
Table F.11: Structural Estimation and Reduced-Form Moments of Investment Spikes

\begin{tabular}{ccc}
\hline \hline & Extensive Margin & Intensive Margin \\
& $\%$ Firms Investing with $I K>0.2$ & Spike Investment Rate \\
\hline Data & 0.073 & 0.035 \\
Model & 0.064 & 0.036 \\
\hline
\end{tabular}

Notes: This table displays additional reduced-form moments regarding investment spike, complementing Table 10. The first row reports difference-in-difference estimates of investment spike responses (column (3) and (6) in Table 6). The extensive margin refers to the fraction of firms whose investment rate is larger than 0.2 , i.e., $\mathbb{1}\left\{I K_{i t} \geq 0.2\right\}$ where $I K_{i t}$ is the investment rate of firm $i$ at time $t$. The intensive margin refers to the spike investment rate, i.e., $I K_{i t}^{\text {spike }}=I K_{i t} \times \mathbb{1}\left\{I K_{i t} \geq 0.2\right\}$. The second row reports model simulated responses of investment spikes. We use the estimated frictions, i.e., $\gamma=1.43, \bar{\xi}=0.12$, for the simulation. 


\section{Table F.12: Robustness of Simulating 17\% VAT Cut}

\begin{tabular}{lcccc}
\hline \hline & & $\begin{array}{c}\text { Upward-Sloping } \\
\text { Capital Supply } \\
\text { Percentage Change in }\end{array}$ & $\begin{array}{c}\text { Resale Price } \\
p_{s}=0.80 \\
(1)\end{array}$ & $\begin{array}{c}\text { Aggregate Pro- } \\
\text { ductivity Drop } \\
(4)\end{array}$ \\
\hline Aggregate Investment & 0.434 & 0.343 & 0.431 & 0.439 \\
Fraction of Firms Investing & 0.098 & 0.087 & 0.097 & 0.102 \\
Tax Revenue & -0.279 & -0.277 & -0.279 & -0.277 \\
Firm Value & 0.114 & 0.090 & 0.114 & 0.114 \\
Ratio of Investment to Tax Revenue & 1.557 & 1.235 & 1.544 & 1.586 \\
Ratio of Firm Value to Tax Revenue & 0.410 & 0.325 & 0.408 & 0.413 \\
\hline
\end{tabular}

Notes: This table displays simulation results for the baseline policy reform-17\% VAT cut-with the following extensions. Column (1) is the baseline simulation results. Column (2) assumes the capital supply is upward sloping with the functional form of $p^{K}=I^{1 / \varepsilon^{s}}$. The elasticity of capital supply with respect to pre-tax capital price $\varepsilon^{s}$ is set to 10. Column (3) assumes the net-of-tax resale price to be 0.8 . In column (4), we feed in a one standard deviation permanent drop of aggregate productivity. 
Table F.13: Robustness of Simulating 17\% VAT Cut: Varying Interest Rate

\begin{tabular}{lccccc}
\hline \hline & \multicolumn{4}{c}{ Elasticity of interest rate w.r.t TUCC } \\
\cline { 2 - 6 } & 0 (Baseline) & -0.05 & -0.1 & -0.2 & -0.25 \\
Percentage Change in & $(1)$ & $(2)$ & $(3)$ & $(4)$ & $(5)$ \\
\hline TUCC & -0.145 & -0.145 & -0.145 & -0.145 & -0.145 \\
Aggregate Investment & 0.434 & 0.416 & 0.399 & 0.365 & 0.348 \\
Fraction of Firms Investing & 0.098 & 0.092 & 0.088 & 0.077 & 0.072 \\
Tax Revenue & -0.279 & -0.280 & -0.282 & -0.284 & -0.286 \\
Firm Value & 0.114 & 0.104 & 0.094 & 0.074 & 0.065 \\
Ratio of Investment to Tax Revenue & 1.557 & 1.485 & 1.418 & 1.284 & 1.219 \\
Ratio of Firm Value to Tax Revenue & 0.410 & 0.371 & 0.334 & 0.262 & 0.227 \\
\hline
\end{tabular}

Notes: This table displays simulation results for the baseline policy reform-17\% VAT cut - with elasticity of interest rate with respect to TUCC at $-0.05,-0.1,-0.2$ and -0.25 , respectively. For instance, column (1) assumes the elasticity of interest rate with respect to TUCC at -0.05 , leading to a $0.73 \%$ increase in interest rate. In our baseline model, we fix the discount factor at 0.95 and thus the interest rate at $0.0526=1 / \beta-1$. 
Table F.14: Simulating CIT Cuts with Deductible Adjustment Costs and Weighted Average Cost of Capital (WACC)

\begin{tabular}{lcccc}
\hline \hline & 17\% VAT Cut & \multicolumn{3}{c}{ CIT Cut 15.4\% to 10\% } \\
\cline { 3 - 5 } Percentage Change in & $(1)$ & $\begin{array}{c}\text { Baseline } \\
(2)\end{array}$ & $\begin{array}{c}\text { Ded. Costs } \\
(3)\end{array}$ & $\begin{array}{c}\text { Varying WACC } \\
(4)\end{array}$ \\
\hline Aggregate Investment & 0.434 & 0.147 & 0.038 & 0.061 \\
Fraction of Firms Investing & 0.098 & 0.062 & 0.012 & 0.025 \\
Tax Revenue & -0.279 & -0.191 & -0.172 & -0.227 \\
Firm Value & 0.114 & 0.103 & 0.065 & 0.049 \\
Ratio of Investment to Tax Revenue & 1.557 & 0.767 & 0.218 & 0.270 \\
Ratio of Firm Value to Tax Revenue & 0.410 & 0.540 & 0.379 & 0.214 \\
\hline
\end{tabular}

Notes: This table displays simulation results for CIT cut from $15.4 \%$ to $10 \%$. Column (2) reports the baseline results. Column (3) shows the simulated results when adjustment costs (i.e., convex and fixed adjustment costs) are tax deductible. Column (4) shows the simulated results when CIT cut changes weighted average cost of capital (WACC), and thus discount rate $\beta=\frac{1}{1+\mathrm{WACC}}$. WACC is calculated as

$$
\text { WACC }=\text { Share }_{\text {debt }}(1-\tau) r+\left(1-\text { Share }_{\text {debt }}\right) r_{k},
$$

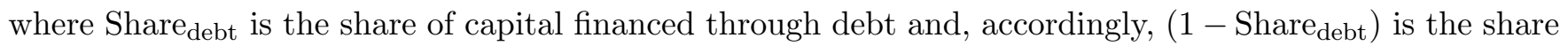
of capital financed through equity. We calibrate the share of debt financing to be 0.65 to match the average debt to capital ratio. We keep real interest rate $r$ and capital return $r_{k}$ constant to match baseline discount rate. 
Table F.15: Tax Cuts with Same TUCC Reduction

\begin{tabular}{|c|c|c|c|}
\hline \multirow{2}{*}{ Percentage Change in } & \multirow{2}{*}{ VAT Cut } & \multicolumn{2}{|c|}{ CIT Cut } \\
\hline & & Constant WACC & Varying WACC \\
\hline & $(1)$ & $(2)$ & $(3)$ \\
\hline $\begin{array}{l}\text { Tax Rate (pp.) } \\
\text { TUCC }\end{array}$ & $\begin{array}{c}-2.8 \\
-0.024\end{array}$ & $\begin{array}{l}-10.0 \\
-0.024\end{array}$ & $\begin{array}{l}-10.0 \\
-0.024\end{array}$ \\
\hline $\begin{array}{l}\text { Aggregate Investment } \\
\text { Fraction of Firms Investing } \\
\text { Tax Revenue }\end{array}$ & $\begin{array}{c}0.067 \\
0.023 \\
-0.029\end{array}$ & $\begin{array}{c}0.274 \\
0.111 \\
-0.359\end{array}$ & $\begin{array}{c}0.108 \\
0.042 \\
-0.421\end{array}$ \\
\hline Ratio of Investment to Tax Revenue & 2.346 & 0.765 & 0.257 \\
\hline
\end{tabular}

Notes: The table shows the results with initial VAT rate at $17 \%$ and CIT rate at $15.4 \%$. We compare two reforms with the same reduction in TUCC: 1) VAT reform cuts VAT from $17 \%$ to $14.2 \%$ (i.e., $2.8 \%$ rate reduction), and 2) CIT reform cuts CIT rate from $15.4 \%$ to $5.4 \%$ (i.e., $10 \%$ rate reduction). Those two reforms have the same impacts on TUCC, reducing TUCC by $2.4 \%$. We use the estimated frictions, i.e., $\gamma=1.43, \bar{\xi}=0.12$, to simulate tax cuts. In column (2) we simulate CIT cut with fixed interest rate. In column (3) we use weighted-average cost of capital (WACC) for simulation. WACC is calculated as

$$
\mathrm{WACC}=\text { Share }_{\mathrm{debt}}(1-\tau) r+\left(1-\text { Share }_{\mathrm{debt}}\right) r_{k},
$$

where Share $_{\text {debt }}$ is the share of capital financed through debt and, accordingly, $\left(1-\right.$ Share $\left._{\text {debt }}\right)$ is the share of capital financed through equity. We calibrate the share of debt financing to be 0.65 to match the average debt to capital ratio. We keep real interest rate $r$ and capital return $r_{k}$ constant to match baseline discount rate. Ratio of investment rate to tax revenue is calculated by dividing the percentage change in average investment rate by the percentage change in tax revenue. 